SB 321

.H2 







\title{
Garden Helps
}

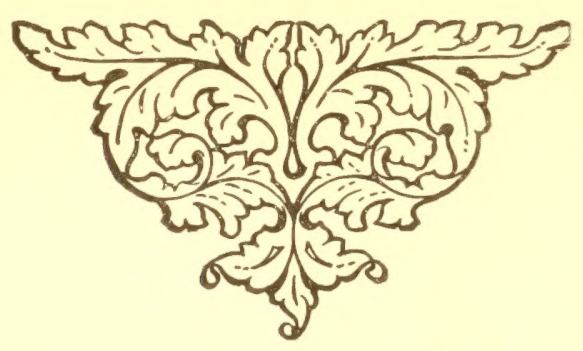

\author{
$B Y$ \\ GEORGE P. HALL \\ Presiden of the Little Landers Colony, San Ysidro. Cal.
}


Dedicated to the
San Diego Floral Association and

California Garden 
Gopyright 1911

George P. Hall, San Diego, Cal. 


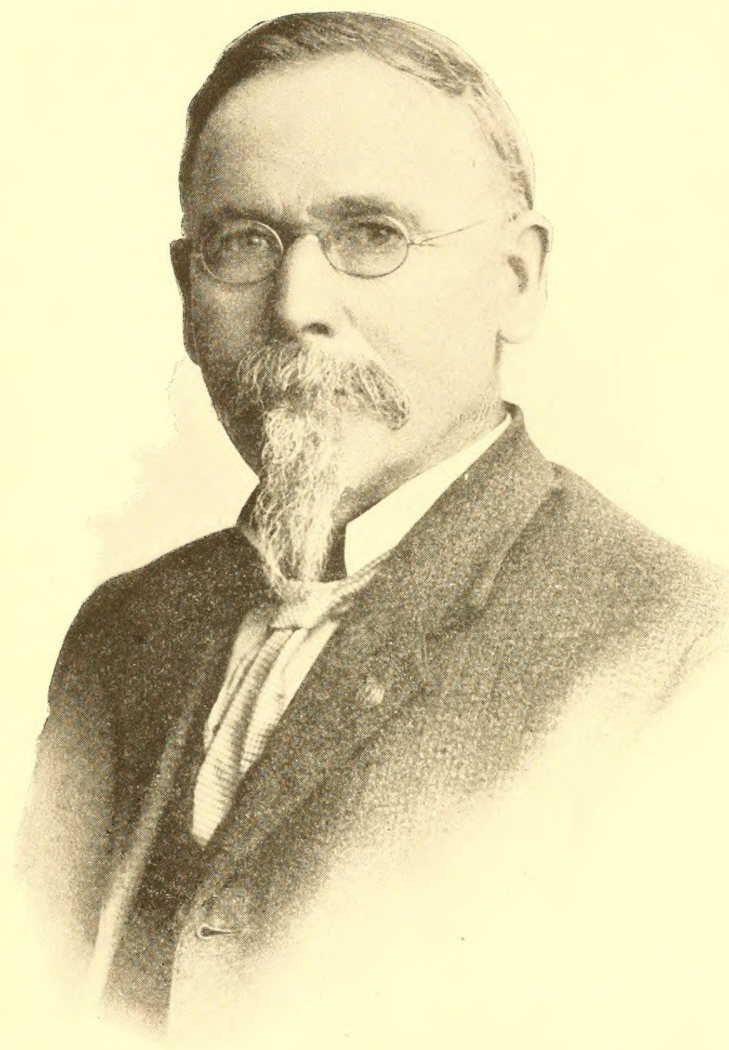

George P. Hall 


\section{A Word About the Author}

Mr. George P. Hall, the author of this book, has the two qualities needed to make it valuable.

First, he has knowledge both theoretical and practical; second, he has a great love for men, for the soil, for trees and for fruits and flowers.

I should not care to trust a work of this kind in the hands of a man whose knowledge, however large, was not warmed by genuine interest in the welfare of those who till the soil either for pleasure or profit. I know that in writing it Mr. Mall's dominating idea is that he may help many men and women to gain an independence, to lead better, fuller, richer lives.

Coming to California twenty rears ago, Nr. Iall almost immediately became a factor of importance in the horticultural life of the state. He exerted a very porerful influence in the development of the lemon industry, devising methods of planting, pruning and spraying that have been generally adopted.

He served for six years as Horticultural Commissioner of San Diego County and was chosen president of the State Board of Horticultural Commissioners.

'Through his contributious to newspapers and magazines he has been and still is, "guide, philosopher" and friend" of great numbers all over the United States.

His work for the Little Lander's of San Ysidro, of which he is president, can not be estimated now nor perhaps for many years. The location of the colony was selected from many offerings upon his advice as an expert. He was consulted about every detail of the scheme of cultivation, of village improvement and of social life when the colony had existence only on paper.

When the settlement was begun, his was the first hoe that struck the ground. What he has since done is prodigions, but what he has inspired is infinitely more. The point for the readers of this book is that the event has shown the soundness of his knowledge and judgment in certain radical departures from old ruts and that his wisdom on matter's treated in the following pages has been repeatedly vindicated.

His authority on matters of horticulture and agriculture is heyoud question, while the spirit in which he works is-well, I know no word for it except "divine".

$$
\text { WN. E. SMIY'IHE. }
$$

San Ysiclro, Calif., April 10th, 1911. 


\section{Table of Contents}

Foreword-Garciening in California .................. 9-10

Soil

Jinluilijul

(n)lisil

('latssiti-attiont

Clinerat sulostanees.

Endurance Measure of Land and Water .................21

Planting

Time to Plant.

2...2.23

I'latutins Tablus ...........

Sowing and Transplanting....

Rotation of Crops...........

Irrigation and Cultivation. . . . 31-33 When to Irrigate...........31 How Much to Irrigate....... $3:$ How to Irrigate............. 3:

Importance of Cultivation..... 37

\section{Culurual Directions for Vege-}

tables $\ldots \ldots \ldots \ldots \ldots \ldots \ldots .33-70$

Asparagus $\ldots \ldots \ldots \ldots \ldots \ldots \ldots \ldots$ s

Beans ..............

listis

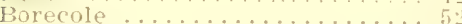

Broccoli ...............

Cabbage ...................

Capers $\ldots \ldots \ldots \ldots \ldots \ldots \ldots \ldots$ is

Caulitlower ............... 4:

Cardoon ................. 4

Carrots ......................

celeriate

Celery

Ciboule ................. 4 .

Collards ................. 44

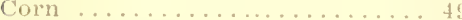

Corn Salad................. th

Cress ................ 46

(5)

Fgg Plant ..............

Endive .................. 51

Garlic ............ 5

Gumbo

Horseradish

Kale ................. 5

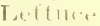

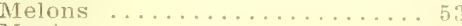

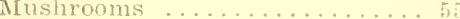

Okra ................ 56

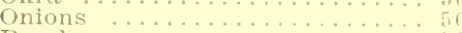

Parsley ............... 5.

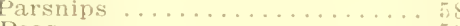

Peas ...................... 5

Pie Plant .....................

Peppers ................ 6io

Potatoes ............... (i)

Pumpkin ................6.

Radishes ............

Rhubarb ..........................

Roselle .............. 6

Salsify $\ldots \ldots \ldots \ldots \ldots \ldots \ldots$ fit

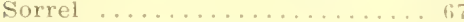

Spinach ............... $66^{6}$

Squashes

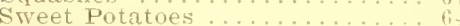

Tomatoes ............... fit

Turnips ...........

Vegetable oyster ............. Go
Aromatic and Medicinal Herbs.71-72

Anise $\ldots . . \ldots \ldots \ldots \ldots \ldots \ldots .71$

Caraway ................ 71

Catnip $\ldots \ldots \ldots \ldots \ldots \ldots \ldots \ldots$

lill

Hurehinima .........

Lavender ..............

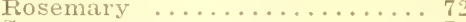

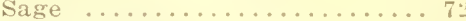

Sweet Basil ................. 71

Sweet Fennel .................

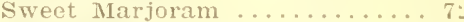

Thyme ...............

IVormwinit

Flowering Plants and Shrubs...73-77

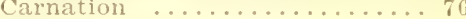

Novelties ............... 75

Ornamental Trees ......... 74

Palms ............... 7

Roses . that enjoy sea ivinas... 75

Shrubs that enjoy sea winds... T

Street Trees.............. $7 \cdot 1$

Tea Roses ............... T

Other flow and Propagation..78-38

Classification and Propagation. 78-36

Pollenization and Hybridizing.. S:

Tultiplication by Cuttings.... 86

Fertilizaticn ...........87-101

Analysis of Fertilizers....... 87

Avalability of Fertilizers..... $\delta y$

Commerical Valuation ........ y.

Formulas ................. 94

Mineral Pliosphates ..........91

Nitrate of soda-use of....... g!

Nitrogen Culture ............101

Plow:mliates

Potash Manures ............ 4

Soil Inoculation ............100

Superphosphates ..........91

Unit System in Fertilizers..... 9

Value of Farm Manures...... 96

What the Plant Takes from the

Soil the............ 96

What the plant wants....... gs

Insecticides and rungicides..102-103

Aquis Ammonia Solution.....105

Alsenite....................

$\mathrm{Bi}$ Sulphide of Carbon. .......

Bordeaux Mixture ...........

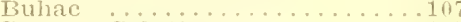

Copper Solution.............. 105

Corrosive Sublimate ............

Hot Water................... int

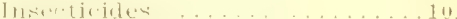

Tierosene Emulsion...........1nt

Lime Sulphux and Salt.........

Lye and Sulphur................

Paris Green .................104

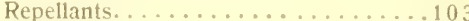

Road Dust. ................. 100

Tobacco............................ 107

Remedies for Each Particular

Pest . . ..................108-113

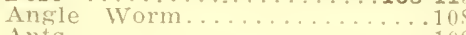

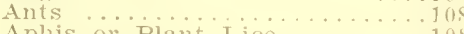

Aphis or Plant Lice ..........10

Caterpillars

Cut Worms..............110

Pod Rust......................

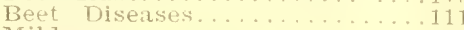

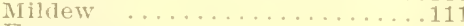

Fungus .................

Calendar of Operations......113-115

Useful Information . . . . . . 116-119

Reference r'alyle ............. 116-119 


\section{Gardening in California}

The author undertakes this work in the same spirit in which for many years he has orally or through the medium of varied publications answered questions that have now and again presented themselves in the minds of the people who have been settling in this "garden spot of the world". MIultitudes come to visit only, but the attractions prove too alluring. Every season therefore witnesses the arrival of those who camnot really make a home here without adding to the number of our picturesque gardens.

So widely do the methods of gardening here differ from the practices of the States East of the Rockies that many people find they have to begin anew. This work is planned as an ever-ready assistant to the home gardener especially, but it will be found of value to the commercial gardener as well. It is the response to frequent requests for placing in accessible form at a moderate price facts and methods in regard to cultivation of garden and field erops.

The variety of questions that appear in the columns provided for the purpose in newspapers as well as in the periodicals more especially devoted to horticulture is of itself indicative of the need of such a work. Every gardener is more or less desirous of knowing his own garden and of fathoming its possibilities. He asks about his soil, what it needs to improve it, the action of the various chemical substances he may apply and how he may supply the foods to the best advantage. He asks about his seeds and plants, their origin and surroundings, their habits, their sowing and transplanting, their irrigation and cultivation, their rotation and succession, their enemies and the remedies.

He asks how he may get all that is possible from the manipulation of the combination of seed and soil. He asks many other questions in order to work the soil intelligently and receive returns from the labor bestowed. We give positive information along practical lines secured from the highest authorities and years of observation, experience and appropriation.

This is a widely spreading theme that should interest thousands who are yet to be the tillers of the soil. We have but 
touched the hem of the great garment Nature has spread out for us to wear. Every student of life not only wonders, but worships, as he gets closer to Nature. How important it is for all to extend the knowledge of the primal source of all life. Mother Earth is the great repository of life. The doctrine of reciprocity is universal. Intellect is dependent on animal sustenance. If the body does not receive from the animal and vegetable the proteids, albumenoids and fats, the chain of destiny is broken. The cow picks up the cream from the vegetable either in growing grass or bolted grain. If the soil is not fed it will not feed you. If the soil is constantly depleted and no return is made for what is taken away it becomes barren and unfruitful. How important is it, then, to nourish the soil and replenish what we so carelessly derive from it for our own sustenance. We can see now the value tc the world of men like Luther Burbank in searching out what a plant or a tree takes from the soil and what improvement can be made in the plants themselves.

In Califonia, where potatoes and peas are planted every month of the year, where corn bears longer than in the great corn centers of the world, and where numerous frostless locations present unsupassed facilities for gardening in all its brancheshere especially should every encouragement and incentive be given to further the study of Nature. Here should the doctor apply his best efforts to open the eyes of mankind to the boundless stores of Nature, largely allowed to remain undeveloped hitherto in om blindness.

Here, it is true, are the desert and the parched ground. But the old Jewish prophecy may yet find a more literal fulfilment in California than ever dreamed of among the hanging gardens of Babylon, when we see the parched ground become pools of water and the desert rejoice and blossom as the rose.

In California, every gardener may be a Solomon. His ships hring the wealth of the world to his door, (superphospates from the Carolina rock, potash from the inexhaustible sources in Strassfurt, Germany) and the queens of Sheba declare the half has never been told of all his beauties, rich and rare.

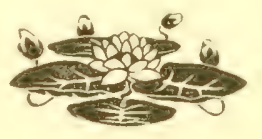




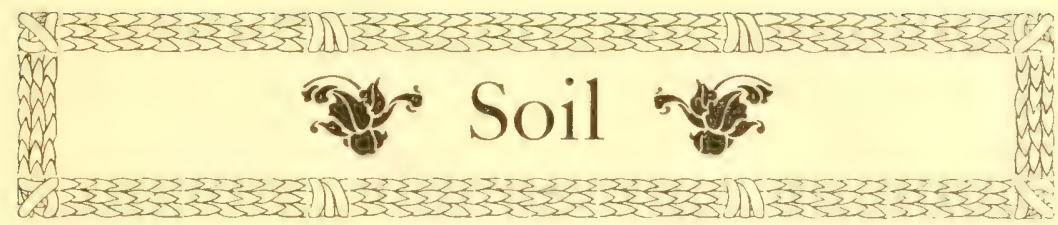

\section{Formation}

Soil is the term applied to that part of the earth's surface that can be cultivated and on which plants can grow.

Soil is obtained directly and indirectly from the decay of rock. If all the soil were removed from the earth the part left would be rocks and water. Soil depends largely in quality on the kind of rocks it was made from. Rocks have been formed by the action of fire or water; those formed by fire are called igneous, those compressed by water are aqueous.

The igneous rocks furnish to the soil silica and aluminum principally and also potash, lime, magnesia, iron and other mineral substances. You can see from this why soils are "spotted", or why one spot contains more mineral than another, or of a different kind. If it happens that a large piece of potassic rock gets ground up in a cextain spot, you get excess of alkali. These are called primary, or first rocks because they were thrown out from the interior of the earth. This view is supported by the fact that the lava now ejected from volcanos resembles "trap" rocks. Trap rock is composed chiefly of two minerals, feldspar and hormblend. Feldspar is particularly rich in potash but poor in lime and magnesia. Hornblend is poor in potash and soda, rich in lime and magnesia. Granite roeks consist chiefly of quartz, feldspar and mica. Quartz is almost pure silica-flint-and contains nearly all the compounds found in feldspar and hormblend.

Aqueous rocks are formed from the minerals washed out of and compressed from the igneous rocks. Limestone and sandstone are examples of aqueous rocks.

Briefly stated this gives you the origin or sources of the different soils you come in contact with.

\section{Subsoil}

This may be considered as imperfected soil. It represents a stage between the rock and the perfected soil. Soil is more finely divided, less compact and mixed with organic and vegetale matter. The subsoil is the feeder of the soil and gradually supplies 
the mineral parts the soil gives to the plants. Subsoil very materially determines the character of the soil. Air, temperature, water all play their part in reducing rocks to soil. The most powerful agent is water, as it acts both mechanically and chemically, being charged with acids or salts by flowing over rocks composed of either. The carbonic acid in the water absorbed from the atmosphere is a solvent of soda, potash, silica and iron, all of which are taken up by growing vegetation,

Growth of plants aids in rotting the rocks, the roots penetrate and force particles of rock to separate. In the decay of plants soil is kept moist, gases are generated, absorbed by the water and again penetrate the rocks to reduce them to smaller particles. Rocks covered with lichens and lower orders of plants are evidence of this principle of plant life being a means of reducing the roek to soil.

The overflow of rivers is an example of the creation of what is called "sedimentary deposit", and where pressure and heat are applied it forms aqueous rock. If a piece of land is underlaid with sedimentary deposit you know the rock can be surely dissolved by water.

Worms and living creatures in the ground aid in preparing the soil for the use of plants; they also carry down considerable vegetable matter, which aids in the development of the undersoil.

Rich mesa soils that are comparatively level are superior in that they do not lose their fertility so soon as soils that are constantly moving, thin at the top of the hill, thick in the valley. The same causes that are at work to make the soil also unite to change its position, thus giving loss. In selecting soil, either high, level mesa or valley, sedimentary soils are preferable because they are more enduring. They are called "soils in place".

Transported or "alluvial" soils are those that have been transported from one place to another by action of water. In the past, geology tells us, glacial rivers moved immense bodies of soil into lakes and valleys. Yet sometimes on the upper heights also may be found these alluvial soils, which are generally rich and well fitted for the growth of erops.

Drift soils can always be told by the presence of rounded rocks or boulders, and drift soils are generally fertile because there has been brought together from varjous sources a combination of many, if not all the constituents of soil. 


\section{Classification of Soils}

Soils are composed of clay, carbonate of lime, mineral and vegetable substances and are classed as sand, clay, lime and peat. These have sub-divisions according as the composition is more or less of a prevailing ingredient.

(a) Sand is not soil really, for sand alone would not directly serve as a source of plant food. "So poor it won't raise beans," is sometimes said of sand. Sand is really siliea or ground-up flint. and alone would be unserviceable in producing crops. Chemically, sand or silica is composed of the mineral silicon united wi h the element oxygen and does not serve directly as food for plants. But it is almost indispensable, as it lightens heavy soil. makes close grained soil permeable to air, moisture and warmth; all requisites for the successful growth of the plant.

(b) Clay soils, which are a compound of aluminum and oxygen, are, chemically speaking, just as useless as sand as a source of plant food. Clay is exactly the reverse of sand, as it is compact. Sand will easily fall apart; clay, especially when moist. adheres so firmly it can be moulded into briek and tile. Sand, from its porous nature, rapidly loses water, while clay retains it. Sand absorbs heat and soon dries, while clay is so compact it is difficult for the air to penetrate, or warmth to reach down beneath the surface. Clay is hard to work. Unless it is well drained, its crops will suffer two ways, too wet and too dry. In the latter case. the land becomes so hard it is difficult for the roots to penetrate. If clay and sand are mixed it makes a loam that is ideal physieally for nearly all purposes in plant growth.

(c) Lime, calcareous or chally soils are so termed when they contain at least twenty percent. of lime. These soils are generally easy to work and when mixed with clay form what in California is termed "mealy adobe", in contrast to the black adobe that lacks lime to the extent of twenty per cent. These soils are particularly adapted to grain raising, since all cereals enjoy a good proportion of lime in order to form the stalk of the grain. Lime is likewise required by animals to form the bones. And again, ground bones are an excellent substitute for lime where it is lacking in the soil.

(d) Vegetable soils are usually found in the vicinity of marshes and lagoons or former lakes which have dried up and 
left the vast accumulation of decayed vegetable matter as the foundation for plant growth. These soils are very rich and are especially adapted for crops like celery, which require unusually rich soil. For most crops, however, the peat needs an admixture of other soil to make it ideal for all purposes of the agriculturist, as there is almost an entire lack of the mineral constituents found in other soils.

(e) Loam. Soil composed of a mixture of clay and sand is called loam, and is best adapted to the purposes of farming and gardening. If soil contains only from ten to twenty per cent. of clay it is called sandy loam; if from twenty to thirty per cent. clay, it is called loam. If the clay is in nearly equal proportion, from thirty to fifte per cent. it is clay loam. Gravel and lime loams are those which contain gravel or coarse lime and sand in large proportion. All the natural divisions of soil are much improved for the use of the gardener according as they more nearly approach the division ealled loam.

(f) Perfect Soil. A soil that contains sufficient proportion of sand to freely admit air, warmth and moisture, in proportion so it will be warm and permeable; sufficient clay to keep it cool, to prevent rapid washing away or leaching of the moisture and the fertilizers added from time to time, and to prevent rapid evaporation and thus assist in the decay of vegetable matter in the soil, is perfect soil. These conditions are rare in the make-up of soils.

It often occurs that it is cheaper to raise only that crop to which a particular piece of soil is adapted than attempt the expense of changing the make-up of the soil. In garden operations, the latter is admissible and even profitable. If the soil is poor and contains nothing but sand, it ean be enriched by the addition of clay or peat. Clay that is too sticky and tenacious to work freely can be changed by mixing lime and sand, or plaster, roughage of almost any material that will ohange its constituent parts. It would be unwise, however, to attempt to change large bodies of soil, that are only adapted to raising grain or grasses, to the use for intensive gardening; better move to a spot that suits your purpose than try to change large fields to meet your convenience.

Soils are called warm or. cold, light or heavy. In warm soils the particles lie loosely together and readily admit air, warmth and moisture. They are also light because the particles can be easily moved, readily changed from one position to another. 
Heavy soils are compact, tenacions, adhesive. They admit water slowly, but retain it for a long time, making thenf heavy to move when wet, and when dry hard and myelding. Heavy soils are much more difficult to eultivate than light, warm soils, but generally infinitely richer in materials that furnish food for plant life. The heavy soils are usually more adapted to the production of grain and deciduous fruits than early vegetables, which are at home on the light, warmer soils. The purpose for which you desire the land to subserve shonld be the first consideration.

\section{Composition of Soil}

Beside the qualities already ascribed to soil there are two distinct classes of substances: first, vegetable or organie, derived from decaying plants; second, mineral or inorganic, derived as we have seen from the rocks on the earth's surface.

Organic substances are composed of carbon, oxygen, hydrogen and nitrogen. The latter is of most vital importance in developing the early life of the plant and is especially useful in the production of early vegetables.

Humus is made up of the four elements above deseribed. It is derived in part from the decaying and decayed roots, leaves and stalks of plants that have grown in and upon the soil, and when decayed and returned to the soil again have given it a darker enlor in sandy soils, and an improved texture in heavy soils. Humus is useful in all deseriptions of soil and is well illustrated in what is commonly known as "leaf mold". People gather it and use it as an improver of soil and say usually it is a direct plant food. Science says that it is not directly a plant food, but in its final stages of decay it furnishes carbonic acid gas. You have seen bubbles come up from pools of water where leaves were decaying. This is the carbonic acid gas escaping. It escapes in the soil just the same, but we camnot see it, and this with ammonia added to water makes food the plant can directly take up. Therefore the older and more nearly decayed the leaf mold, the nearer it approaches the condition where it can be called plant food. Humus improves light, sandy soils, in that it gives direct absorbing power to the soil as well as giving it at the same time retentive power to hold moisture. It will absorb and retain more moisture than any other ingredient in the soil. It acts as a sponge to take in, store 
up, and give off the moisture, thus playing a most important part in making ready the food for the plant in the only form the plant can take it, i. e., liquid. Humus improves stiff clay soil through its property of loosening up and consequently aerating otherwise impervious soil. It will be seen that humus is important in giving the physical quality soils need to enable them to retain heat and moisture, and to supply plant food.

\section{Mineral Substances in Soil}

The mineral substances of the soil are called "inorganic" and are identical with the ash found in a plant after you burn it. These are silica, alumina, lime, potash, magnesia, phosphorie acid, soda, iron, chlorine and sulphuric acid. The most important constituents are phosphoric acid and potash. Phosphoric acid is usually found in combination with lime and sometimes with iron and alumirum but especially in rocks that contain fossils and large quantities of bones. The Carolina rocks from which "superphosphates" are made are examples of this stored plant food, which when treated with sulphuric acid makes the phosphoric acid soluble in water. When put into moist soil it becomes available to the plant, while in the rock form it never could be. There is a long list of articles that contain phosphoric acid in more or less proportion.

(a) Lime is essential in setting free elements locked in the soil. Lime is obtained from decaying limestone rock, or ly the process of burning the rock, and is found in the fossilized rocks that contain animal deposits, as lime has existed in the bones of all animals since the dawn of creation. The use of lime in agriculture antedates the Christian era. The necessity of lime as a food for the higher order of plants has been indisputably demonstrated. Its physical effect on the soil is marked and positive, changing stiff, obdurate soil to tillable conditions. It is an indirect food in setting free other locked-up elements in the soil. Lime assists in the assimilation of atmospheric nitrogen in the case of alfalfa and other leguminous plants. It attacks inert combinations of potash and phosphoric acid, and renders their fertilizing qualities available to the plant. Lime both cures sourness of soils and prevents the combination of sour humus that might be injurious to the plant. 
Liming makes clay soils more friable, and sandy soils more compact, thus improving the texture of both. Large quantities of lime should not be used on sandy soil, at one time-sufficient lime with sand makes mortar-but small quantities used frequently give compactness. Too much lime and wood ashes combined give excess of alkali, which will increase the tendency to make potatoes scabby, if the disease is already in the soil, as it is of an alkaline, erosive character. On the other hand, club foot in turnips and cabbage is diminished by use of lime. You can apply lime even in large quantities on sandy soil if you combine it with the application of barnyard manure and plow it under well. Lime is valuable in redueing coarse vegetable matter to an assimilable form, by put. ting it in the heaps of decaring vegetation or compost. If a little common salt is added the process will be assisted materially in formation of earbonates of soda or potash. Plants like lettuce, spinach, beets, onions, melons and blue grass, that are total failures on sour soil (as is almost any plant) thrive vigoronsly if given lime to correct the acidity of the soil. The use of lime in the soil is an important study as to its effect on both the soil and the plant. Not all plants of the same family desire lime. For instance, the Delaware grape is greatly helped by it, but the Concord eares little for its assistance. Watermelons detest lime, while the musk melon is in full accord. Black cap raspberries are not helped by liming, but the red Cuthbert responds with vigorous growth to its applications.

(b) Potash. Crops of all kinds remove from the soil each season considerable potash, which must, as in the case of all elements removed, be returned in some form, if the fertility of the soil is to be maintained. All sandy soils if not underlaid by red or yellow clay are apt to be deficient in potash. In the early days of farm operations woor ashes were the principal source of potash, and are still valuable in furnishing lye (alkali), but the present souree of supply is the Strasturt mines in Germany, and though worked constantly since 1862 , the supply seems to be inexhaustible. These potash salts are mined and in their erude state contain, mixed with the potash, other salts that are some times injurious to plant life. The crude products shipped to this country consist of Kanit and Sylvanit.

Kanit is mixed with a large proportion of ehloride of sodiumcommon salt-with the chlorides of sudium and magnesium and 
sulphates of magnesim and potassimm. It has not more than 12 per cent. of actual potash, or potassium oxide. Sylvanit is even cledited with a less per cent. of actual potash than kanit; the average showing is 16 per cent. Both are not so marked as lime in their physical influence, but act on the soil as solvents in certain cases. They are slow in action and must be applied a considerable time before any effect can be observed.

Muriate of potash is manufactured from the above mentioned crude forms of potash and from them is resolved an article that contains from 40 to 50 per cent. actual potash. The prineipal impurity is common salt. Purity and price depend on the method of its manufacture. which varies with different producers of the fertilizer. This sulphate form of potash is also called "highgrade" sulphate. For use on certain crops, like potatoes and tobaceo, it is very desirable. Fruits generally it sweetens. It is the direct inflence in the hand of the Great Artificer that puts the finishing touches of beauty and flavor to the fruit. Without it they all would be insipid and practically valueless.

(c) Phosphoric Acid. One of the three prineipal elements that a plant must have is phosphoric acid. It is an ingredient in all fertile soils, but generally is present in very small quantities, and is quickly taken $u p$ by the plant and must be replaced by some outside agency, or the soil will degenerate far below the normal standard renuired for sucessful production of crops. Phosphorie acid is usually found in comnection with lime and especially in fossiliferous rocks. While nitrogen is the element that accelerates growth of leaf and wood, and potash is the one that sweetens and makes the product approach perfection, it is the office of the phosphoric acid to impart tissue and fibre. With the assistance of lime it adds virility to seed and abounding life through the whole structure of the plant. We have said its deficiency must be supplied by artificial means, or manures derived from phosphates. Phosphate is a salt formed by the union of phosphoric aeid with some base that will make it available to the plant. Much of the phosphoric acid in soil is not available until lime is put in the soil to set it free. Many of the phosphates that contain phosphorie acid are not available until treated, or lie in the soil a long time and become emancipated from the element with which they are united. Bone is a source of phosphoric acid, but a plant cannot assimilate bone until by some means it is softened and liquified. 
If the bone must lie in the soil till the action of elements in the soil reduce it, it would be a long time before the plant would receive any benefit from it. So there are ways of reducing the bone to a condition that it may become arailable. (We cite bone because it is commonly known and the process of reclueing bone to food that is ready for plants is similar to that of reducing rock and other material in which there is a per cent. of phosphorie acis sufficient to warrant the expense of reducing it.) Bone is gromel and it can readily be seen that the finer the particles the more readily they will decompose in the soil and hecome food for plants. Another process is to acidulate the bones. Plants have no teeth and cannot chew bones. But treat them in a solution of sulphuric acid and the substance obtained is readily soluble in water and can of course be taken up by the plant. The amount of phosphoric acid in bones depends on the kind of bones, whether from an old ox or a young calf. The bones of the ox are matured and are richer in phosphate of lime and poorer in nitrogen. while the young bones have the proportions retersed. The story of the men that buried seven tom cats under the cherry tree and got only a crop of leaves hints at the proportion of nitrogen in the bones of animals that only have soft hones and a preponderance of ligaments and muscles. Raw bone is estimated to contain 22 per cent, of phosphoric acid and 4 per cent. of nitrogen. Bone meal, if well ground, soon becomes available in the soil, but would have to be put in some time ahead in order that the processes of soil disintegration might accomplish what you would by the quicker method of treating the bone with acid. Bones are steamed in order to obtain by-products found in them. as gelatine and glue. The steamed bone loses more of its nitrogen but retains its per cent. of phosphoric acid. Steamed bone brought under high pressure to extract the glue and nitrogenous substances, is often reduced to finer particles than when ground. As a source from which the plant can obtain its food, it is superior to the ground raw bone, and may become available in the soil the season it is applied, which is seldom the ease with ground bone.

Bone biatk, is another valuable source of phosphoric acia. The best bones are selected, dried and then made into chareoal by heating and evaporating all vegetable substances. They are then ground to a powder that can be applied direct and is arailable immediately when the moisture of the soil unites with it. It 
contains about thirty-five per cent of Phosphoric acid and a small amount of nitrogen.

Bone ash is the residum of piles of bones burned. It is shipped in bulk from South America, and usually does not contain more than twenty-five pel cent of Phosphoric acid. Bone Phosphates, of any kind are, by reason of the fact that they are obtained from organic materials, more useful in the soil than those obtained from mineral sources.

Mineral Phosphates (containing lime and Phosphoric Acid) are found largely in earth, elay and rock deposits in Carolina, Florida and elsewhere. "Sand Phosphates," from a clay formation: "Pebble Phosphates" from river beds and rock or boulder phosphates come from Florida, but far superior is the Carolina rock which contains as high as forty per cent of Phosphoric Acid.

Iron phosphate or basic slag is obtained in the process of manufacturing steel when lime is put in the furnace to aid in collecting the phosphoric acid from the molten metal. The cinders when finely ground are excellent tor clay soil, also for sand and for grass lands. Iron phosphates are raluable as they are soon made available in the soil.

As before stated, mineral phosphates require more acid to reduce them, and consequently are not always thoroughly dissolved. Where there are some undissolved portions, it sometimes happens that when they come in contact with other undissolved minerals in the soil they "revert" or take more inaccessible form than before. In computing the worth of phosphoric acid it is usually the custom to calculate that all the sources for the reverted portion is supposed to make good at some future time and is simply counted as being "disfigured but still in the ring."

The diacalcic or reverted phosphoric acid is available, in this way. It stays just where it is until the roots skirmish and reach it. On the other hand well dissolved phosphates flow directly to the roots and act both as host and waiter.

(d) Nitrogen. One of the most useful and costly elements requisite as plant food is nitrogen. It is largely a product from the air. Of recent years legumes or cover crops, used as green manures, gather the free nitrogen from the air and by the process of nature transfer it to the soil. Peas, some beans, clover, alfalfa and several members of the pulse-pea family gather nitrogen and enrich the soil with the supply obtained and given to the soil 
through the roots of the leguminous plants. In addition, nitrogen is obtained from many articles but the prineipal one is nitrate of soda, obtained from the nitrate fields in Chili. 'This product when purchased in sacks is ready to sow on the soil and is immediately avalable to the plant as soon as it is dissolved by water. It dissolves like common salt. Nitrogen is an indispensible element in making early vegetables force ahead, and is required in more or less degree in the production of all vegetable products, fruits and grains. It is especially useful in all instances where rapid and abundant leaf growth is desired and is exceedingly helpful to growing grasses, either as fodder for stock, or in giving color and vigor to the lawn. For growing musery stock it is almost indispensible or as an assistant in growing garden vegetables. It is generally used as a top dressing, though not in California, when it is expected excessive rains will soon leach it out of the soil. It is hest applied in small doses at intervals of a month or so. It 100 pounds were to be applied, it would be better to divide into three equal parts and add after a rain when it must be cultivated in to reach moisture. It can be applied in trenches a distance of a foot or more from the row or drill and water applied slowly. It will dissolve and the plant will soon receive the benefit. It should not be put too far away from the plant or it may not receive any benefit directly from its application. If sown broadcast before a light rain is would all be melted into the soil; it is an immediate aeting compound when water is applied. It should not he left in piles and bunches close to a plant as it would burn it. Nitrate of Soda used skillfully is of great advantage to the gardener and of as great value as lime itself.

\section{lindurance Measures of I and and Water}

One gallon. liquid measure contains 56,000 grains. If an analysis of water shows 10,20 or more or less grains of salt of any kind, it is that many grains of the 56,000 to be deducted from its purity. The deleterious matter, found in the water and generally left in the soil after prolonged irrigation, includes chlorides, sulphides and carbonates, or common salt, glauber salt and salsoda. Of these common salt is the most dangerous to plant life as it eannot be changed; it is always salt no matter how minutely diluted. The glauber salt (black alkali) is the next in its proportion of 
danger to plant life, but it can be changed to the carbonate. 'This is a less dangerous form (white alkali) which is produced by the application of gypsum in sufficient quantities to neutralize the glauber salts and make them less erosive to the tender bark or skin of the plant.

The govermment experiments and determinations are based on the estimate that the weight of an acre-foot of salt is $4,000,000$ pounds, one per cent. of this would be 40,000 pounds and onetenth per cent. would be 4,000 . We give below a partial list $\mathrm{nf}$ endurance of plants or the total amount of these combined salts they will tolerate in the acre.

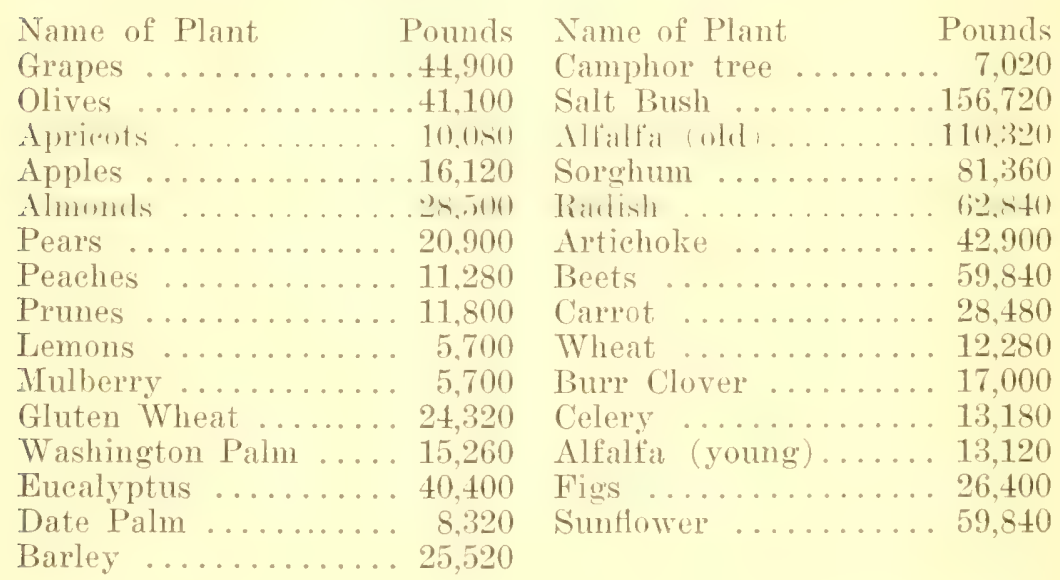

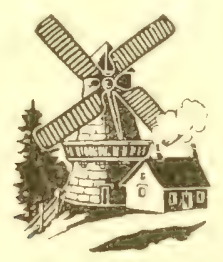




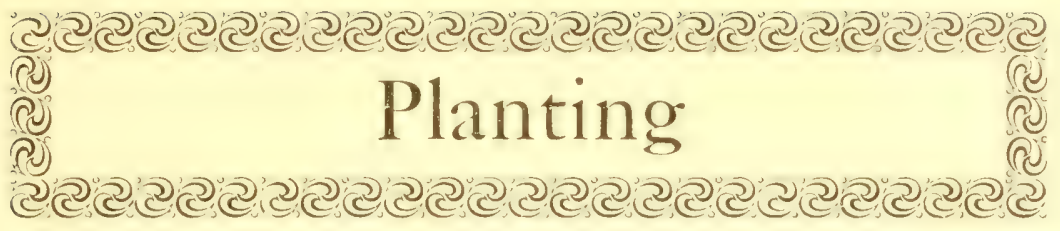

Time to Plant

While there is not a month in the whole year in California that you may not put seed in the ground as a successor to a former crop or a follower of the same, yet there are two distinct planting seasons best suited to certain plants, according to whether they require more or less homrs of sum. 'The sun nearly always shines but in some months there are many more hours of it then in others. All sum-loving plants should be given the time of the longest days which are their source of power and growth. It is wise not to attempt to disarrange the plan nature has provided, but follow out as far as possible the intimations of the plant for its development in the season best suited to its reaching satisfactory perfection. If this is not done the effort and best intentions may be mremmerative and disappointing. For instance, to plant canteloupes except in the Imperial country-in Jammary in the open, and expect rapid growth and development would be as much an attempt to change the order of nature as it would be to try to raise early cabbage in July. Both would be out of the seasonable order of planting and in most portions of California shonld be reversed. The seasons are divided into Summer and Winter, or moist cool conditions for one class of plants and warm dry conditions for others. There are a few plants that can be grown during the entire season and by adjusting their enviromment as regards position and aid of irrigation you have their product the entire rear if you so desire. Members of each family of plants are selected for this purpose that will most easily conform themselves to the ehanged conditious of temperature, for it is the few varving degrees of temperature that cause the two distinct divisions of time to which you adapt the growth of plants. There are a few plants that are at home during the entire season and conform themselves to the slight variations of temperature that oceur in the months of December and January. The list given below will give a substantial guide as to times of planting each variety named. 


\section{Planting Tables}

Artichoke-Globe, plant seed in March and April.

Artichoke-Tuberous, plant tubers from February to June.

Asparagus-One or two-year-old roots, plant from January to March.

Asparagus-Seed, sow from February to April.

Beets-Table varieties, sow seed from January to April and July to September.

Beets-Stock varieties and sugar beets, sow in March.

Beans-Broad or Windsor, best in the cool months, sow in September to December and January.

Beans-Dwarf or bush, plant from February to April, (early crop) July to September.

Beans-Pole, March, April, May and June.

Broceoli-Seed or plants, from January to Mareh and from July to December.

Cabbage-Early, seed from Jamury to March and July to December.

Cabbage-Late, plants: March to July ; seed, May to July.

Carrots-Seed from January to April; transplant from March to May.

Cauliflower-Seed from January to April, and September to December.

Cauliflower-Plants, from February to Nay and from September to December.

Chervil-Plants, February to May and August to December.

Chives-Plants, February to May; September and Oetober.

Collards-Seed or Plants, February and Mareh, September and October.

Chicory-Seed, February to April.

Corn, Sweet-Plant, from April to August.

Corn, Salad-January to April and September to November.

Cress-Seed, every month in the year.

Cucumbers-Seed, from April to August.

Egg Plant-Seed from March to July, in hot bed. Set plants from April to August.

Garlic-Sets in December.

Horseradish-Roots, Oetober to March.

Kale-Seed, Jamury to March, July to December.

Kohlrabi--Seed, January to April, September to December.

Leeks-Seed, January to April, September to December.

Lettuce-Seed, all the year, in summer months, partial shade. 
Melons-Seed, March to July.

Mustard-Seed, March to July.

Onion-Seed, February to May, October to December.

Parsley-Seed, Jamuary to April, October to December.

Parsnip-Seed, January to April, September to October.

Peas-Every month in the year; sulphur in summer to prevent mildew.

Peppers-Seed, April to July.

Peppers-Plants, April to August.

Potato-Plant in February for summer crop, and August for winter crop.

Potatoes, Sweet-Plant, Mareh to .July.

Pumpkin-Seed, Narch to August.

Rhubarb-Seed, March to April, Roots from January to March.

Radish-Seed, all the year round.

Salsify-Seed, February to April.

Spinach-Seed, all the year.

Tobaceo-Seed, February to April.

Tomato-Seed, January to May; plants April to August. August gives winter crop.

Turnip-Seed, February to September.

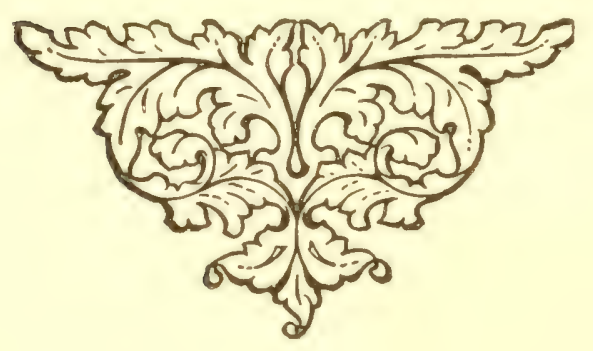




\section{Sowing and Transplanting}

All small seeds, like celery or seeds of similar size, should be sown in boxes or beds, very lightly covered, not more than three limes the size of the seed in depth of soil above them) and the bed kept warm and moist, the best growing condition, and allowed to grow in the bed till large enough to transplant. Seeds like cabbage, radish, turnips, beets, etc, can be sown in rows where they are to remain, but if protection from either heat, cold, insects or birds is desired they are best kept in boxes or beds that can be covered at will, either with lath shutters or cloth tacked on movable frames. Cabbage, cauliflower or broccoli can be kept exempt from lavages of insects, or prey of moths and in a small compass a large number of plants can be raised in vigorous health.

Care must be taken in watering plants in boxes or small beds ; the tendeney is to overdo the matter and keep them too wet, which induces mouldy conditions as well as an invitation to fungus disorders which thrive best under excessive dampness.

Sow the seed in drills slightly indented in the soil. Sow quite thickly, especially if you intend to take out when plants are about one inch high and plant in other boxes or cans, to give them a stronger root force and a steadier growth. Use nitrate of sola at rate of one tablespoonful to a gallon of water in the watering can once a week.

If you can, reset plants from the bed into bottomless cans. furnips or beets seooped ont and filled with well-emriched soil. and permit the romg plants to grow in these for a few weeks, then set in the open without removing the plant from its receptacle, and you do not for a moment check its growth. Seeds of tomatoes, eggplant, pepper, melon, squash, cucumber or canteloupe put in such receptacle as noted above and started in a warm sheltered place, can be advanced several weeks in growth before being planted in the open, withont removing them from their cradle. Transplanting should be done in the evening of cloudy weather, if possible, but if in bright sumlight small plants should he shaded with paper cones. 


\section{Environment}

By enviromment is meant that condition and surrounding of circumstances best suited to the development of the plant or animal. A polar bear does not enjoy the tropies; the surroundings are all different from its native environment. The banana is a native of the swamp, hence thrives best if given the conditions as nearly as possible like those where originally raised. If you know the habit or liking of a plant even very diverse conditions may be tempered and modifiod so they will become tolerable and even acceptable to the plant changed from its native enviromment. The trifoliata orange is an example. The orange naturally of the tropies, by being grafted to the trifoliata, or wild species of orange, may be made to live and produce in climates diverse from its native home. We do not aim here to enter the broad field of plant transterence, migration and transfusion, but to show that in a semi-tropical country very many things are possible by reason of the equable climate, in the line of introducing plants that live in a similar degree of temperature, but under diverse conditions. The banana is a fair example of what might be done by as nearly as possible giving it its enviromment. We see people rasing banana plants; some have fine fruit and again some have none, from the very same class of plants. Why the difference? One plant is fed liberally with liquid mamme, is never permitted to suffer for water, is planted in a sheltered nook where winds will not annoy and sum will always warm and the plant grows and smiles as if in its own native tropical swamp. It probably will never measure up to the plant in the tropies as far as making a commercial showing, but it demonstrates the fact that good, wholesome bananas can be raised if thought is given to its natural requirement. A lady who tries to raise violets and pansies in the heat of the blazing sum on the west side of the house soon finds they are short lived and are only a memory; as compared with those raised on the north side of the building along with the English ivy, calla lilies and many plants that prefer shade to the hot sum. Reverse the operation and put the gaillardia, the rose and the carnation in the shacle and they will prove matisfactory and a disappointment. Put ou prolific climber, the delicate blue solanum, out of the sun and it loses its leaves and refuses to bloom. The plan of "sticking things out" in any place inde- 
pendent of the claims it has upon you for the very best judgment you can supply, is disastrous alike to you and your delicate protege. It is true that occasionally au acorn will split a rock and raise a spreading oak, but the exception proves the rule that it would be unwise to plant acorns on rocks in the hope they would raise a forest, while if you planted them in the soft, yielding soil you would soon see them exceed the rockbound brother.

Before sowing or setting out plants, vegetables or shrubs, try if possible to find out or understand as nearly a possible just what condition the plant best thrives under, and then strive as nearly as possible to give the plant its enviromment. If you have adobe, loam and sand in distinct divisions on your premises, select the plant best suited for the place; cereals or stone fruit for the adobe, vegetables and small fruits for the loam, and for the sand, strawberry, melon, corn and kindred plants that love plenty of sun and warm soil. MLst small fruits will thrive on any quality of soil that has depth for their roots. The plants that are not particular where they are, if only they get plenty to eat and drink, can be put on soil not so easy to work. It is particularly necessary in bringing plants from other countries that you know what are the conditions under which they grow and thrive. A lady recently received a beautiful specimen of the cactus family from Mexico. She potted it and watered it and watered it again. She gave it wet tea leaves, soaked it with ammonia water and all the wet things she could think of to make her pet grow, but it drooped and began to rot. A friend told her one day the cactus grew without any water, save what came sparingly in the rainy season and that she was killing the plant with supposed kindness. The plant was laid out in the sun for a few days and began to revive and from the part not rotted away a new shoot started out and the plant finally became one to admire. It is said that when one of the Esquimaux that came back with Peary was given his choice between a tallow candle or a stick of candy, he invariably took the candle and ate it with a relish. The Esquimanx, after a while, ceased to crave the candle so much, and gradually became aceustomed to eivilized diet. So plants ean be gradually taught to desire changes of treatment and change of country, and the introduction of plants from distant countries is constantly being made. The Department of Agriculture has its explorers searching the ends of the earth to find plants that live in a similar environ- 
ment as alfalfa that will produce another crop in colder weather. and another species that will live with only a little water. Plants of all descriptions are being investigated with a view to their introduction to our even climatic conditions.

The whole history is as important as interesting, and as necessary to understand and take advantage of, so we may get the best results from our investigation and application of the principles of suitable enviromment.

\section{Rotation of Crops}

Rotation means not only the change of crops, but change in the order of their planting, so the successive plantings may receive the full amount of mutrition in the soil.

Where manures are applied with regularity, it has been found that rotation is not so absolutely essential, but in the absence of the replenishing power the elements become exhansted in the soil, some much sooner than others, in proportion as the crop takes more or less of its favorite element from the soil. Rotation helps keep up the productiveness of lands constantly eropped.

If a crop like sugar cane or sorghum was planted and grown previous to planting potatoes, there is little hope of receiving a medium yield of potatoes, because the cane has taken so much of the nitrogen away that there is little left for the potato, which requires both nitrogen and potash in about equal quantities. It matters not that the potash be sufficient if the nitrogen is absent or the phosphoric acid has been nearly exhausted. The crop would be a failure and either some crop, like peas, that requires less nitrogen, must be planted or the loss of the nitrogen made good.

Some reasons for rotation of crops are:

1st. It is a means of aiding in maintaining the fertility of the soil. While all crops are made up of the same chemical elements, the proportions in which they are used varies greatly, as does the quantity or proportion they leave in the soil for the use of the Enture erop.

2nd. The range of the roots of different crops makes a material difference. A shallow-rooted plant does not penetrate the depth of soil that the deep-rooted one does, hence its range is more superficial. If a deep-rooted plant had preceded it would find the element it needed had been taken away to a greater depth than it 
could reach, consequently would languish for the missing element.

3rd. Crops differ in the length of time consumed in making their growth or coming to maturity and the season in which they grow best. The nutrients of the soil are more quickly exhausted in warm than in cold weather, but in a climate where growth is perpetual the process of exhaustion is continuous. An ordinary grain crop will take away much more potash than will potatoes or most root crops. While peas and beans take nitrogen from the soil, they also impart much in return that they gather from the atmosphere. Clover, for instance. requires a large amount of nitrogen (more than a crop of grain), yet it leaves a large portion behind, which crops like barley, oats and wheat do not. The knowledge of this fact has led to the process of green manuring in orchards, using plants that, like the clover, will gather from the air, whereby new supply of nitrogen is obtained, and then such plants as require a large amount of this element can be suceessfully grown.

There have been various theories regarding the necessity of rotation. As early as 1556 Camillo Tarello presented to the senate of Venice a better plan of agriculture by alternating crops and letting the "tired soil" have rest. Dr. DeCandolla assumed that plants threw off excretions from their roots that poisoned the soil for a continuation of the same crop, but served as nutrient material for other crops. This excretory theory, while accepted for a time, was finally set at nought by Lebig's "mineral theory", as it was called, which was quite generally accepted as explaining the facts accomplished by rotation. According to this theory plants obtained their mineral or ash constituent from the soil, and from the atmosphere the supply of nitrogen and carbon.

The loss of nitrogen through drainage is less when successive crops are grown, as the plant takes up what the drainage in wet portion of the season would leach out. Intensive culture, constantly keeping the land at work furnishing food for the plant is the means of seeuring the very most from the soil.

The plan of rotation must be learned largely by experience as quality of soil, range of temperature and physical composition of the field or garden have much to do with the changes that may be made, as well as the crops you may grow. But the unerring rule may be adopted that where you follow one crop successively for several seasons there is a diminution in returns. The lesson 
is that you should seek the remedy in changing location and seed and add those fertilizers which you think have been largely drawn upon and need replenishing.

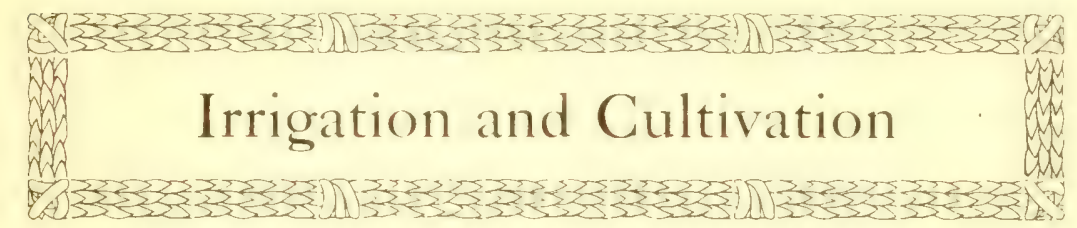

In a country that depends a portion of the year on artificial means of watering, it is necessary as nearly as possible to follow nature and study her ways so we may avoid mistakes. The natural inquiries you will make if you have not been accustomed to raising garden vegetables and fruits by irrigation are: When, how much and how shall I irrigate?

\section{When to Irrigate}

The time to irrigate is before the plant really needs it. At least, it must never suffer for the want of water. It largely depends on the nature of the soil, whether elay, sand, gravel or adobe, whether on the hillside or level ground, and on the nature of the plant, whether shallow or deep rooted. The top soil should never be permitted to bake, nor to be constantly muddy or sloppy. Nature rains and then gives sunshine. Where irrigation is used it is almost always a fact that the days are nearly all sumn ones and one of the dangers to aroid is sprinkling plants during the heat of the day. Nature never attempts the scalding process; she covers with a clond and then sends her grateful shower. In the case of orchard irrigation or where water has to be run in furrows. it frequently, in fact most of the time, has to be done in the broad sunshine, but the effect is different as the water is seeking the roots of the plant and will reach where there is coolness and shadow, just as Nature intends.

The pernicious custom of ruming water and flooding the garden or orchard, then leaving it until it dries hard, and turning on the water again and again, as often as the soil gets encrusted, is to be avoided. Air is needed in the soil. As soon as possible when 
the land is sufficiently dry after irrigation so there is no danger of making and leaving clods, cultivate or make the upper surface so it is left as a soft blanket to keep in the moisture below, preventing the evaporation that would follow if the trenches or drills were left untouched to bake and dry to the roots again. It is waste of water, time and money to let the sun lick up the major portion of the moisture intended for the plant. When a plant is starting, it requires more water in proportion to its size than afterward. When a plant is blooming and preparing to set its fruit it must have water. When a plant has formed its fruit and is preparing to ripen the erop (whether above or in the ground), water should be sparingly used. Shallow-rooted plants, especially strawberries, will want water at least every three days, as they are usually grown on sand, which dries quicker than elay soil. Much depends, however, on the character of the subsoil and how far it is from the roots of the plant. If only a foot or less it will be very retentive of water, and if the surface is kept mulched the irrigations will be required not oftener than once a week. If it is sieve soil, like gravel, and the water goes out of sight almost as fast as you put it in, it will require for ordinary vegetables watering once a week or at most two weeks. You know how often we hear: "If we could only have a shower every two weeks." Well, just supply the shower after sundown, or if in the day time in a slow, soaking stream close by the rows. If you have an acre in vegetables, fruit and small fruits, there will hardly be a day when you will not see the need of the water working on some portion of the tract.

\section{How Much to Irrigate}

How much water you will use, again depends on the kind of plant you are raising. If it is alfalfa you will want ten times as much as if you were raising spineless cactus, globe artichokes or pie melons. There are but few of the vegetables that want an excessive amount of water, and the rule as to how much is again governed by the quality of the soil for absorbing or retaining it. In past years it has been customary to use from one inch to an acre foot, according to supply, and quality of the land. An inch of water is practically 13,000 gallons rumning in a perpetual flow for 24 hours. 'This has been in many orchards sufficient for the needs 
of twelve year-old trees, but as the trees grow larger more is required and if cover crops are irrigated in, the amomt is largely alugmented. If you rum nine gallons of water from a hydrant in a minute you are getting an inch, or at the rate of an inch of watcr. And a garden growing vegetables will recuire fully as much water as the five-acre orehard the inch is supposed to amply supply. Short rows and slow streams are better than long rows and cutting. fast streams that wear away the soil and rum over the field and do not penetrate. The object shomld be to get the water into the soil rather than to see a stream run swiftly by. 'That does little other good than ageravate the plant by disappointment. Use only as much as the plant needs in the soil to keep the molerstrata filled and permeable, so the roots can reach out and get the plant food you may have supplied. It is a matter of intelligent judgment to keep the plant so it never wants, the soil so it is not overeharged with moisture and the surface so it will assist you in keeping moistme beneath, and help you reduce your water bills. Seventy-five thousand gallons per acre of garden, will be required.

\section{How to Irrigate}

Water is either piped to the land or flows in cement ditches. The means of distribution is by hose, by wooden flumes and by open ditches through the garden or orchard. For many reasoms the hose delivery is the most satisfactory, as it is the most direct and can be run over the gromed without wetting the entire surface to bring up weeds. It depends largely, of course, on how closely you have trees and plants set whether the entire surface needs the application. If trees and plants cover the entire surface, the root system beneath needs filling to meet the requirement of the plant. Again. the hose is convenient in the matter of turning a stream directly on one point or tree for a considerable time. And if you want to run water through a box containing manure, so as to liquify it, the hose can he put up over the box; also the water can be run up hill, and in many ways you can reach conchsions with the hose you could not with gravity water. as we call water ruming on the ground from a higher to a lower level point. Again, if your tract is not properly graded, you will find it difficult to run gravity water over the hummocks. So, if you do not have water from a hycrant by force through a hose, you will have 
to grade the land so the water will flow in some one direction from the highest to the lower points. Basining, or making a ridge around a tree or a bed of plants, is sometimes practiced and is especially good if you have gophers or insect enemies to drown out. Where water is abundant it is the custom to block ont the entire surface in immense basins. You need to cover the entire ground in old orehards, and this generous supply will serve the orchard for a month or six weeks, even in the driest portion of the season, August and September.

Water is often conducted in wooden flumes with gates set apart at suitable distances which can be opened by metal slides and for the entire distance small pencil streams can be run which make slow streams that thoroughly soak the ground. These flumes can be made permanent or so arranged they can be taken up and laid aside while cultivation is in progress, either by horse or by hand.

By taking inch rubber hose and three-quarter-inch iron pipe, another system of irrigation that is convenient and satisfactory is obtained. Cut the one-inch hose into pieces about four or five inches long and then comnect the iron pipes, which you can lay in any direction at any angle, even inclined slightly upward. 'Thus you may deliver water at any point within the distance you have length of pipe enough to connect. This is quite handy, as you can disconneet the joints in a moment and deliver water at a nearer point along your line, if you so desire. If your land is not graded. you can lay the pipe to connect from one hummock to the other and water at any point you wish. The iron pipe is cheaper than hose; is far more durable, as the pipe above gromud will last a lifetime and the only expense will be to occasionally get some new pieces of inch hose for the connections. Pieces of old threequarter-inch hose will comnect up halt-inch pipe and give you a smaller stream. At the end of the piece of hose that is comnected to the hydrant you will need to have threads put on a piece of three-quarter-inch pipe, and then you make your comnection complete as far as you have lengths of pipe. In watering a canyon or hillside tract of several aeres $I$ have found the pipe plan very serviceable and saving of water, as it gave the opportunity of putting the water just where I wanted it without wasting it in open ditches. 
A device has recently been invented by former Councilman Goldkamp, of the city of San Diego, whereby he delivers water in force directly to the root of the tree, beneath the surface. The implement has a valve enclosed in a pipe which is forced into the ground, and when the water force is turned on it delivers the stream beneath the surface, no evidence of any water being seen above ground. When a tree or spot is sufficiently watered the machine is readily pulled up and set down in another place to repeat its work. As a beneath-the-soil irrigator it has special advantages in the matter of saving water and cultivation, as it does not disturb the surfare of the ground.

The pit sistem of irrigation is sometimes used on steep sidehills where it is difficult to even make contour ditches. (And here let me say, never lun water straight down a hill by the side of trees or plants. They should he set in the first place, so they can be watered by the contour system, which practically makes level, or nearly level, land of descending hillsides.) A pit in the center of a square of trees or beds is made of suffieient size to hold several barrels of water and the water is run into these pits by any means you have at hand, either by gravity, or from a hose. The pit is filled with water, then covered with brush, trimmings or debris of the orchard and the water permitted to soak down under the roots of the trees. By this method there is no washing of land and the pits are placed so the cultivator can avoid them. The surface is kept in a mulch and the water is secure from evaporation. It is a useful expedient in some steep hillside situations.

If an alkali spot occurs in a new tract the best way to be rid of it is to make a drain, flood the spot with water and wash it away.

To ordinary land, a quarter of an inch per acre, based on the perpetual flow, or 3250 gallons each 24 hours, is sufficient for vegetables, fruits and erops like carrots, beets and eabbage. Even this can be divided into one-half on retentive soils underlaid by elay that holds the water in the subsoil.

The rapidity with which you can apply water by irrigation must be governed largely by the texture of the soil to admit it and allow it to spread down and through the upper soil. If it is stiff soil you will find it will require twice as long for the water to percolate through, as if it is sand, loam or gravel. 
The distance apart your crop is planted, either in rows or hills, will govern the number of furrows you must make in order to fill the soil or satisfy the requirements of the plants, and how thoroughly you stir the soil after the How of water has ceased and gone into the soil.

It is best, if possible, to arrange to irrigate in short rows from opposite directions so it will meet in the center, rather than in the usual way of wasting your water in the run-off at the end of the rows where it will do no good, mnless you have trees at the edge of your tract that will be benefited by the water that runs from the irrigated lows.

Excess of water washes away the plant food in the soil by "leaching" and taking it in light sieve soils down beyond the reach of the roots of the plant. Excess of water often brings up alkali from the under soil, destroys the germinating quality of seed and erodes the tender plants. The only remedy in such a case will be to put on more water and wash out of the soil the alkali that has reached the surface; there must be good drainage to carry it off or you will lodge the dangerous salts in some portion of the tract instead of ridding the soil of the difficulty. In such cases an "acre toot" of water is used, meaning as much water as would cover the acre a foot deep in water. On a small tract the inch in perpetual flow would put 13,000 gallons on the surface in 24 hours.

Do not as a rule flood crops; there are but few vegetables that will endure frequent flooding, even in destroying gophers and insects that congregate under the leaves of plants where you cannot reach them by any other means. Water should not be permitted to stand more than $2 t$ horrs, and less than that time is better, especially if the clay subsoil is but a short distance beneath. It is possible to drown plants with irrigation.

If you mist flood crops, use the occasion when the sun is obscured. Do not sprinkle plants except when sun is obseured, and only as a means for refreshing the leaves and opening the pores, not as a sufficient plan of irrigation. Sprinkling tends to harden the upper crust of the soil and prevents aeration. It does not sufficiently open the soil beneath so the root system can spread with sufficient power to properly support the upper structure of the plant. 
The hotter the weather the more unwise it is to either continually flood the land or let it go uncultivated.

Letting weeds grow in order to conserve moisture is a dehion and a snare. The weeds sap more moisture than their shade tends to save. Rain treats all plants alike, but irrigation gives you the opportunity to regulate the sum of water needed to suit the plant. You can segregate the plants that need less and water them aceording to their needs. Sorghum and kaffir com would not want the amount of water celery does, hence you would put them in different sections of the tract and give them each their portion in due season.

Irrigation is generally begun at the time when the winter rains have been nearly used up by the plants and you can tell by their appearance when they need a new supply. To constantly pour on water because you have an abundant supply would be unwise. because fou would soon have a lot of sickly plants that by their yellowness would try to show you the error of your way. It is a greater mistake to use too much water than too little. 'The remedy for the latter condition can more easily be applied than the former, rip to a certain stage. Most excellent crops are raised in the semi-arid regions without any irrigation, simply keeping the upper soil so loose and dust-like that it retains all the moisture beneath for the benefit of the plants; while excessive flooding and no cultivation or stirring the soil is certain death to the plant.

Irrigation can never be a substitute for cultivation and aeration, and is not a complete process any more than rain is in humid sections, where the plow, cultivator and hoe must follow to supplement the action of the water received from the clouds. Irrigation rightly applied is superior to rain, in that it gives the gardener and farmer complete control of the amount, time of application and withholding, and the latter is often quite as essential as the application. Line head ditehes with strips of cloth or gumny sacks and so completely control the flow down the ditches without eutting.

\section{Importance of Cultivation}

Stirring the surface of the soil, especially as soon as possible after a rain or irrigation is necessary in order to assist in the development of the giowing plant, and prevent disaster that would oceur if the surface soil remained untouched after being beaten 
down by the rains or flooded from irrigation water. The effect of water is to compress and solidify the surface, all of which processes are antagonistic to the easy and healthful development of plant life.

Not only does the plant require elements in the soil on which it can feed, but to make these of easy access after the water has done its work in moistening them so they will dissolve or liquify. An essential requisite is aeration, or the introduction of air in the soil, thus assisting the fibrous root system of plants to more easily appropriate the stores of food residing beneath the surface.

Cultivation prevents the hardening or baking of the soil at the surface by converting the surface into a mulch that acts equally as well as if the soil were covered with some extraneous material. It not only lets in the air, but prevents the escape of the moisture from beneath, which if left undisturbed would soon form a crust on the surface. By this means the plant would be retarded in growth from two causes: constriction of the soil, packing firmly around it, preventing natural expansion, and drying of the moisture from the surface roots of the plant.

The benefits of eultivation are so numerous and essential, so far reaching in effects, that a system of "dry farming" has been profitably built up by successive cultivation which has produced unquestioned profitable results. If the soil is so manipulated at the surface as to present a continual soft blanket or mulch, in which one's feet will leave an indention, you may safely be assured that you are griving the erop the best of treatment, conserving the full benefit of the water applied. This dust soft covering can be obtained best with some implement like a harrow, drag-tooth cultivator or hack and rake in the garden. Any tendency to muddy or sticky coudition must be avoided and the soil must be left entirely alone until the water has subsided and the top soil will easily fall apart in minute particles in the wake of the harrow or cultivator.

\section{ASPARAGUS.}

Napoleon raised the best asparagus in France, because he had the military stables of Versailles from which to draw his supply of plant food. The hint gives you the cue to the desire of this plant for abundance of rich manurial support. It will grow well on lands partly saline, in fact, if the soil does not contain considerable chloride of sodium (common salt, say half a pound to the 
square rard) it is hardly satisfied. An ounce of seed will give 500 plants, if sown in deep, rich, loamy soil. The seed should he sown in drills a foot apart and not more than half an inch deep. When large enough transplant to rows three feet apart and two feet apart in the row. It has been the custom to allow the plants to be two years old before cutting any of the tender shoots that are so highly esteemed. If you can purchase the roots two years old vou have advanced the time when you can begin to use firom the plant by two years. A bed 15 by 40 will give sufficient supply for an ordinary family. If planted as above ( $\left.3 x^{2}\right)$, it will require, to plant an acre, 7,200 roots. The roots are planted in California from November to Maroll. There are several named varieties: Conover's Colossal, Palmetto and the Bouldin's Island, the best of all. for tenderness and flavor, combined with ease of culture.

In sowing asparagus seed it is well to mix it with about fifteen parts sand; put seed and sand in a cracker box, pour on water to let it get well soaked, then you have prepared a loamy or peat made piece of soil; sow the seed and sand in the drills; make the drills four feet apart and the ditch a foot or less wide and sprinkle in the seed from the sand box as evenly as you can. Cover carefully with fincly pulverized soil; only about half an inch deep, and if the ground is in good, moist condition the plants will soon start. Keep weeds down. If you are griving field culture, and the rows are fom feet apart, it is easy to get through with the cultivator and give subsequent hoeing. As the plants in the depression grow, rou gradually at each cultivation, after irrigation, draw the earth about the young plants. 'The garden plan is usually to make a trench and fill it nearly full with wellrotted manure; dig a second trench and throw the dirt from it into the one just filled with manure, so keep on till the whole is trenched and thoroughly fertilized. Plant the asparagus roots in rows, set a stake so you know where you have planted them, and then you can occupy the ground between with cabbages, carrots and any vegetable you desire that will be out of the way by the time the asparagus is up and needs the room.

In the autumn, after the growth of the season has been made. all above ground should be cut away and burned, especially if there has been any indications of rust, a disease that is redueed to a minimum by timely use of Borleaux Nixture. Another reason for removing the feathery foliage before it drops seed is, if the 
seed were permitted to grow it would spoil the bearing capacity of the bed. as it would be filled with young plants that would sap the nutrition of the bed and make cutting difficult when the lime came to sever the shoots for either table or market use. Asparagus is one of the most desirable of vegetables and should be more widely cultivated and not relegated to the table of the epicure alone. Asparagus bears in California from January to June and is a profitable crop.

\section{Artichokes}

The Jerusalem artichoke is used more for fattening swine than for the table of the family, though the potato-like tubers are very palatable and wholesome when prepared by a skilful cook. They grow best in sandy soil and being of the sunflower family delight in warmth and moisture. They are grown like potatoes, only you turn in the swine and let them do the digging.

The Globe is quite different. It is a decidedly striking, ornamental plant and the large purple flowers it sports place it in the class of the coarse and the showy. The flowers which are well set in the light olive grey foliage, were models in ancient Greece for architectural ormamentation. The plant is a striking figure in any landscape and can be used in landscape effects. The large buds, cut before any sign of opening to bloom, are boiled and the flakes of the bud removed singly. At the base of each is a small portion of delicious vegetable marrow, the center being a solid mass of it, if it is taken before the change takes place which advances it to the flowering stage; this is important as the buds if left till just beginning to open are worthless for table use. It is a perennial. Sown in the spring, it will be ready for use by autumn; sown in the autumn it will bloom the next summer. Sow seed in seed bed and transplant to rows 3 feet apart each way. It will stand considerable drouth, but if you wish good edible florets, water well.

\section{BEANS}

California is essentially a bean country. Ventura county sends beans to the antipodes, and there is no place where some one or two of the whole catalogue can not be used with generous results. Of the dwarf or bush beans there are a dozen or more different sorts. The early Mohawk, will stand more cool weather than any other bush bean, except the Windsor. The latter, though included in the bush varieties has a very distinct form. It grows 
well in the cool months, and when the pods turn brown the matured beans are fit to use, shelled like limas, making excellent strong food. In rich land they grow five feet high and produce pods all up the stalk. Burpee's Bush and IIenderson's Bush are standards for summer use.

Beans should be sown or planted 2 inches deep, and 2 inches a part in the row in any good soil. If soil is sticky, always add samd, plaster, old plaster composed of sand and lime, or lime if the soil is deficient in that element. The Wax or yellow podded varieties are desirable; there are some eight kinds of the wax beans, including Ventura Wonder Wax, Black Kidney, Wardell's, Davis, and Golden Wax. One pound of seed will sow 100 feet of drills. If you soak the beans before planting to accelerate their germination be sure and plant in moist gromud, for you will destroy the germ if you place them in dry dirills.

The pole or ruming beans comprise quite a mumerous family, including Kentucky Wonder Wax, and the King of the Garden Lima. Of the 8 sorts generally used, the Scarlet Runner is more desirable as an ornamental climber than as a bean for the table, though they bear quite prolifically.

The Broad Windsors are planted from September to January. the dwarf bush varieties from Jamury to July, and pole beans from March to September.

Beans sometimes are attacked by anthracnose or pod rust. or with mildew. Brown spots come on pods and leaves for which use the all fungus remedy, Bordeaux mixture. For mildew (white powdery mould over the plant) use sulphur dry or made into spray with concentrated lye. Coal ashes mixed with kerosene and sown with either peas or beans will prevent the attack of the Bean bug or weevil. If on gathering your beans or peas for seed you discover the presence of the insects, put the seed in a closed vessel and submit it to a heat of 145 deg. Fahr. for an hour. or use bisulphide of carbon in an open dish in the closed vessel when the fumes will kill all insect life.

Beans can be started in a warm sheltered or covered place and then tramsplanted to the open when the soil is warmed enough for them to grow rapidly. Soil should be kept moist; the bean soon goes into a rapid decline if permitted to go dry. 


\section{BEETS}

A man once coughed up a chunk of red substance which he declared to the doctor was a piece of his lung but his good wife relieved the puzzled phrsician by stating that they "lived on pickled beets."

In California this is an all-the-year vegetable as there is no day in the year you cannot, if you wish, go to the garden and procure a supply. As in harvesting, so in sowing, there is no time when it is out of season to sow beets. 'This refers to the table and stock varieties; for sugar manufacture there are special seasons and special varieties to be grown on special soils that will conduee to the highest per cent of sugar content. There are half a dozen similar sorts of early table beets, of the round Egyptian type, quick growers like Crosby's Egrptian. All of them are dark red except Bassino, which is light colored and early. The Long Blood is excellent for deep soil. Sow in drills at any time; irills a foot or 15 inches apart; thin to six inches apart in the row. The young beets make excellent "greens." Swiss Chard or Sea Kale is a member of the family but so distinct that it is not a beet at all as it has no bulb like the other beets. It is noted for the wide white fleshy midribs of the leaves that make excellent greens or sweet pickle, but most of all as a great forage producer for the poultry yard. The plant does not attain to its best until the second year, when the midribs can be served up like asparagus.

Stock beets comprise the mammoth kinds, too coarse for table use, and can be sown from November to April in drills 3 feet apart thinned to a foot apart in the row. The Giant IIalf Sugar Rose Mangel has been known to yield as much as fifty tons to the acre. It is fine to feed to milch cows, imparting a sweet flavor to the milk and cream. Golden Tankard is a find beet not so large, but of fine quality ; Long Red and Yellow Globe are all medium sized and good stock feeders. All need deep rich soil, permeable so the roots will have no trouble in penetration. It takes six pounds of seed to the acre, generally costing about 20 cents per pound. Beets at a low estimate bring $\$ 5.00$ per ton, and there is hardly a erop that brings such large returns for so small an outlay for seed. In sandy river bottom land they make immense roots. The Improved Imperial is largely grown to feed stock and is also counted in as a sugar beet representative but it has been superceded by Vilmorin's Improved White, which is raluable because 
of its richness in sugar content. Clean cultivation is essential and expert knowledge is reguired to rletermine the degree of value in sugar content.

Beets are sometimes troubled with a fungus disease called (Cercos) or grey spots on the ieat, which if permitted to range nudisturbed will destroy the entire plant. The remedy is early application of Bordeatux Mixture.

\section{BROCCOLI.}

This is a sort of a renegade member of the cabbage family that tried to ape the mamer of the Cauliflower. It is too slow in growth, as most people who desire a flowery cabbage prefer to raise cauliflower for it grows quicker and is better in flavor when it is grown. Broceoli cuts a small figure in the California produce market and is relegated to the plane in vegetable society along with the Kohlrabi (the turnip that tries to be a cabbage)Brissels sprouts, collands, chives and similar chicken provender.

\section{CABBAGE}

'This important vegetable is at home most of the year in California, preferring to do its best, however, in the cool months and taking a brief summer vacation. Yet to keep a supply both early and late there is hardly a month in the year when cabbage is not sown or transplanted. There are tive chiet early varieties of which Early Winningstedt takes the lead, followed by Early Wakefield, Fureka and Improved Early summer. Henderson's succession, Drumheads and Danish Ball Head are among the favorites and as their name implies suceeed each other. An ounce of seed will produce 5000 plants. Sow early kinds in September.

\section{CAULIFLOWER.}

The cultivation of this plant is practically the same as for cabbage, it being a florescent cabbage. It is more sensitive to the warm weather and needs to be planted so it will attain its best between Jamury and Apilil. Dry weather Cauliflower, however, matures when other varieties come short of making good. Henderson's Early Snowball, Nonpareil, Algiers and Autumn Giant are among the named sorts. If the planting has been deferred till late and the heads are not well formed when the summer is advanced it will be helpful to skewer the long side leaves over the head to protect it from the sum, thus keeping the head crisp. 
Diseases and insects that trouble the cabbage family are incident to all alike and generally those that affict the radish, turnip, mustard, collards, chives, kale, and kindred plants, all require similar treatment. 'The green aphis, cabbage louse, cabbage worm. Hea beetles and Harlequin bug all visit the plants. In the cauliflower all these enemies are most to be dreaded because the insects conceal themselves in the florescence making it extremely difficult to dislodge them. At the first appearance use brine water, or hot water up to 112 deg., burn tar paper under the plants, dust on pyrethrum; or knock them off with force of water from the hose. Avoid if possible using any poison especially on cauliflower. From cabbage the outer leaves can all be stripped off before the cabbage is used. For the cabbage root maggot which works at the root of the plant, use bi-sulphide of carbon, prodding a hole in the soil near the root but not close to it, pour in half a teaspoonful of the liquid and close the hole quickly. The vapor diffuses through the soil and destroys all insect life near it, either worms or maggots. The Harlequin bug, a calico colored, orange spotted insect half an inch long that feeds on the plant, is best caught by decoys. Lay around pieces of boards, gunny sack or something they can hide under, gather them up and burn them. If cabbage show signs of "elub root"-contortion or swelling of the stump and roots, - which attacks allied plants, burn the first plant you see showing any signs of the disease. Lime the soil. Lime is not only the warden of the soil mulocking elements the plant needs that are locked away from it, but it is also a corrective of sour soil and soil fungus and destroys soil insects that prey on the roots of the plant. Nost of our California soils except the marls and mealy adobes are defiejent in lime and the addition will in nearly every instance be beneficial.

The novelties in the cabbage family are the Savor, giving curious curved and crimped leaves, but of excellent flavor. The Autumn King is the giant and produces enormous heads of great weight and is among the late-growing sorts. Mammoth Red Rock is the largest pickling cabbage, has solid heads and deep red color. Sow seed in beds or boxes, transplant to rows, 2 feet apart, 12 to 18 inches apart in the row according to size.

\section{CARROTS}

The carrot is a thrifty Californian and has an abiding value that is represented by hardly any other regetable, because if 
the drouth comes on it just simply stops and rests till the rains. or timely irrigation helps it to fill out the measure of its life. 'The seed is very fine and therefore camnot be covered deeply nor sown too thickly, though young carrots are, as well as the fops, relished by fowl. One ounce of seed will be sufficient for 150 feet of drills. The soil should be moist, free from lumps and kept uniformly damp until the seed germinates, which recpures only a few days.

There are ten or more varieties from the Early Short IIorr. which represents the shallow soil grower, to Mastodon the heariest carrot grown, yielding more tons of feed for stoek, than any other carrot, white and sweet and relished by both eows and horses. It is not important, when you can raise a crop at any time, that you select the very earliest-French Foroing-but the Ox Ifeart and Danvers Halt Long are suitable for any depth of soil. The Large White Belgian is grown exclusively for stock and is useful to mix with the dry rations for any domestic animal. In two months from sowing small carrots can be obtained; and to have them erisp and of good flavol they should be evenly watered. The winter season is the time to make the largest crop. If raised for poultry the tops can be cut several times and will be as often renewed. By the time you begin cutting the last row the first will be almost ready to cut again. One onnce of seed sows 150 feet in drills. Sow thinly in drills 15 inches apart; thin to 5 or 6 inches in the row.

\section{CHERVIL}

This is one of the ummsual plants, an aromatic herb, liked by some to flavor sorps. It is raised in the cool months, sown from September to June. Sow seed in open ground as you would onions.

\section{CHIVES}

This is really a grood border plant for edging in the vegetable garden. The leaves have an onion flavor and are used in soups. Of no commereial value and rather a novelty, its room can be much better occupied, unless used as an adjunct to an orderly arrangement. It can be left in chmps inclefinitely and the leaves nsed as wanted.

\section{CIBOULE}

Here is another not very useful plant and where good onions can be raised with profit, the "Welsh" Onion is not needed. Cultivate same as onions from seed. Of no commercial value any 
more than their cousins the Shallots, and all of them are not so good as leeks. They need no cultural directions as there is little incentive for growing them except the novelty of having one more variety in the garden.

\section{CHICKORY}

The only kind to grow, if one wishes to raise a substitute for coffee, is the Large Rooted Magrlenburg. It is used in the adulteration of coffee and the leaves are liked by some as a salad. It has little commercial value and is prominent among plants for being distasteful to army worms. The leaves, used to cover other plants, make resistance and partial protection.

\section{COLLARDS}

This plant of the cabbage family is used by some as a substitute for cabbage. It has a tall stem covered with miniature rosettes that have the flavor of the cabbage. It is known as Creole or Georgia Collards and furnishes an excellent supply of green feed for poultry. Sown in the cool months from February to May it is preferred to wrinkled kale for green feed for chickens. Sow and treat the same as cabbage.

\section{CRESS}

Really a window garden relish, ean be sown in a bowl and set in the window and in a few days you can cut it off close to the soil and have a delieious salad, or relish like lettuce. Pepper grass is its other name, as it is really a warm member of the vegetable family. Sow it very thickly. Write your name in the soil and carefully sow the seed and, if kept moist, in four days it will be up and your signature plainly set in the soil green and verdant. You can repeat the sowing and if you only have a window and a bowl of soil you can have a growing garten in your room.

Entirely distinct is Water Cress which delights to fill up a bubbling spring or a running stream of shallow water. Like its little name-sake, it is used as you would lettuee. It is altogether an aquatic plant and seed sown by the waters will give you returns for years to come, if properly cut and preserved.

\section{CORN SALAD}

This plant is sown in the wet months and used as lettuce which it resembles. Some kinds are disposed to make heads, but it has never filled the place of good well-grown lettuce. It is in the substitute list and of Italian origin and preference. 


\section{CELERY}

Celery is one of the important products of California. Anywhere on moist, party peat land it can be grown to best advantage. as is done on the peat lands of Orange county. There are river bottoms adjoining the sea in San Diego and other connties that can be successtully used. But celery can be raised in any good permeable garden soil provided the important consideration is met: It must be kept moist, as the plant is of semi-aquatie origin and if deprived of a sufficient amount of water to keep it advancing rapidly it soon runs to seed. It is most successfully grown in the winter and autumn months, endures very well any frosts that may come in interion valleys, but does not stand the heat well enough to make its culture profitable in the summer months. Ordinary garden soil can be well adapted by a liberal supply of well rotted manume and by the aid of deep digging and trenching similar to work done in asparagus culture.

Celery is sown in a seed bed and transplanted. 'The seed is small but not hard to germinate, if it is kept in equal temperature never sodden, never dry. Cover seed lightly because it is small and will not come through a heary load of soil. Sow in a seed bed and when the plants are up thin to about one plant to the square inch. When they are three inches high, clip off the tops about half way; and when they get four inches or more high clip back again. 'This is to give root power. Keep moist and in about a week or ten days transplant earefully without disturbing the roots, taking a good chumk of soil with them, to the shallow furrow you have previously prepared. Set about six inches apart. A wooden dibble to drive down and pull out is a good tool for making the hole to put the plant in. Put it down straight and firm the soil well around the plant hefore you leave it. Keep the soil away from the plant instead of drawing it up to it until it is a foot and a half high. Then pull the earth up to the stalks to blanch or whiten them. The Chinaman wraps strips of gummy sack around the plants to blanch them. It takes about three weeks to satisfactorally blanch the White Plume variety.

There should be four cool months in which to grow the celery. Commercially it is harested and sent east in the winter so the seed should be sown so as to meet the 'l'hanksgiving and Christmas demand. To do this, it must be sown in summer, say August, and 
must in hot locations be shaded till it has firmly established itself; and abundant moisture must be applied.

An ounce of seed will produce 3,000 plants or sow about 200 feet of rows. Mix the seed with fine sand when you sow it or you will get it too thick. Set the plants six inches apart in the low and keep well cultivated or hoed. If you bleach it with boards, set wide ones on edge and with a wire staple and hook to hold them apart and together. A crate is made to hold ten bunches, a dozen in a bunch. If plants are small it will take more, as the size regulates the bunch. A fair field of celery will vield 20,000 plants to the acre.

In hot weather and in dry places celery is subject to leaf blight and sun seald, leaves turning yellow and brown. It seldom comes if the celery is on moist land. Spray with Bordeaux early in the season and repeat later.

Celery belongs to the same family as parsnip, carrot, parsley, dill, anise and caraway. The varieties most nsed are Golden Self Blanching, White Plume and Pink Plume. The Golden Self Blanching is the favorite.

\section{CELERIAC}

This is a turnip-rooted celery and has tried to imitate the turnip-rooted cabbage kohliabi. It can be gathered and stored like any root crop and gives you celery in slices in the winter.

Sow seed as for Celery. Plant in rows 2 feet apart and 8 inches in the row. No blanching or earthing up is required as the roots are the edible part. Keep roots in cool place, when stored, and cover with straw. Long smooth Prague is a standard kind.

\section{CARDOON}

This is a plant strongly resembling the globe artichoke except that it attains a much larger growth. The edible portion is the mid-rib of the leat and stem and not the flower bud. It takes six months from seed to maturity and near the elose of its growth the leaves are gathered up, covered and blanched and the whole plant, root and all, is used as a vegetable. It is not much in favor. though some esteem it a delicacy. It takes four months to mature plants. It grows best in cool weather.

\section{CAPERS}

"Cutting capers" can be actually accomplished if you get one or two of these ornamental vegetable plants. The buds are 
hand picked and used for pickles, just as gherkins can be gathered from the nasturtium. The caper is a novelty and can be grown anywhere along the coast. Like many other plants it may be grown in boxes and multiplied by entting. As many other novelfies it has not attained commercial recognition.

\section{CORN}

While California is not a eorn state there can be corn grown for a longer period of the year than in any other state in the Union. Sweet corn can be had from June to January if planted in succession. In many portions of the state the first planting is in Nareh and it can be continued till september. Corn matures in 75 days and the roasting ears in 60 days, if the right kinds are planted. The standard kinds are Early Minnesota, Black Mexican, Comntry Gentleman. Stowell's Evergreen and Golden Bantam. Sown thickly in drills corn makes most excellent fodder for milch cows. One pound will plant 100 hills. 8 pounds an acre, 3 feet apart each way. Field varieties in the interior valleys bring splendid crops on subirigated land, and on any good moist land if planted early in March. Worms are the enemy, the same worm that aftlicts the tomato.

Planting successive crops closely together as regards time is a method of minimizing the ravages of the worms. The moth deposits its eggs in the silk, and the larva crawls into the ear and often makes sad work. If they get in the early crop, cut it mp and feed it bodily to the eow and the next oncoming corn will be comparatively free because the worms have been destroyed. Both field corn and pop corn suffer less than the sweet garden varieties from the ravages of the worms. When Agricultural Science is taught in our schools, there will be less time devoted to baseball and more to the lucrative employment of catching the moth that ammally destroys thousands of dollars worth of corn. If the moth were hunted half as vigorously as the dove, meadow lark and quail, there would soon be com erops raised as perfect as any in the United States, as there is no place where the season is so well adapted as in our interior valleys. The earliest dent corn is the Improved Leaming. The Iominy, eight rowed white flint has been a favorite. Three successive crops can be raised for table use and two or more for fodder. Stowell's Evergreen is as useful as any for that purpose. 
One pound of seed will plant 100 hills. Corn is planted in hills 3 feet apart each way, or in drills 3 feet apart and plants 6 inches apart.

\section{CUCUIMBERS}

An ounce of seed will plant 100 hills. If wanted very early, seed can be sown in February in hollowed-out turnips, beets, strawberry boxes, flower pots and raised under shelter or by a warm window or under a cloth frame, and put out in the open as early as the ground is warm. If raised entirely under cover they will have to be pollenized by hand with a small camel's hair pencil, as there are no bees or insects to carry the pollen, nor wind to blow it from the anthers of the staminate bloom to the pistillate.

About 8 seeds in the hill may be planted, but only half of these should be left if good strong plants are wanted. Roots crowded too elosely together struggle for existence. If you put manure in the hills before planting, be sure it is well rotted, otherwise it will absorb all the moisture the plants should have. The Early White Spine is one of the best tor table use; Improved Long Green is a standard; Boston Pickling is a cluster cucumber. A good erop is reckoned at 150,000 encumbers to the acre. From seed to maturity requires 60 to 80 days.

The cucumber, like most of the cubierate family, is subject to blight and mildew. For the blight, a disease that causes the entire vine to droop and die, there is no known remedy but to pull up the plant and prevent further infection. Mildew is cured and prevented in the early stages by liberal use of sulphur and spray with ammoniated carbonate of copper solution.

A double brood of pickle worms, will try to destroy the vines and the caterpillars must be hand picked. The Diabrotica punetata, a yellow spotted beetle, feeds on the leaves as does its companion the striped cucumber beetle (Diabrotica vitata). To prevent attack, use small boxes covered with cheese eloth, when plants are young; covered with these protectors the insects do not reach them. The following repellants are useful: ashes, lime. plaster, fine road dust, air slacked lime, plaster and kerosene mixed to a powder, or tobaceo powder. Apply remedies every two or three days when dew is on and be sure and reach under side of leaf. To kill the beetle use any of the arsenites mixed with flour dusted on and around the plant. See remedies. 


\section{DANDELION.}

In California this is an obnoxious plant nearly everybody is trying to exterminate, but some people want a change of "greens" and so let it grow. We have so many much safer and better plants for the purpose (spinach, kale, beets, New Zealand spinach among the best) that mustard and dandelion become easily obnoxious weeds hard to eradicate if once established.

\section{EGG PLANT.}

One ounce of seed will produce, under favorable conditions, 2000 plants. It requires strong uniform heat to germinate the seed, in finely pulverized, warm soil. Plant in April, June and July. Treat about as you do tomatoes 3 feet apart each way and give support with frames. The egg plant likes to be near the hydrant and if it receives water most of the time it shows its gratitude by increased size of fruit. The New York Spineless is early and free from spines. Black Pekin bears large round deep purple fruit and the Early Long Purple is fairly good.

Egg plant requires 160 days to mature, with most of the days warm, and is content with yielding about half a dozen fruits to the plant. It, too, has an enemy, the potato beetle, and the arsenites must be applied before fruit appears and again before it is large enough to pick. It belongs to the solanaceous family of plants like the potato, tomato, pepper, husk tomato, belladonna and nightshade. The genus to which it belongs contains from 700 to 900 species. It is very nutritious made into patties and the slices fried make a good substitute for meat. To start the seed well it is wise to sow it in boxes and put the boxes where they can have heat at the bottom from a manure pile, or other source. All its life it desires heat and moisture and detests drouthy conditions.

\section{ENDIVE.}

This plant is not used largely by our American people but esteemed highly by French, German and Italian residents. It is similar in habits to the curled lettuce. Sow in ordinar soil in drills one foot apart covered lightly. When 2 inches high, thin to about 12 inches apart in the row and when the plant has attained its full size gather up the outer leaves and tie them over the center of the plant. This excludes the air from the inside and blanches it in a few weeks. It is a hardy plant and can be had all the year. The Staghorn, a curled variety is chiefly used 
and the broad leaved Escarolle is also planted. One ounce of seed will sow 150 feet of drills.

\section{GARLIC.}

This plant, as well as leeks is an inferior sort of onion and but moderately used. In fact, both are plants on which moderation can be used with no danger of violating the rules of propriety. Culture for both is about the same as for the onion, requixing about the same rich soil and growing in the cool months. The garlic is usually grown from sets in rows 18 inches apart and 6 inches in the row. Plant in December.

\section{HORS RADISH.}

This plant needs partial shade and moisture and does not thrive in dry situations. Back from the coast, better results may be expected, thomgh good sized roots are grown if the native environment of the plant is partially supplied. It is a perennial plant and does not attain its full size in one year, the roots contimuing to enlarge with age. It is classed with the Cruciferae family with about 2000 other species. Tumip, radish and mustard are near relatives and the stock, alyssum and wall flower are among the ormamental plants of the group. The horseradish delights in deep rich soil, shade and moisture. Use small roots, planted two feet apart in rows two feet apart.

\section{KALF OR BORECOLE.}

This plant is much used for feeding poultry. It is sown in beds then set out like cabbage thinned in the row a foot apart. The dwarf curled is excellent for early use. It grows in the cool months and can be planted from August to January. The Jersey cow kale grows from 6 to 8 feet high and is for stock and poultry especially. The "Sea Kale" or Swiss chard is called kale; it belongs to the beet family but is used for the same purposes as the other kales; it is a perennial and needs two years to bring it to perfection. An ounce of seed will produce 2000 plants. The Siberian curled kale is very ornamental as well as useful. It is of a bluish green tinge and like scarlet beets can be used in color effects or masses of color if desired.

\section{LETTUCE.}

There is no more satisfactory garden plant than lettuce, in California. Lettuce sown on moist ground will give returns the 
year round and the surprises come when there is little in the market. After taking out the winter garden, soak the ground and put in lettuce, or after the summer garden repeat the operation. It is an ever ready plant if it has the right treatment, which means rich soil and plenty of water. In summer sow lettuce om the shady side of large vegetables that must be irrigated and it receives the shade and moisture needed. The cabbage varieties are preferred and the Improved Large Passion-black seeded produces large solid white heads. There are fifteen or more valrieties. Among the best are Boston Market and Paris White Cos. Royal Summer stands heat much better than some of the loose headed ones. An onnce of seed will give 2000 plants if sown in the open drill in light rich soil. For day soil mix in sand and lime. Thin to from 8 to 12 inches apart. Sown every three weeks. Improved IIanson is one of the very best and seldom is afflicted with bitterness. Cover the seed very lightly or it will not get through. especially if a crust is permitted to form, however slight. Nip out seed stalks early.

\section{MELONS.}

Musk melons, cantelompes and water melons are all considered muder this head. California soil and dimate bring all of them to the acme of perfection. An ounce of seed will plant nearly 100 hills, and 2 poinds an acre, in hills 6 feet apart each way. The green fleshed and netted skimed varieties are distinct from the smooth and ribbed musk melon. The former are found in the Rocky Fords, Mackensacks and Nutmegs. Most of them are round but Champion Market is slightly elongated. is one of the very sweetest and has light green flesh. The Rocky Ford is inclined more to the oval shape and is a favorite in the home garden. The musk melon camnot endure lack of water as well as the watermelon and will die where the watermelon will continue to struggle on till the rains come. All melons delight in warm sandy soil or light clay loams but if planted in stift soils should have some sand and lime added in the hills. Namure in all soils should be added or rather have been put in a considerable time before planting. unless you are in a position to add liquid manure, which is immediately available to the plant. As with the cuember, the seed can be planted in boxes or scooped out turuips, beets or any receptacle and that will hold soil. Yon can get the plants started in February and keep them from the cold winds under a cloth or 
lath cover till the ground is warm enough for them to make vigorous growth. A pile of fresh horse manure spread out flat, about a foot deep on which you can set the boxes containing the seed will give "bottom heat" and push the plants ahead. From summer planting as late as July you can expect good returus, as it requires only 150 days from time of planting to ripening, if the plants are kept growing. A speciality is the new Cassaba variety, which is best sown late. When at full size pick the melon from the vine and store it away in a cool place and it will ripen and keep good till the holiday times, from November to Jannary. Much is lost by letting the vines of all melons grow too long before pinching them back, which should be done when the vines are about one foot long. This strengthens the growth of the vine, makes it branch and causes the fruit to mature some days earlier.

It takes more seed in weight to plant the same number of hills of the watermelon; an ounce will only plant 30 hills and it will take 4 pounds to plant an acre. The hills should be wider apart than the cauteloupes and musk melon, or at least ten feet each way according to the kind used. Plant seed in well prepared mellow hills in any good soil. Do not place dry manure in the hills; use only well rotted decomposed manure, finely mixed with the soil. If rough manure is used it should only be for mulching to keep the hills from drying out. There are more than a dozen named watermelons: Cannon Ball, Kleckley Sweet, Rattlesnake, Dixie, Cuban Queen, Cole's Early are among the best. Nammoth Ironclad has a thin, but very tough, rind and is a good shipper, as is Cannon Ball.

The diseases of melons, particularly the Cuban, are as follows: mildew, (Plasmopara Cubensis), gives the leaf a violet frost-like appearance and is cured on the first appearance by plentifully spraying the vines on top with Bordeaux and turning them up and spraying the miderside. Watermelons are afflicted with anthracnose or pod rust of the bean. Wilt, watermelon disease, makes the vine suddenly wilt and die. It is a disease of the vessels of the stem and is most serious, as the only cure is to pull up the vines, burn them, lime the soil and plant again in another spot. Melon aphis causes the vines to have a greasy appearance, to blacken and soon die. Spray with hot water or kerosene emulsion; or put small tub or tent over the vine, then put in a small dish of bi-sulphide of carbon and close tightly with earth at the bottom 
so that no vapor can escape and the carbon will kill all insect life and not injure the plant. Use a spoonful to a vine two feet in circumference. Squash bugs, cucumber beetles and melon worms will all be destroyed by this method if used carefully. A small fight tent not more than a foot high can be made to cover the vines and a man will in a day cover a large space and kill all insects. If the melon root worm is working in the soil use unslacked lime. Spade in a short distance from the roots, and then apply water. The bi-sulphide of carbon will destroy insects in the soil if put in a hole made with a sharp pointed iron or stick, say size of picket pin. Put the carbon in several holes around any plant and close with wet dirt. Cut worms, white grubs and wire worms all meet the same fate. The carbon used too strong will also destroy the plant. 'The pie melon or as it is called in the east. "citron" is used for stock and will resist more drouth than any member of the family. Large crops are raised in unrigated disfricts, if planted where the natural drainage gives mellow soil and under moisture. The same plan as with cucumbers can be used in protecting the young vines from ravages of the striped diabrotica, hy using eigar boxes corered with mosucuito bar or cheese cloth. Poultry enjoy a melon as an increase in the rariety of food, and thus augment the egg supply.

\section{IVIUSHROOIS.}

If you can, get good spawn (seed). But much of it is shipped in and is devitalized largely in crossing the desert, for it cannot be subjected to long dry spells, or short ones either of unusual heat. 'The mushroom grows in the showery days of spring and hides away when the clouds fail to give it shelter. From this yon can understand the conditions best suited to its growth and development. If you have a shed, cellar or stable where you can keep the temperature at a range from 50 to 70 and reasonably moist and if you have good spawn, you can raise mushrooms. Get some good soil from the cowyrd or from under the trees and mix this well with an equal amount of horse manure. Nake a trame of boards a foot and a half deep, and $t$ feet wide (like the florists makes their benches only deeper). Pour in a thin layer of the compounded soil and pound it down hard, repeat this until you have a foot or a foot and a half deep. 'This will heat so you camot bear rour hand in it. When the temperature gets down to 75 Fahr. (but not below 50) break off pieces of the spawn (it is in cakes 
like large yeast cakes) and after making holes about 2 inches deep and six inches apart, put in the seed and eover with loamy soil and again beat down evenly and firmly. If the temperature is kept right with no cold drafts and with a little sun from above in about six weeks you may expect mushrooms and the bed will bear for about 30 days. Then renew the bed with an inch of fresh soil, moisten with water, cover with some rough litter and wait for the second crop. In the meantime rou can be preparing other beds to begin bearing when the first are about done. Keep the room as near like a showery day in spring as you can; moist, not too warm, with a little sunshine and lots of patience. The English spawn comes in pressed bricks weighing about 20 ounces and sells for $\$ 1.25$ a pound. French spawn is a little cheaper. Write to the Agricultural Department, Washington, D. C., for the free bulletin on Mushroom growing. A pound of spawn will plant 10 feet square.

\section{OKRA OR GUMBO.}

This is one of those vegetables not generally used but growing in favor. It does not take kindly to dry situations and gardeners consider that better vegetables ought to have the water it demands. It is easy of cultivation as it does not seem to be particular about soil. Plant about 2 inches deep in drills two and a half feet apart and when well established thin to a foot apart. It is a sun plant and wants the warm months and about the same treatment as egg plant; liberal warmth and abundant moisture. Long Green and White Velvet are the two varieties grown. It is used to thicken soups, principally.

\section{ONIONS.}

One of the most important and remunerative vegetables grown in California. The crop is produced both from seed and sets (which are small seedlings that have been pulled when about like small marbles). An ounce of seed will sow 100 feet in drills; 6 pounds will plant an acre. It will pay to have the soil very clean from weeds, let them all come up and turn them under and rake the soil well before sowing the seed and you will save a lot of back aching work weeding them out. To sow the seed, mix it with sand, wet the sand, let it stand overnight, or until the seed begins to swell, then sow in shallow drills about one foot apart, cover lightly and keep from drying out by keeping a slow stream 
of water ruming. Onion eulture requires deep rich, loamy or sandy soil ( the river beds in California generally furnish excellent provisions in soil material). You can hardly make the soil too rich as the onion is a gross feeder.

Sow seed as early as Fehruary so the erop ean get well established before warm weather comes. The plants should begin to appear in about 6 or 8 days, and if you have a wheel hoe it will be very useful at the stage when the small weeds appear (purslain generally comes). Cut the soil away from the rows first, then after they are larger reverse and throw toward them or give level cultivation. 'The dirt should never be thrown on the bulb of the plant. If you prefer the seed bed plan you will sow your seed in a bed and transplant to the open rows you have prepared and emriched before hand. The transplanting method gives more miformity in size of bulbs and a larger per cent of large onions. When the plants are growing from seed you cannot tell which are runts and should be discurded.

Some growers make a seed bed over a bed of horse mamure, so as to force the seed ahead for early transplanting, sowing from September to February. Seed in bed are sown broadcast and when pressed down, covered with some mulching or cloth to pre. vent drying, and watered throngh the light covering. The covm ering is to protect the bed from washing by rains as well as to conserve the moisture. Warm, light soils bring the crop forward most rapidly. When moved from the seed bed the plants are lifted with a shovel; separated, top and roots shortened about one-half and then dropped in the prepared rows and set with dibble three inches apart and the soil well firmed around them (a most important matter in all transplanting to keep out dry wind and to retain moisture). The cost of growing a crop from seedlings and then transplanting is more than growing from sets. but weeding and thimning rows from seeds in the field. add to the cost of cultivation.

Some onions produce "top onions" or sets instead of seed and should be planted 8 to 10 inches apart in the row and rows 2 feet apart. Let the sets get well dried and then store them in a cool place, not in a deep pile. It is risk to place in sacks or barrels, where they are apt to mould in damp weather. Plant sets in February in rows a foot apart. If you camnot make straight rows without, use the garden line. When they are up well, spread a 
top dressing of well-rotted manure over them, just before a rain if you can strike it. 'Thin ont for use and leave the rest far enough apart to grow large onions, some for winter use and some for more sets. You can make "bottom sets" by sowing seed thickly and when they are about the size of marbles pull up and dry thoroughJy and store in a cool place till you want to plant again. If you sow seed as often as you plant the sets you will have a succession.

The prineipal varieties are Bermuda, Anstralian Brown, Large Red Wethersfield and Prizetaker (a beautiful yellow onion). Large Mexican grows to weigh 6 pounds. Yellow Cracker is an onion that matures quickly and is desirable for early culture. The White Bermuda is also an early favorite. White Portugal (silver skin) is a good keeper and fine for the garden. Six hundred bushels per acre is a large erop.

Onion diseases: Rust (leaves turn yellow and plant wilts and dies) comes from soil infection. Rotate erop and burn all diseased onions. Black smut kills first the leaf and the death of the whole plant follows. Drill in sulphur and lime, about an ounce of the mixture to a fifty foot drill. The onion maggot, much like the cabbage maggot, feeds at the roots. Lime the soil and use bisulphide of carbon by piereing holes in the soil, pouring in the liquid and closing hole so it will penetrate the surrounding area. Chives, Ciboule and Shallots are all onion flavored plants not much used but raised like onions.

\section{PARSLEY.}

Grown much the same as lettuce, parsley makes a fine border plant in the garden. It is used both as a salad and as a garnish and is especially useful made into tea as a specific for urinary troubles and is properly classed with the members of the herb garden. It desires rich soil and plenty of water. It is ornamental as well as useful but by no means can be classed as having much commercial demand. Sow in drills 1 foot apart, cover seed $1 / 2$ an inch, thin to 4 inches.

\section{PARSNIP.}

'This useful vegetable needs deep permeable soil and prefers the cool months and ean be planted from August to Jamuary. It resents being placed in shallow, hard, soil, but responds with liberal quantity and quality in the right location. Sow in rich soil in drills 18 inches apart. The seed being small must not be cov- 
ered more than half an inch deep. When they come up, thin to 8 inches apart. The Long Smooth and Student are the two varieties of standard growth and used either for field or garden. 'The insects that occasionally trouble it must be treated to arsenites. (Paris green and flour, one part green to 20 parts flour, dusted on the plant for the worms to eat.) It has often been said that parsnips need to be frozen to give them the required flavor, but this is a mistaken idea as far as Califomia is concerned, and fine flavored parsnips raised in rich deep sandy soil not one-fourth of a mile from the salt water are very fine in size, texture and flavor.

\section{PEAS.}

Both for garden and field culture, the pea is an all-the-year crop and is planted during every month of the year. But it is more productive in the cool months and less liable to mildew. It is an ever present erop if rightly managed, though in hot interior loeations it is not so profitable. It prefers light frost to drying heat, and will endure more of the cold than of the heat, so the summer erop should be planted where it can, if possible, have the protection of shade from the hot afternoon sun of summer. Near the coast peas that come in in mexpected times always bring good prices, for there is no more desirable vegetable than peas produced from California soil. Peas grown from September to March should be placed on the sumiest slopes or situations, for while the pea will resist much cold, it must have sufficient warmth to amply supply its demand for rapid growth. Seed sown in August and September can be depented on to give you a supply in December, but there is not a month in the rear when you may not plant and expect and receive returns commensurate with the care and management used in raising. Warm situations are preferable for winter crop and cool half shaded locations for summer. North hillsides facing south and east where the afternoon sum is soon hid are good summer resorts for the pea.

Peas are divided into early, medium and late, aceording to the time in which they bear their crop. Alaska is the earliest of all, followed by McLean's Little Gem, American Wonder, Nott's Excelsior and Gradus. The "medimms" are Advancer, Strategem and Heroine. 'The larger, later standards are Yorkshire ITero, Telephone and Champion of England.

Peas are much used for gathering nitrogen from the air and giving it again to the soil, Canadian Field peas, Whippoorwill and 
Scotch Blues are used for this purpose extensively in orange and lemon orehards.

The first early variety should be sown in October. One pound will sow 60 feet of rows, if sown thickly, though this should be governed largely by the soil; if light and thin the seed should be sown thinly. Too much nitrogenous manure make the peas rum to vines. The peas do a large amount of nitrogen gathering themselves, as you will see if you examine the nodules (little warts) that come on the roots which are really nitrogen sacks filled to give back to the soil. If you pile in too mueh nitrogen it is like "carrying coals to Newcastle".

A good plan for summer peas is to plant a row of sweet corn several weeks before you do the peas; the corn will furnish shade if planted on the west, and the peas will cling to them for support after you have gathered the corn. In winter plant the rows east and west so the sum will shine longest down them.

Mildew attacks peas as well as beans, in long continued warm weather. A sovereign remedy is to put in a small quantity of sulphur in the drills when you plant, and as soon as up sprinkle sulphur to prevent the appearance of mildew. Pea weevil sometimes attacks the seed peas and beans, in which event use bi-sulphide of carbon in the closed receptacle that holds the peas; it is a small black beetle that lays its eggs in the growing peas and develops after ripening. A repellant composed of sand mixed with phenyl and sown with the peas will keep the bugs from coming to the peas. If the weevils are discovered in the peas they may be subjected to a bath of hot water up to 145 dgrees for one hour and it will not destroy the germinating qualities of the pea but it will effectually dispose of the weevil.

Perhaps there is no place in the world where the florescent variety of peas are so easily and profusely grown. Sweet peas laden the air with their perfume and will climb a six-foot wire netting and still go on above it. They can be planted as often as the garden pea, and similarly cared for, except that yon keep the blossoms continually picked off and the crop is almost perpetual.

\section{PEPPERS.}

'The pepper is usually an anmal, and the field crop as well as the garden product is gathered at the end of the ripening season. Often in the tree form it lives for several years and is both ornamental and serviceable in culinary preparations, as well as hav- 
ing positive medicinal qualities. Peppers are usually started early in the season in boxes in sheltered places and after gromud is warm are put in the open. In ounce of seed will produce 1500 plants. It needs strong uniform heat to germinate them. Then plants are 3 inches high transplant in rows 3 feet apart and allow 2 feet between the plants. Keep soil well ("ultivated to conserve moisture for while the pepper does not do its best in water soaked soil. vet it requires even moisture from time of sowing seed till it is harvested. It will endure drouth and hardship, but it is unprofitable to permit it to suffer for a nexded supply of water. The ciistance apart we have given is where a horse and cultivator is to to be used but for garden culture they may be as near as one foot apart and rows eighteen inches.

The Bull Nose is a lares, early variety. Nammoth is as larere but of milder disposition. Golden Dawn is really a Yellow Bull Nose. 'The tomato-shape pepper has no particular merit over others except for making stufferl pickles. Ruby King is the popular favorite, in having red pods $50{ }^{2} 6$ inches long and 3 inches in diameter with Hesh thick, sweet and mild. The long red Cayenne is pungent and used for pickling. Ped chili is small and pungent and used for making pepper sance. Cherry Rexl, the tree form. is ornamental as it has blossoms and ripe fruit on the shrub at the same time. The pepper has f'ow enemies and seems pungent enough to ward off all comers. It is planted from April to July.

\section{POTATOES.}

There is no more important crop than the potato, for if wheat is the staff of life, the potato is its first assistant. On subirigated land, river bottom lands, and bench lands skirting on rivers or valleys, the potato is grown without irrigation. but almost everywhere if two erops are raised in the season irrigation is a valuable help. On the high mesas the winter crop is planted in February and generally the rains are sufficient to make a generous erop. In the irrigated portions of the state potatoes are planted at almost any time. but usually in August and September or February and Narch. But where irrigation is provided there is no reason why potatoes cannot be produced nearly the entire year, care being taken to rotate and not follow several crops of potatoes in sucecession, as the soil sometimes becomes infected and the tubers are spoiled by scab). December and Jamuary are the frostiest months in California so the aim is to have the erop dodge these months 
by the planting in August so the crop can be harvested by Novenber, then plant in February and dig the crop three months after. Now if you have sandy, moist soil there is no reason why you should not plant again in April and make the third ciop. Light rich soil is best for potatoes so the root system can extend readily, if heavy soils only are obtainable they must be improved by adding limes and roughage, all plowed or spaded in and thoroughly decomposed before the seed is planted. It will be seen from the nature of things that deep working of the soil is essential in order that the tubers may not be constrained in their effort to expand. The level system of cultivation is best muless you have a superabundance of water, and then it is not wise to use too much; sogged potato is next thing to a dose of pikery. The hill system presents a double surface to the sun and the evaporation from the soil is increased. With level cultivation, the soil should be kept very fine to prevent as much as possible the moth laying egg's near the roots of the potato as it will do if clods and lumpy ground are prevalent. Some iaise potatoes under mulching after a thorough irrigation or after the winter rains, spreading a thick mat of straw or hay through which the plant pushes. The dependence is that there is sufficient moisture beneath to serve the crop till it is matured, the straw mulch keeping out the sun and holding all moistme beneath. 'This will do if there is an abundance of litter at hand to cover the patch good and deep, say six inches, and of conrse all hoeing is dispensed with and weeds do not appear. Greatest are in harvesting should be used not to leave the tuber exposed any longer than possible, as the potato moth is instant in season and out of season to fill the eyes of the new tubers with eggs which when stored hatch a crop of worms to eat the potatoes. Burbank. Salinas, Early Rose. Early Ohio and many other kinds are sold but the first mentioned are the standards and produce clean, smooth tubers.

It is best to change seed every year and get it from the north as better crops are secured thereby. Potatoes are planted in rows two and a half feet apart with hills a foot apart. The seed may be in whole tubers or potatoes cut in quarters. The government reports are of the opinion that whole, fair-sized potatoes produce best crops. If you were to save your own seed, it would be wise to select the smoothest, hest specimens, and if this were followed in every season the time would be well spent as the improvement in "breeding up" would show marked artvantage. 
Fortunately we are not troubled with the Colorado potato beetle, but the potato moth (same pest that attacks the tomatoes) is always ready to get in its work. This or any biting insect is discouraged and eventually cast down by giving the plants a sprinkling of Paris green mixed with Hour. (See article on remedies.)

If the potato vines get the "early blight" (follage turns brown and spotted and soon plant dies), use Bordeanx mixture by spraying it on just as soon as you discover the disease. No time should be lost as the disease works rupidly.

The potato dealers when they store their potatoes resort to the use of fumigation with sulphur candles or bi-sulphide of carbon to destroy any insects that may hatch after the potatoes are in the sack or bin. The bi-sulphicle is as explosive as gasoline and care must be used in preventing a light in its neighborhood.

In the spring before planting it is well to give the potatoes an immunity bath made by dissolving one ounce of corrosive sublimate (rank poison) in 16 gallons of water. Put the tubers before eutting in a sack and hang them in the solution for an hour and a half. It is a preventative against "scab". 'Three hundred bushels is a tair yeld of potatoes from an acre.

Some people demand that potatoes be sprouted before they plant them. The danger is if the sprouts get too long they will get rubbed off and the potato has lost just that much time. If potatoes are good and sound and have well defined eyes they will grow in any fairly good soil, the more pliable the better.

\section{PUIMPKINS.}

These grow to immense size in California. An ounce of seed will plant to hills, enough for several families if nothing befalls them. Big 'Tom, Nammoth Tours and Cushaw are all large and you might as well have the largest going. 'The Connecticut Yellow is rather indifferent and hard to get over its staid New England ways. It seems to aroid the spread of the grants and does not over work itself save on color, for it is as yellow as ever only more so. It has the same enemies to contend with as the other members of the family find are insulting to them and the treatment for the enemies of the melon, cucumber and cantaloupe will apply to the pumpkin. We plant four months in the year and they grow eight months. Like the smaller members of the family if they rum too much to vines ent them back and let them know they are 
expected to raise pumpkins, and not make a survey of all the adjoining territory. P'lant in hills 8 feet apart.

\section{RADISHES.}

All kinds, shapes and sizes grow the entire year and if you do not sow them they will sow themselves. Round, long, oblong and spiral; red, white and purple; strong. medium and mild; from the little French Breakfast to the long White Chinese, which grows large enough to fill a quart measure. Sow at any time and place, where your fancy dictates and you know you can give them water, and they will give returns in about 30 or 40 days. The Trimmph will mature in 21 days. The Chinese and Spanish kinds are especially used in the cool months and French Breaktast in the summer months. An ounce of seed will he sufficient for a bed \pm feet square.

Being a near relative of the tumip and cabbage it gets some of their enemies when they have more than will go round. We never do anything to them, but just make a new bed in a new place. You ean not put or spray anything on them with safety if you want to eat them in a few days.

\section{SWEET POTATO.}

The sweet potato in California is usually "great", and in any loamy, sandy soil with enough water to keep it growing will give good returns. Flow deep and level well. In large fields the shouts are planted by machinery in shallow, wide furrows and as tney grow the earth is pulled toward the plants and in some localities finally made into ridges, but what we have said abont level cultivation respecting Irish potatoes applies to the sweet potato. The tubers want to go down rather than up for their moisture and plant food. The sweet potato grows readily from euttings, if planted out directly after severing from the parent vine, and in moist ground; this method is followed if you only have a plant of a rare kind and you want many plants in a short time. The usual method is to plant whole sweet potatoes in a seed bed of sand where hundreds of sprouts will come on the potato. These are carefully broken off and planted in the drills as before mentioned. You can make a drill in the open garden and fill a trench with horse manure then spread on good sandy soil six inches or more deep, wet it and tramp it down, thus improvising a hot bed and when it has steamed some of the heat away plant the potatoes, keep moist and in about eight weeks more or less you will get 
sprouts to plant; when you pull them off the tuber's they will take with them the small bunch of roots they have made ready to start in business with. The tubers in the pit will then send up more sprouts for a seeond crop if you need them later. We plant in the open from March to July according to locality.

To get early potatoes, instead of pulling off the sprouts you take a whole potato out of the warm pit and cut a piece of potato with each bunch of sprouts and plant that. It goes on undisturbed, while the sprouts have to eateh on again. You have to enltivate or hoe the weeds ont after planting till the vines cover the ground. The rows should be at least 3 feet apart and it is wise, when the space is all filled with vines with a sharp spade to cut the ends of the vines to prevent them piling over each other. 'They also give more attention to making tuber's and a better crop is the result.

To preserve the potatoes after digging you must in some way sweat them. Pile them up around a cone of wire netting set up endwise, make the cone or roll fast with stakes, pile the potatoes up around this wire roll and form a sort of chimney. Cover the pile with straw and the potatoes will sweat like a beaver. Uncover in the middle of the day and let the perspiration dry off, then cover again and repeat till the potatoes are dried out sufficiently to permanently cover with hay or straw enough to keep out sun and rain, but so that air can penetrate. This will be found the safest way to keep sweet potatoes, which if piled up and left to themselves get dry rot, wet rot, black rot and several other kinds, because they are so thin skimned. The varieties used are Yellow Nansemond, Large White and Jersey Red. Make seed bed in February and plant until May.

\section{RHUBARB OR PIE PLANT.}

Sow the seed early in February in drills 18 inches apart, cover an inch deep and thin the plants to 6 inches apart. Keep down all weeds and when the plants are about one year old, plant in a bed well enriched by an abundance of well rotted manure. Set them 4 feet apart each way, and do not cut the stalk till next year. Keep them well supplied with manure. If you plant roots in the fall you may expect to cut pie plant the next year. After the second year it can be increased by division of roots. Rhubarb needs rich soil, not so particular as many plants about the texture, if it is only retentive of moisture, it cannot endure a high degree 
of heat and must have good mulching to keep the moisture in the soil. It grows to perfection in the foothill regions of the state. The Crimson Winter is considered a decided acquisition and will grow so much better under all conditions than the older kinds, that many are raising rhubarb who could not raise it before. It matures six months earlier than the Linneus and is a constant instead of a periodical bearer.

A grub $3 / 4$ of an inch long is its enemy and has its home in the wild dock. Burn the wild dock and the roots of rhubarb that are attacked, or the eggs will be laid in the roots.

\section{ROSELLE.}

This plant of the hibiscus family has flowers something like a small hollyhock. The calyx of the flower, in fact the whole plant is of a mucilaginous nature and all can be used to make a very appetizing form of jelly, about the color of cranberry. The calyx of the flower can be dried or kept indefinitely and made into jelly at any time. While not much used because we have so much fruit, yet it supplies a place, where fruit is scarce in the form of jelly that costs no more than other kinds and is produced from the plant the first season. It should rather be classed with the fruits than the vegetables, though the jelly can be used to thicken soups if wanted. A row of it is quite ornamental as a border plant or backing for smaller plants. It is a sum-loving plant and wants a long season. Plant in boxes early and transplant.

\section{SALSIFY OR VEGETABLE OYSTER.}

This is also quite an ornamental plant as the purple thistlelike flowers grow from 3 to \pm feet high the second year on going to seed. It is the roots that are particularly useful (grown about like carrots or parsnips) and give a most valuable addition to the list of table vegetables, having a decided oyster flavor and being very appetizing either boiled or fried. The "Sandwich Island" grows to an immense size. Sow from September to May in drills 2 feet apart. Thin to 6 inches.

\section{SPINACH.}

This may be an all-year plant in California under irrigation and is like parsley a beautiful border plant for the vegetable garden. If raised in connection with that plant the shadings of green blend most harmoniously. It is used for "greens" and by successive plantings may be had coustantly; its handsome curly 
leaves are ever bright and clean. The New Zealand variety has won praise in California for its better drouth resisting powers than our native American plant. The trouble has been that some have not learned how to use it, taking the whole plant and boiling it, and in so doing finding it very tough in spots. It grows so prolifically that only the tender ends need be used, and those before any sign of seed pods are visible. When boiled tender, not even Missouri can furnish "greens" to beat it. The native spinach should be sown in drills a foot apart and thinned to six inches while the New Zealand will cover several feet in circumference, shading the ground with a thick mat of vegetation which helps it to resist so successfully the dry heat. But to have tender spinach it must have enough water to keep it erisp and green. Chickens that are confined under the new methods of poultry raising enjoy it as they do the companion plant from Australia, a triplex semibaccata. The latter also can be used ornamentally with good effect. Sow when you feel like it.

\section{SQUASHES.}

All kinds and shapes can be raised nearly all the year. From the little summer variety to the giant Chili, Summer Crook Neck, Boston Marrow and IIard Shell Turban, there are in all more than a dozen to choose from. All require about the treatment accorded melons and pumpkins and the same enemies need the same treatment. Plant the bush varietics about $t$ feet apart. Hubbard aud Turbaus 8 feet apart. Plant in February in boxes to transplant again.

\section{SORREL.}

A plant not generally in use but cooked and used as spinach. Some persons prefer it mixed with spinach as it has a tart flavor that is quite agreeable. It is sown in the cool months at any time and in drills 18 inches apart. It remains in the ground and makes an excellent border, if on the north side, and not too much exposed to the sun, as the action of heat increases its acidity.

\section{TOMATOES.}

One of the most useful and reliable garden products in California and in what is termed frostless ground the plant lives and bear's nearly the entire season. The seed can be planted in such locations as early as January in boxes in sheltered places away from the night winds and put in the open in March, when seed can 
also be sown in the open ground if desired. The success of the tomato depends largely in keeping it in vigorous, rapid growing condition, and if unchecked in its early stages it will soon develop fruit. In respect to fruiting it must be remembered that hardfy any plant will successfully pollenize below a temperature of 70 degrees. Often complaint is made that the blossoms do not set fruit; the reason is obvious, there has not been sufficient warmth to make the pistillate blossoms receptive to the pollen from the staminate flower. Both are borne on the same plant and require warnth, a light breeze or the action of insects to perfectly accomplish the work of pollenization.

An ounce of seed will produce 1500 plants and if sown in boxes should be transplanted into other boxes a distance of 4 or 5 inches apart and when strong and stocky should be set out in well enriched soil 4 feet apart. By supporting the vines and vigorously trimming the non-hearing laterals the plant will produce more fruit. It is enstomary with some to train to a single stock. tied to an upright stake, leaving only enough foliage to prevent sun-scald.

Early plants can be secured by planting seed in bottomless cans and starting them in the house, letting them grow in the eans leaving them undisturbed until you transplant to the open ground after removing the can. The cans are prepared by putting them in the fire, when top and bottom will fall out and the side seam open leaving only a cube. This you fasten together with a piece of wire (old cans and baling wire are a public asset here), this set in a flat box and fill with good sterilized soil (soil that has burned under a brush heap killing all weed seed and insects). Then sow seed, and water carefully, finally leaving one or two in the can to transplant. By this means your plants never receive a check from start to time of planting in the open, and if carefully watered will grow on without hesitation.

There are more than twenty different kinds. Earliana is, as its name implies, one of the earliest large smooth vigorous, growing tomatoes, and very prolific. The several Stones are bright, smooth and meaty. Crimson Cushion is a good variety for winter bearing. Ponderosa is the largest fruited tomato grown, often weighing from 2 to 4 pounds each. It has few seeds, with firm meat and is a healthy, luxuriant grower. Acme and Beanty are both meritorious, produeing smooth erimson fruit, of a fair size 
and excellent flavor. The small tomatoes like cherry, pear, strawberry and yellow plum are prolific, but little used commercially. All are very easily grown, as is also the husk tomato which onee in the garden, is hard to eradicate. In favorable seasons large shipments are made to markets in the eastern states and the winter crop of tomatoes is a source of profitable income. 'To secure a good winter crop plants must be set as early as August and kept vigorously growing when an abundance of smali fruit set on the vines before the days become too cool for pollenization. All the fruit set no matter how small will grow and come to perfection under the winter sum.

The diseases of the tomato are not many but the "wilt" is the most distressing. Where it appears, the best remedy is to immediately pull up the plant and bum it before others are infected; it is a sudden collapse of the entire plant without evident cause. The brown spot of the leaf, similar to the potato disease, will soon destroy a plant, and Bordeaux should be applied to the diseased plant, and all in its vicinity, as soon as discovered. Nematodes is a disease of the roots, the plant begins to fail and faint, turns yellow and finally dies. On examination you will find the roots are covered with nolules (warts) which prove it to be a soil difficulty. The plant must be pulled up and the soil treated with a good application of unslacked lime. Plant some other regetable before you put tomatoes there again. The worm that is so severe on your com, likewise attacks the tomato and either must be picked off by hand or applications of Paris green and flour. one part to twenty. must be used to destroy inseets of any and all descriptions that bite the foliage or the fruit.

The rot of the tomato is a very serious malady, if permitted to spread. The ripe fruit, and fruit in all stages, are infected by a spot, at first violet colored then turning to brown that rots the tomato. The application of Bordeaux in the early stages is a partial preventative, but it is found that the application of one ounce of bluestone in six ounces of water, well dissolved, then applied with a brush, rubbing in the liquid on the spot, is a cure. All diseased tomatoes should be sathered and bumed, not left on the ground near the vines. If the "ringer" or leaf hopper appears, a repellant of ashes mixed with kerosene is obnoxious to these insects which erode or eat the young plants. The fruit worm before mentioned (Helioanthis armiger) feeds ravenonsly on the 
fruit. If possible it should be destroyed without putting poison on the tomatoes, unless the fruit is small.

\section{TURNIPS.}

This is a useful crop for the cool months and can be better sown broadeast or in drills 15 inches apart and thinned to 8 inches apart. An ounce of seed will sow 150 feet of drills. Turnips thrive in almost any soil but prefer deep loam well enriched with manure. They can be sown from September until April. If sown in drills they are more easily cared for, weeded, or irrigated.

There are ten or more varieties to select from. Both the white and Swedish rutabagas bring good returns for care bestowed. Sweet German is one of the very best for table use, as is the Improved Yellow rutabaga. The turnip has some of the family troubles left over from its cabbage inheritance. A serious one is the fly which can be subdued by sprays of kerosene and water, one part kerosene to 10 of water.

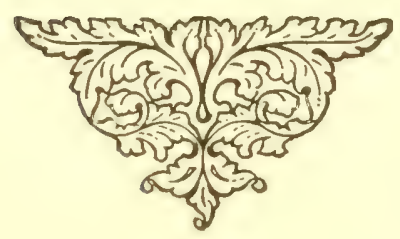




\section{Aromatic and Medicinal Herbs}

The climate and long period for garden operations in California make it desirable and almost indispensible that the garden be supplied with the herhs so nseful for both flavoring and medical uses, so effective in the hands of on elderly murses. The dirertions for sorring the seed, most of which are very minute. are to cover them in well prepared soil in drills with not more than twice their thickness of earth, and keep moist till they germinate. They can all be sown in the cool months and some of them will mature the first season. To get the most out of them they should be gathered before they get into full bloom and be earefully hung away in paper sacks to dry and be ready for use on demand.

\section{ANISE.}

This plant is so common as to be eonsidered one of om wild roadside plants, yet it possesses an agreeahle aromatic flavor. The seeds as well as the plants are used for cordials and garnishing.

\section{SWEET BASIL.}

A seasoning of very high flaror and used in somps and stews and spiced meats.

\section{CARAWAY.}

This is well known for the seed it produces abumdantly which is used by confectioners in bread and pastry, giving agreeable Havor.

\section{CATNIP.}

Catnip grows well, but few however raise it. It makes good bee pasture as well as having medicinal qualities of a seclative nature. The leaves are used for seasoning.

\section{CORIANDER.}

The seeds only of this plant are employed by confectioners and restauranteurs to give flavor to licuors.

DILL.

The seeds only are used. They have a pungent aromatic taste 
and are used as a condiment and for mixing with cucumbers as pickles.

\section{SWEET FENNEL.}

Both leaves and seeds are used. The leaves boiled are used in sauces and make a beautiful garnish. The seeds are used for Havoring drinks and confectionery.

\section{HOREHOUND.}

Entire plant is valuable, when dried, for seasoning and in the manufacture of well known cough remedies and candies.

\section{LAVENDER.}

One of the most beautiful as well as fragrant plants, emitting a most delicate and delightful perfume. Used in the manufacture of perfumery. No flower border is complete without it.

\section{SWEET MARJORAII.}

The leaves and tender shoots are highly prized for seasouing by culinary department of the home.

\section{ROSEIMARY.}

A native wild plant yielding a distinctly agreeable perfume and by a few used as seasoning in dinner preparations of vegetable composition. Cultivated, it makes a most beautiful shrub.

\section{SAGE.}

One of the most easily grown and extensively used of all our family of aromatic herbs and in seasonings and dressing almost indispensible. While it grows so profusely and easily, it is so often put in neglected places and forgotten that when the leaves are needed an order has to be sent to the drug store or grocer, when the garden should supply it at small cost.

\section{THYME。}

Mnch prized by some persons, but not so generally desired as sage for seasoning meats or vegetables and soups.

\section{WORIMWOD.}

This plant possesses medicinal qualities of a bitter nature. It is quite as valuable in the poultry yard as anywhere, as a preventative of some prevalent disease in fowls. It is cleansing in its effects. 


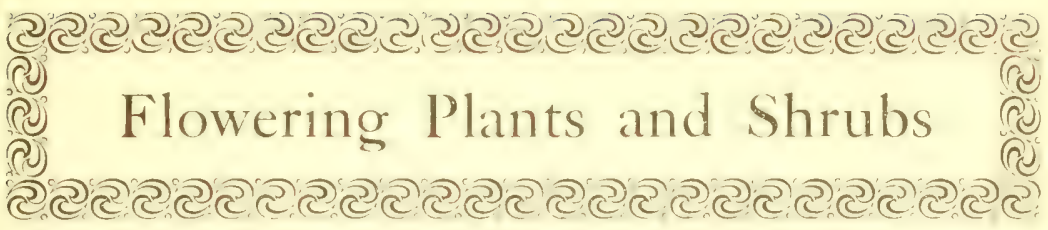

This list will grow and thrive where there is an annual rainfall of ten inches and endure with less, lout all are benefited by an occasional irrigation.

The first on the list are the Acacias, in many forms from a delicate fern-leaved shrub to the tall spreading specimens like A. Melanoxylon. Most of them have dark green, slender foliage and an abundance of yellow bloom. There are some thirty-five specimens to select from, nearly all of which will giow with the annual rainfall of Southern California.

Ceretonia siligua; Casuarina, several sorts growing to majestic trees; Guadalouperisis Cupressus, or Guadalompe eypress and Cypress sempervirens; Phomician .Jniper and Lawson eypress are among the evergreens that make imposing objects in the landscape. Of the pines there are Pims IJalpensis, P'. Insigna, P. Pinea, P. Monterey and P. Torreyana. P'epper or Schinus molle is a great favorite, Grevillea Rolusta is a tall growing tree with old-gold colored bloom, commonly known as Australian Silk oak. The grevillea family is quite extensive. The handsome shrub with scarlet blossoms is the best of the few used in California.

The Eucalyptus group are abounding growers and can be selected to suit almost any locality, from the E. globulus, which delights in low moist situations to the E. rudis which will endure the extreme heat of the desert situations. E. rostrata. E. corynocalyx and E. robusta are fine specimens for dry situations. Mysoporum and Pittisporum, low growing shrubs with thick leaves and fragrant blossoms, are desirable. Mysoporm latifolia has a lighter shade of green and is well liked.

All the Lantanas endure light rainy seasons and all cacti, some of them giving exquisite masses of bloom. The Euphorbiascrown of thorns-the Melalucea or bottle brushes; Lavendula, and the wild native shrub of the same order, bearing feathery, olive green foliage. known as rosemary, completes a partial list (which might be greatly extended) of the groups most serviceable in resisting drouth. 


\section{SHRUES THAT ENJOY SEA WINDS.}

Shrubs and plants that will grow if exposed to heavy sea winds are: Tamarisk plumosa, most graceful and desirable for aclornment near the ocean front; most of the acacias; Ceretonia silinua; Mrsoporum; Pinus Torreyana; the Pepper; Atriplex Halimus (old man); the Bottle brushes; Oleanders in various colors; Cupressa Macroearpa; Juniparis Phoeniciana; all the low growing Veronicas.

\section{STREET TREES.}

Trees suitable for avenues and streets are Camphor, Acacia dealabata and A. decurrens; Araucaria Bidwillii and A. Brasilisnsis; Eucalyptus ficifolia (red flowering) and E. rudis (will stand much hardship); Jacaranda miamosafolia; Nagnolia; Rubher and Grevillea robusta. The last named stands drouth well, but drops leaves constantly and on that aceount is not so desirable along sidewalks.

\section{ORNAIVENTAL TREES.}

Some of the most desirable ornamental trees are: Arancaria excelsa. A. Bidwillii; Cedrus deodora; Acacia riciana fern foliage); A. Baileyana; A. Cultriformis (odd shaped olive green leaves); Arbor vitae; Thuyas; Banksia Australis; Italian Cypress; Casuarina equistifolia; C. Cunningham; C. tunus; Crasus illicefolia; Cestrum nocturnum; Cryptomeria; Cryptomeria elegans, from Japan; Brachychiton acerifolia, or Australian flame tree; Jacaranda; Nagnolia grandiffora; Pinus Canariensis; Sequoia gigantea (redwood); Melia or umbrella tree; St. John's Bread; Monterey Cypress.

\section{PALIMS.}

All the Chamaerops are not obtrusive like the Phoenix or wide spreading specimens we see so frequently monopolizing the entire front yard. Chamaerops excelsa (windmill palm) is modest but gets up out of the way if planted near the sidewalk. 'The Cocos is very graceful and desirable, especially C. plumosa, C. Anstralis and C. butyracea are not so well and favorably known. Cycas revoluta or sago palm is a specimen of individual beauty, adapted to almost any situation on the lawn. The Dracenas are numerous and odd but not especially ormamental, except for their positive tropical effects. Seaforthia elegans is the most graceful subject to place in any ormamental grounds; it has a grace and 
beauty all its own. All are easily grown in California, but like the banana should be put in a sheltered position where the wind will not injure them. The Washingtom palms, Robusta and sonora are familiar objects in our landscape, and a long arenue of either is always a striking illustration of the value of miformity in planting.

\section{NOVELTIES.}

The Yuceas, Aloes and Bamboos grow in magnificent profusion. Camnas, Callas, Caladiums, Hydrangeas, Hibiseus, Eehum simplex (Honey-plant), the graceful crep-flowered Matilija poppy are among the novelties. The Marguerite and Eschscholtzia are familiar to all and never out of place. Melianthus, Poinsettia. Poinciana and Papyrus are ever objects of beauty. 'The Spanish broom. Sedum, Crinums and Amaryllis are useful. A profusion of bulbous plants by which to adom the home, are varied in torm and color. A wealth of climbing rines is requisite for ormamentation.

\section{ROSES.}

The rose is here not only the queen but in some form can be found in fragrant exposition nearly the entire year. It delights in a soil that is loamy at the surface underlaid by permeable clay. It should be planted in the full sumlight; if it mildews and refuses to produce perfect hlossoms in the shade move it to sunny spot; if it continues to mildew discard it and plant the varieties that do not blast so easily. If mildew comes, use sulphur plentifully; if the red rust use the Borleaux. (See formulas.)

Standard or tea roses are usually budded to thrifty stock of the native wild rose. Plant some wild roses to be ready to bud on any variety you wish. The Tea roses are called ever-blooming and if rightly cared for, produce new wood constantly, and thus fill up the season with constant masses of fragrant bloom.

Banksia roses or cluster roses produce small flowers, but an abuntance of them. Bengal or China roses are moderate growers. not over fragrant but give compact growth and brilliant colors. The Bourbons make moderate growth and need close pruning. They have thick foliage and blossoms generally of light color. Hybrids are constant bloomers and nearly always give full returns from pains bestowed. Hybrid Perpetuals are not perpetual bloomers, but are striking in form and color. Irbrid 'Teas are 
stronger growers and combine freer blooming qualities with rich coloring. The Japan or Rugosas are usually single flowers with glossy foliage. The moss roses do not thrive well in Southern California. The Noisettes are of American origin, and vigorous growers with a tendency to grow in clusters. The Polyanthas are from Japan, rich in colnt, bearing panicles of almost perpetual bloom.

The Prairie roses are not used much in Southern California. There are constantly being grown new shades and forms of exquisite beauty, some of these are climbers. Kaiserina Augusta Victoria, Meteor, La Marque, Cloth of Gold, Niphetos and Marechal Niel.

\section{TEA ROSES.}

Bon Silene, dark crimson; Bridesmaid, Catherine Mermet, light flesh; La France, pink; Duchess, Maman Cochet, Etoile de Lyon, finest yellow; Gloire de Dijon, buff center, hardy; Madame Joseph Swartz; Papa Gontier, brilliant carmine; Reine Marie Henriette. This comprises a partial list, but one generally admired and satisfactory in cultivation. The rose needs feeding liberally with nitrates combined with farm manures.

\section{CARNATIONS.}

Next to the rose the camation thrives and delights thousands who find them in profusion here during the winter months. They are easily raised from entings with bottom heat. Their variety is as charming as their fragrance. 'They can be raised in any good garden soil well emriched. The carnation does not enjoy poverty of soil, responds to liberal stipplies of liquid manure and is generally robust in growth.

\section{OTHER FLOWERS.}

Ageratum, tall blue and dwarf white and blue, fine for masses and bedding, from half a foot to one and a half feet high.

Alyssum, white, dwarf and compact for border and edging, easily grown and spreads rapidly.

Amaranthus, three feet high, good for background to mass among shrubbery; colors: red, crimson, purple and gold.

Argemone or Mexican poppy is showy with mixed colors, but not a great favorite.

Asters for Autumn blooming are indispensible for the humblest flower garden and are a close rival of the Chrysanthemum 
and a bed or border is a souree of pride and joy to its possessor for several months in the year. They can be planted in suceession and made to cover a long period of blossoming. One to two feet in height.

Balsams, the old time Lady Slipper with their mixed colors are the gay firiends of the summer, one to two feet in height.

Cosmos, from white to scarlet, from one to four feet high, good for back of border.

Califormia Poppy-Eschscholtzia-golden yellow and the recent ereation of scarlet. Cammas, Linum, Nigelia, Marigold, Mignonette, Nasturtiums, Delphiniums, Lobelias, Nemphillias, Phlox, Chrysanthemums, Stocks, Salpiglossis, Sweet Peas.

Among the list of peremials are, Dianthus, Shasta Daisy, Gaillardias, Petunias and many others.

A few flowers require partial shade. 'The following are best suited for the north side of building: Callas, English Ivy, Pansies, Violets, Campanula, Gloxinia, Wallfower and the Swan River Daisy, free bloomer with flower's similar to the Cineraria, native of Australia.

Calendula is a sunloring plant of the portulaca type, low growing and good for rock work. Calceolaria (sown in August) beautifully mottled, blotched, striped, one and a half feet high. Calendula, yellow striped, one foot high; Calleopsis, profuse bloomer, brown and yellow, fine for masses and border, two feet high; Candytuft, good for horder or masses, colors range from scarlet to white, one foot high; Catchfly (silene) mixed colors, one foot high; Celosia or eoxcomb, mixed colors, from dwarf to two feet, - the list could be continued through all the range of the annuals and biemnials with profit, but search flower catalogues that make yearly lists and select from them.

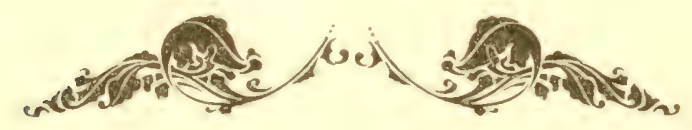




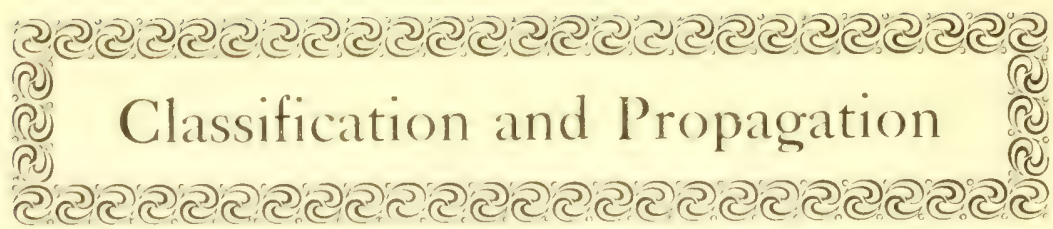

THE BEST KNOWN FAIVILIES.

We give from various authorities on horticulture, some statisties in relation to the great families of plants as now known and classified. The botanieal family name usually ends in -aceae. There are two hundred families or orders of flowering plants: 7,000 genera; more than 100,000 species described. There are many mole flowerless plants, as ferns, mosses, mushrooms, fungi, lichens, sea weed and microseopic plants.

The Crowfoot family includes the elematis, marsh marigold, cow slip, columbine, adonis, buttereup), larkspur, aconite, peony. nigelia and others, making over 12,000 species of plants living in all parts of the world. There are one hundred species of clematis known, and fifty distinet species of larkspur (delphinium) only a few of which are cultivated. Sonthem California has some of the most intense indigo blue varieties. The peony is found wild in vieinity of Pala and the Palomar momtains and in foothill districts, but does not thrive near the eoast.

The magnolia is a well known tree in California having been introduced from China and its immense blossoms and robust proportions make it a striking figure in park and residence grounds, in all parts of the state. Ot the seventy species about fourteen are magnolias proper.

The waterlily family (Nrmphaeaceae) is represented by eight genera and thirty-five species, all aquatic. The lotus, water lily and bladder plants are well known representatives.

The Mustard family (Cruciferae) embraces many of the well known vegetables, all the cabbage group, turnips, horseradish, sea kale, cress and radishes. It contains 2000 species, among them flowers like stocks, alyssum and wall flower.

The Violet family has about two hundred and fifty speeies distributed over the world, the larger portion being violets. Some of this family attain the size of shrubs.

The Pink family (Caryophyllaceae) has fully 1,000 species and thirty-five genera. The ornamental genera are the dianthus. camations, saporiaria, silene (catchfly) lyehnis. Dianthus, 
"Jove's Flower" number's two hundred species and the corn cockles and eatch flies are included in the family.

The Mallow family (Malvaceae) in its entirety is at home in California. The best known of the seven hundred species are the hibiscus, holly-hock, malva, African mallow, abutilons, gossypium and cotton.

The Linden family is represented by the flowering maples and the chestnut, both European and Japanese. Only a few of the seven hundred species are represented in California.

The entire Pulse family (Leguminosae) is especially used in agriculture. In the orehards as cover crops several are used and there is hardly a place in the world that can excel the California display of sweet peas, beans, clover, locust and acacias. The sensitive plant is among the representatives of the 15,000 species and from the garden pea to the mesquit of the desert are all represented in California.

The Rose family (Rosaceae) is here as elsewhere the very first among the families of plants. It embraces the apple, pear, quince, strawberry, dewberry, blackberry, peach, plum, apricot, almond, cherry and mountain ash. All have blossoms in form like the wild rose, Chexokee or Manchuria rose.

Of Roses mole than two hundred and fifty have been named, but three dozen will include those really valuable for culture. There are five thousand species of strawberies. The entire Rose family has one thousand species divided among seventy genera. It is the most important group of plants in California.

The Vitas or Grape family is equally important as far as its value to the fruit grower is concerned, as grapes from all countries in the world can be successfully produced here. There is no nobler specimen than the IIuscat species which anmually produces an immense revenue in the form of raisins. The Emperor and Tokay are shipped to European markets.

The Cactus family has a thousand species. The latest and best are the spineless varieties being cultivated for their utility as food for stock and poultry and the improved fruit they bear. Some of the most brilliant, but generally of brief existence are the blossoms of the group, especially the Phylocactus.

The Carrot (or Umbelliflora) family includes in the thirteen hundred species, parsnip, parsley, celery, caraway, anise and dill, all well known in om state. 
One-ninth of all the flowering plants belong to the Composite group with ten thousand species, of which the sunflower is the type. Lettuce, endive, cardoon, artichoke are all inchuded, but by far the larger number of eomposites are ornamental plants.

The Heath (Ericaceae) family includes the cranberry and huckleberry. Among the flowering shrubs of the group are azaleas, rhododendrons, and lilacs a large number of which are found in the mountains of California and Mexico.

The Primula or primrose family have about two hundred and fifty species. Florists divide the group into auriculias, polyanthus, primioses and cowslips.

The Olive or Oleaceae family comprises the privet, jasmine, ash and our well known olive so reputable in commerce. There are one hundred and thirty species of jasmine, two of forsythia, half a dozen syringas and twenty-five privets. Of the thirty-five olives, the Mission, Manzanillo, Ascalan Oblitza and Servillana are the best varieties for pickling.

There are some eight hundred species of the Convolvulus or Morning Glory family which includes the valuable sweet potato but the opposite is found in the parasitic dodder which is injurious to the bee plant. wild buckwheat.

There are thirty species of the Phlox family but the annuals thrive better than the peremials in California.

The Solonaceae or potato family is an economic one of great importance as it includes the tomato, pepper and egg plant. Among the fifteen hundred speeies are included the night shade and belladonna. The light blue flowering elimber solanum so frequently seen in yards and ormamental gromuds is one of the most conspicuous.

There are about two thousand species of the Mint family composed principally of the aromatic herbs, not extensively grown in California.

The Nettle (or Utracaceae) family have the most dissimilar gromping of any of the families of plants. To place the fig, mulberry, bread fruit, elm, hop and osage orange under the same classification seems to any one but the botanist sheer absurdity, yet a close study of some points will disclose a family resemblance.

There are about thirty species of the Walnut (Juglandaceae) family. There are several waluuts and eight or ten hickory nuts, natives of the western states. California has a native walnut on which it is best to graft all other rarieties. 
'The Cupuliferac or Oak family numbers four hundred species: beeches, bixches, hazels, filberts, alder, hornbeam and iron wood are classed in the cupuliferae group. Our California Live Oak is one of the noblest specimens of the group.

Orchidaceae or Orchid family numbers five thousand species, most of them uncommon and rare, many of them are epiphytie, or grow ahove ground on other plants. They grow chiefly in warm bogs and deep shaded woods of the tropies. Our Lady slipper is related to the family.

The Iris (Iridaceae) tamily is at home in California, and comprises many showy garden flowers well known as iris, gladiolus, ixias, tigridias and eroens, seven hmmed species in all.

The Amaryllis family comprises many lily like plants producing rich profusion of bloom. They include the crinums, Guernsey lily, nareissus and others, some seven humdred species, divided into sixty-four genera.

There are more than two thousand species of the Lily family. Tulips and hyacinths are included in this group, also some treelike specimens as aloes, yecas and other ornamental plants. The garden onion and also the sea onion are relatives of the family.

There are eleven hundred Palms, some of which produce edible fruit like the date and cocoanut. They are divided into one hundred and thirty genera.

The Pine, coniferae or cone bearing family include plants and trees of very dissimilar form. Most of the family have needle like leaves sometimes deciduous and the ginkgo has broad flat leaves. There are three hundred species in the family. There are about seventy true pines, thirty of which are native to the United States. In California the Monterey pine and spruce, the pinus halpensis, Torreyana, Canaresensis are among the best known. Many spruces, larehes and arbor vitaes are objects of beanty in our ornamental grounds. The Araucarias, Cryptomerias, Lawson and Italian eypress and the graceful Cedrus Deodora the most useful and best known.

The classification of plants has been the patient work of botanists and scientists for a century past and the new era of development will add many valuable additions to the multitude now known and rlassifier. 


\section{POLIEITIZATION AND HYBRIDIZING.}

'The process of plant creation is similar to all other pro-creative processes, the male and female organisms being requisite in union to produce the life of the plant. The majority of plants and trees have the staminate and pistillate organisms on the same plant and produce different blooms that by the pollen (seed dust) of one flower entering the ovaries of another flower, the life process is begun. The walnut is well known instance of this, the catkins or male flowers blooming and hanging above the female bloom. If both are in condition at the time, if no violent winds or storms blow or wash away the pollen, it falls into the ovaries of the pistillate bloom and the tree produces a crop of walnuts. The hop and the date are instances of the opposite form. where the trees or vines are male and female, but individually separate. The pollen from the male tree must be carried by insects, by winds or by the artificial process of hand pollenization from the male to the female, or no perfect fruit will be developed. In the case of the hop, about one male plant is set among a hundred of the female and wind and insects convey the pollen that produces the future crop.

It will be seen at a glance how important the process is to the gardener and farmer, and how often blame is attached to seed, plant or seedsman, when the truth is that conditions have not been favorable to perfect pollenization. Tomatoes grown in the winter when the temperature is below 70 seldom produce fruit, and in the early spring the same difficulty oecurs. They bloom profusely and wonder is expressed that they do not show signs of fruiting but instead the blossoms fall off unfertilized. We do not use the term "fertilized" with reference to application of manures and compound fertilizers used as food for the growing plant, but refer to the action of the pollen as the life seed introduced from the staminate to the pistilate or aranism of the plant, which produces; future life, variation, perfection or non-perfection as the case may be.

In greenhouses and places where the ageney of bees or other insects, or light winds cammot come, it is often necessary to assist nature in her work by "hand pollenization", or by taking some of the pollen grains from the male plant and with a camel's hair pencil introducing the pollen into the fiowers of the pistillate, which can be distinguished by their having no stamen and anthers. The pistilate form, if ent open, would be found to contain minute 
seeds waiting the coming of the pollen grains to give them the vivifying touch of the power to change into perfect life, which is withheld withont the mion of the two.

The requisites for perfeet pollenization are the proper degree of heat, the blooming of the sexual flowers at nearly the same time so insects can carry the pollen from one flower to another when the pollen dust will remain in the viseid, warm cup of the ovaries that receives it. The pocess is wonderful and by it the multitude of varieties in plant life are comstantly being produced in form, taste and color that are astonishing and alike miraculous, to those who do not investigate the reasons for the changes in form and hue of the flower and the texture and flavor of the fruit.

The Divine plan of pollenization being a systematic one, it opens ride the door of diseovery, investigation and development of myriads of diversified forms that in their change, which seem mysterious, add new creations to please both the eye and the appetite of man. Pollenization is a means placed in the hands of the careful operator to add multitudes of blessings to the world. Patient minds like that of Luther Bubbank and others have by the use of pollenization suceeeded by this, and selection, in produeing hybrid forms of fruit, vegetables and flowers that constantly add to the use and pleasure of mankind.

The development of plant life to higher and better orders or forms of the same species is every where present, and on every hand can be seen creations that have been developed from some wild and untutored species into the broadest usefulness. With the eye of prophetic promise, Mr. Burbank looking into the future has grandly said: "A day will come when man will offer his brother man not bullets nor bayonets, but richer grains, better fruits and fairer flowers."

The work of the botanist of a few years ago was to select and classify the mummies of plants, a work both needed and beneficial. But the work of today is to step into a broader arena than the mausoleum of plants. It was supposed that they had no destiny beyond the fixed classification griven them, that heaven and earth would pass away but not one jot or tittle of the stilted classification could be changed. But we have learned that the entire range of growing beauty from the humblest violet to the majestic sequoia, are as clay in the potter's hand to shape into forms of either usefulness or' dishonor, as he may see fit. The changes 
that can be made in the most plastic forms are simply marvelous. We have not space here save to hint at some of the ways nature has the mirror held up to her face before and after her transformations from the insignificant and dingy to the magnificent and gorgeous in color, form and utility. That the time has come when every body can be a Burbank is not quite evident. Few people have the untiring patience to grow thousands upon thousands of plants just to get one that is suited to the purpose, or to understand just what they want, or know when they have secured the right element in the plant to set it out as a new creation. But the light is dawning, the apostles of new creations are multiplying and under difficulties are blazing the way for future horticulturists to follow the same trail, or blaze ont one of their own that shall lead to ulimate triumph in the realization of the fact that they have perfected, changed, hybridized some new plant that placed beside its former relations does not seem like one of the family.

The theory and practice of stock breeding, improvement and selection for certain types are well established and by crossing different breeds the qualities of one are combined with those of the other and a new "type" is obtained. The "beef type" and the "dairy type" are now well known to people who a generation ago only knew the quality of a Texas steer by the length of his horns.

In early times the process of "selection" only was used, and it look hundreds of years to search out the king plant; by the system of the "survival of the fittest". Now by crossing species of plants of the same order, changes in hue, form, texture, growth and commercial value are obtained. It is the wisdom of the ages concentrated in the epoch of the new era of plant development.

In the method of eross-pollenization, two or more seed parents are prepared by first eutting off a large proportion, leaving not more than an eighth or tenth of the buds on the plant, so the whole force will be concentrated in the buds to be operated on. When they show signs of coming to bloom the emasculation is performed. With a sharp pen-knife the anthers, stamen and corolla are removed from the hloom left on the plant and the bright corolla being gone it is no more attractive to the bee that would bring the pollen haphazard from some objectionable flower. Or the emasculated buds are covered with gauze or thin paper sacks so no intruder can approach the floral altar with strange. 
fire. From the anthers of a flower of a better plant the pollen has been gathered and the fine pollen grains caught in a glass receptacle and then carefully dusted over the emasculated buds and the work of intelligent pollenization has heen begum. Sometimes it is necessary that a camel's hair pencil shall be used to introduce the grains into the receptacle of the unpollenized flower. If the work is carefully dome fruetification immediately begins and the Hower gives birth to a new seed, which in turn must be planted and the result is only known after one, two or three seasons waiting in patient expectation, sometimes only to be disappointed. The new seed may hark back to some of the indiscretional habits of its great grand-parents and the change may have to be gone over again: sometimes as high as 10,000 changes are made before the right combination is obtained; as many as this were manipulated by $\mathbf{M r}$. Burbank before his tamous potato was secured.

It often ocours that "freaks" are developed and there seems at first to be no assignable reason. But the theory of accilental pollenization acoumts for it. By some means a bee or other insect got some special pollen grains on its wings or body and at the right time flew to another blossom and deposited its precious grain that gave new form to the flower, or fruit, that so surprised you with its superior qualities.

Gathering and planting the new seeds, watching the seedlings as they develop, and selecting the one needed to cross again, and again, is the work of hybrdizing. It is painstaking, patient, anxious labor, but amply repars all the expense of time and skill. These hints are given that possibly some one who reads these lines may be induced to make experiments along lines of least resistance and finally produce something worthy of his day.

"Some mute inglorious Milton here may rest,

Some Cromwell guiltless of his countries blood."

If you camnot originate, you can secure some of the new creations, but your trees to them and thus directly secure the benefits of the improvements in such finits as the plumquot. Bartlett pears. ladeless flowers and yellow lilies, and many other worthy productions that you can grow while in your own way experimenting to produce new forms your ideas may suggest.

Accidents sometimes happen to trees. TTe see them loaded with bloom and the promise of the erop is manificent, but we are disappointed; nearly all the fruit drops. We think bak and re- 
member about the time the tree was showing its bank of showy blossoms, a blistering storm of wind and rain came and the pollen was destroyed; in some places the frosts prevent proper pollenization, and so nature has to withstand her rebuffs just as we mortals do, but she smiles and says the burden is lighter this year, so I can do better next.

\section{NULTIPLICATION BY CUTTINGS.}

The following list is intended to show at a glance what plants and trees are multiplied by cuttings.

Figs-Either soft or mature wood, cut slips eight or ten inches long, plant so one bud will be out of the ground.

Mulberries-Cuttings of mature wood, plant in February.

Olive-Cuttings of mature, even old pieces of stumps, large chips with bark on planted so the shoots ean push through.

Pomegranate-Cuttings or by laying down a limb covering with earth, and cutting from parent tree when rooted. Seeds ling thrifty plants.

Quince-Cuttings which are sometimes grafted.

Grapes-Cuttings of three buds long, one left above the ground.

Tomatoes-Cuttings ' $\mathrm{T}$ shaped, horizontal part in the soil.

Currants-Both currants and gooseberries are made from hardened wood planted in moist soil.

Blackberry-Root cuttings and suckers from the roots.

Raspberry-Root cutting and tips from end of rumers that have rooted.

Loganberries-Root cuttings and cuttings of the vine and tips that have rooted at the end.

Dewberries-Root eutings and layers that have rooted.

Strawberries-From runners, tip cuttings and divisions of plant.

Cranberries-Layers and divisions.

Begonias-From leaves.

Verbenas-From layings cut from the parent plant.

Sweet potato-Pieces of vines, both ends inserted in the soil to form an arch above ground. 


\section{Fertilization}

The important fact very often lost sight of in intensively cultivating the soil is that as fast as plant food is exhausted from the soil it must be renewed, by means of applications of fertilizers, either organic or inorganic. Barnyard manure and debris of any character that will impart food to the soil are organic. If mineral or inorganie substances are used, they must be reduced by acids, a process called acidulation. This reduces the solid chemical matter to liquid form, the only form in which a plant can absorh or take up any fertilizer. If unacidulated hard substances are put into the soil, they must wait to be dissolved by the chemical action of the carbonic acid that comes in the rains or in irrigation water and often will wait for months and years before the plant can be benefited by them. Liming the soil is very impontant in soils that do not carry lime, as it is a solvent for many of the substances already in the soil or those you add mechanically and while not a direct plant food is a material that eamot be dispensed with. especially in sandy soils. And in stiff clay soil it is essential for its mechanical effect, in breaking up the clay so it can be more easily worked, and made more receptive to air and water.

\section{ANALYSIS OF FERTILIZERS.}

Somrees of nitrogen and the per cent they contain showing the best material to procure to replenish the waste taken out by plants; Ammoniate 3.43. castor bean pomace 1.91. cotton seed meal 1.91, fish 8.25, dried blood 1.9:3, waste of horse hoof 1.83, lobster shell 3.52 .

Substances furnishing Phosphoric Acid:

Apatite contains, per cent 36.08; bone black, 35.89; bone meal, nitrogen, 4.12; phosphorie aciel, 8.28 to 23.50; Carribean guano, 18.90; Cuban guano, 13.35; Mona Island. 21.88; Nassau phosphate, 34.37; Peruvian guano, 16.26; S. Carolina rock, 28.93; Carolina rock dissolved, 15,20.

Potassic sources: Carmallite, 13.68; cottonseed, 23.80 potash and 8.50 phos. acid; Kanit, 13.5t; knigite. 8.42 ; muriate of potash. 52.46 ; nitrate of potash. 45.19 and nitrogen, 13.09 ; spent tan bark ashes, 2.04 and 1.61 phos. acid; sybarite, 16.65 ; wood ashes, 5.50, 
and phos. acid, 1.85; leached wood ashes, 1.10 and phos. acid 1.t1. Nitrogenous fertilizing substanees:

Ammoniate 11.33 and p. a. 3.43; Castor pomace, 5.56 and potash, 1.13 and p. a., 1.10; cotton seed meal, 6.66; dried blood, 10.52; fish, 6.81 and p. a., 8.23; horse hoof, 13.25; lobster shell, 4.50 and p. a., 3.52; meat scrap, 10.t1; water sprats, 4.04 ; nitrate of soda, 15.75; sulphate of ammonia, 20.50 ; tankage, 6.82 , and p. a. 11.25 ; tobaceo stems, 2.29 and potash, $6.4 t$; wool waste, 5.64; corn cob ashes, potash, 23.30.

Nitrogen is very essential in all organized life whether animal or vegetable. It is the basis of albumenoids in plants, the casein in milk, the fibrin in blood. The various forms of nitrogen mean ils combination with other chemical elements: nitrogen as nitrates, nitrogen as ammonia and nitrogen as in organic matter-decaying substances. Nitrogen as nitrate is nitrogen combined with axygen in such proportion as to form nitric acid. United with some other base as for instance soda or potash, it is nitrate of soda or nitrate of potash, lime and whatever the base may be. Nitrogen as ammonia means its combination with hydrogen in a proportion to form ammonia, one part nitrogen and three parts hydrogen; this gas readily unites with different acids and forms sulphurie and nitric acids again forming ammonia salts. Animal and vegetable matter contain chemical constituents, carbon, hydrogen and oxygen. A large number of materials differing widely in their characteristies contain nitrogen in some form. Plants deriving their nitrogen from the soil receive it in the form of nitrates that have been reduced so the plant can assimilate it. Nitrogen in organic matter is first changed by decay into ammonia and from ammonia into nitrates. It is often the case that the best forms of plant food are found in material that is not so costly nor so long in becoming available as in slowly decomposing forms as rock, hair and substances that stand chemical attack a long time. Nitrate of soda is the best form, for when pure it contains a larger per cent of nitrogen and is so chemically constituted that it immediately dissolves in moisture and the plant takes it up directly. Nitrate of potash or saltpetre furnishes potash in addition to mitrogen. Dried meat or azotine is meat dried and ground without the bone and is an excellent source of nitrogen. Tankage is the dried refuse of slaughter houses and is usually classed as a nitrogenous substance, though it contains a fair per cent of 
potash. The waste from fish eameries is a good somree of nitrogen. "Menhaden pomace" made from fish refuse is a source and all fish refuse is advantageously secured in regions near the sea where the maxim of Franklin can be practically used: "A herring in every hill of corn." Leather meal, horn and hoof meal, cotton seed meal are all products obtained by steaming or grinding the substances mentioned and are among the variable sources of nitrogen.

Nitrogen must be carefully used because when soluble in water it is easily movable in the soil and by rains can be washed beyond the reach of the plant and lost while the other elements phosphoric acid and potash, become fixed in the soil and remain sometimes in an unused state for a long time and of no service to the plant till aeted on by lime or some solvent as the agent for converting it into a form the plant can take up. So nitrates are not applied in large quantities in the fall to lie in the ground all winter as is the case with barnyard manure. Materials that contain nitrogen in organic matter must wait in the soil.

\section{AVAILABILITY OF FERTILIZERS.}

In cold countries, where the ground is inactive a portion of the year through frost, applications of manures may be added prior to the closed season and will be in the soil to become active with the return of warm days. It is mwise to apply nitrogen when rains are abundant, because it is easily leached out and lost bnt organic forms that must stay in the soil a long time in order to become available by being sufficiently rotted may be put in at any time. Materials like blood, fine ground bone and fish will decay in one season and be taken up by the plant, but horn, hoof, hair, leather, wool, etc., will require several seasons to complete their decay and become available to the plant. So of course rotting slowly only a small per cent of their content is given off at a favorable time and they must be applied in larger quantities.

\section{Phosphates.}

Phosphoric acid derived from phosphates means that the phosphoric acid is united with some other material like lime, iron, alumina and form phosphates of lime, phosphate of iron, ete. Lime being the best form is more generally used as basic slag, which is a combination of lime with the phosphoric acid from iron in the making of steel, is united by fusing with fire and collects the 
phosphoric acid from the iron and makes a valuable powder that is readily taken up in the soil and by the plant. Mineral substances as a rule do not yield up their phosphoric acid so it will become soluble in water, a condition that must obtain with all material intended as plant food. Bones of animals are a fertile source of phosphoric acid. Bones from the same animal differ in composition according to the age of the animal and the location in the carcass. Young bones are less rich in phosphates and richer in nitrogen and in older animals the order is exactly reversed. If bone is treated with diluted hydrochloric acid and the phosphates of lime dissolve, they leave a soft pulpy matter in its original shape but with the lime extracted. A similar condition obtains when the grain falls in the field, for lack of lime to sustain the weight of the head on the stem. If you burn bones, the heat drives off the organic matter and leaves the lime in dense and compact form, so it happens that the manner in which bones have been reduced or their phosphates secured is governed largely by the method of reduction. Raw bone free from meat or fat should contain on an average of twenty-two per cent of phosphoric acid and four per cent of nitrogen, but its usefulness largely depends on the fineness to which it is reduced by grinding; the finer it is ground the quicker it will decay. Steamed bone contains more phosphoric acid and less nitrogen than raw bone. It can be reduced finer by pressure and mechanical manipulation than by grinding and is therefore directly more useful than the ground bone which if not fine must lay in the soil till suffieiently disintegrated to be taken up by the plant. It has been shown that in two seasons steamed bone will be taken up while ground bone sometimes takes as long as four seasons to be absorbed. Bone is the only substance containing phosphoric acid that is used directly or without the intervention of other chemicals to secure its phosphoric acid. Bone black or animal charcoal is a source of phosphoric acid and its first and chief purpose is to clarify sugar and then the material is used as chemical source of phosphoric acid. Only the best bones are used for this purpose, hence it contains the highest per cent of phosphoric acid. When received from the refineries it contains added vegetable matter but is charged with from thirty to thirty-two per cent of phosphoric acid. Bone ash comes from the south where bones are collected and burned and the ashes thus reduced are more easily transported. Good 
samples contain from twenty-five to thirty per cent. The phosphates derived from bones are considered more useful than the mineral substances from which phosphoric acid is obtained, as they are derived directly from organic materials.

\section{IVineral Phosphates.}

We have thus far spoken of phosphates derived from animal substances, but there is another class equally valuable, not combined with organic matter and generally more compact in strueture. South Carolina rock or rock and river phosphates which d.o not differ materially though obtained from two sources, the land and the river, both contain about twenty-five per cent of phosphoric acid and a small per cent of other minerals. These phosphates when finely ground are called floats, are applied directly to the land needing phosphates and will dissolve in the soil after some time. Florida phosphates oceur in differing forms : clay, pebble and rock taken from river beds. The soft or clay deposit yields about thirty per cent while the pebble when washed and crushed contains as high as forty per cent and the clean boulder phosphates yield forty per cent and a better quality than the Carolina rock. Canada apatite is erystalized rock. It is expensive to mine but yields forty per cent of the mineral phosphate. Iron phosphate is the waste product from the manufacture of steel by the basic process, hence is called "basic slag", odorless phosphate and Thompson's phosphate meal. It is produced in large quantities in Europe and the "odorless" is an American product. It contains from fifteen to twenty per cent phosphate of lime, as lime is added in the process to concentrate the phosphoric acid when the iron is in process of melting; combined with bone meal it is particularly good for suudy soils. Guano has been used as a source of phosphoric acid, but later it has been better applied for its content of nitrogen, and Peruvian guano is now used for that purpose. These are all called "raw material" and if used without treatment by acidulation would remain a long time in the soil before they would be available plant food. All material to be usetul must be by some means reduced to a liquid form in order that the plant may be fed by it.

\section{Superphosphates .}

The raw materials we have mentioned exist in combination with lime and are divided into three classes, differing in their 
proportions of lime and called by the name the proportion indicates. "Tri-calic" "tri-basic", or three parts lime and one phosphoric acid, is insoluble in water; the two part lime and one phos. acid is called "diabasic", is insoluble in water but can be taken up by the roots of the plant when moistened by the soil; the "monobasic", or one lime and one phos. acid is completely soluble in water. The fourth form "tetrabasic" crumbles readily though not soluble in water and is soon available. These combinations are called "superphosphates" and are formed by treating the raw material with sulphuric acid which will change the insoluble to soluble forms. The sulphuric acid removes the excess of lime from the phosphate and forms sulphate of lime which leaves the material a "monocalic" or one lime superphosphate. A superphosphate is a union of a soluble phosphate with a phosphate of lime or what is commonly called gypsum or "land plaster". A phosphate means any material containing a large quantity of phosphoric acid and by the process of acidulation already mentioned is changed to a superphosphate or a phosphate in a form the plant can absorb. In buying fertilizer be sure you make the distinction between phosphate and stuperphosphate. You might pay a high price for a fertilizer whose analysis showed a large amount of phosphoric acid, but it world have to lie in the soil a long time before the acid in the rains conld change it to a form the plant could take up. But the superphosphate is immediately available because it has been divested of the excess of lime and made soluble in water.

Superphosphates differ in their content of the required phosphoric acid, depending largely upon the raw material they are made from. Those from organic materials like bone black and bone ash are richer in the phos. acid than from ground bones or mineral substances. If too much stphuric acid is used in dissolving bones they become gummy and the dry soluble powder you wanted to procure is destroyed. The superphosphate from bone black is practically all soluble while those from mineral substances contain quite a per cent of nitrogen. When this is the case they are termed ammoniated superphosphates. Soluble phosphoric acid is valuable again on account of its ease of distribution through the soil, it being taken up by the water and distributed to the plant. The reverted is rich in content of the required food but the plant must go to it or go without, as the reverted remains 
just where it was placed in the soil. In the first instance the food goes to the roots, in the seeond the roots must go to the food or go without and when it finds the food it must by the minute particles of moisture it can impose dissolve the meal. Thus superphosphates are more desirable where immediate results are desired. If the reverted or insoluble phosphate is allowed to remain in the soil during rains and inactivity of the soil, it has the quality of being retained rather than being washed or leached away, though this does not oecur as disastrously as with nitrogen which is a silt washed beyond the reach of the plant. Phosp"iates become "fixed" in the soil by combining with minerals already there. It is less useful in soils very sandy and not contrining iron or lime. The value of "fixation" is that the soil is furnished with a mradually" diminishing somee of plant food and fertility; that is it is not all given up at once but a supply is left to draw upon gradually.

\section{Potash Manures.}

In the early history of agriculture the stipply of potash was chiefly derived from wood ashes either leached or dry to replenish the sum removed by plants and trees. Ashes were used because they "helped to make them grow." 'The reason was not always sought. At the present day, potash salts are mined principally in Strassfurt, Germany. The crude products shipped here are kanit and sylvanit and the manufactured articles are muriate of potash and sulphate of potash with magnesia. Potash combined with chlorine forms chloride of potassim or as it is commonly called "muriate of potash" and is a more resirable form than when combined with sulphuric acid which forms "sulphate of potash." Kanit is the crude product and contains only about 12 per cent potash. Combined with common salt, chloride of sodium, magnesium chloride and sulphate of magnesium and sulphate of potassium, its effect on soil and plant is quite similar to muriate of potash because of the large quantities of chlorides it contains. Sylvanit is also a crude salt and while it shows sixteen per cent potash, it is not used as much as the other. Both kanit and sylvanit are rather more classed as indirect manures on account of the solvent effect they have on other substances, particularly phosphates. Potash should be put in the soil a considerable time prior to the need of the erop, that is, its application should be a sufficient time before planting any crop so it may be well incorporated with the soil. Then it will not be in heavy proportion in any part of 
the soil. An excess of magnesia is often more than beneficial to tender roots of plants, the same applies also to the chlorides. In countries where the heavy rains are not apt to wash it out of the soil, it is best to apply it at least six months ahead of the planting of the erop it is intended to benefit. Muriate of potash is the richest of Strassfurt products and contains about fifty per cent of actuai potash or potassium oxide. Sulphate of potash is called the "high grade" and for crops like potatoes, beets and fruits is preferred to the muriate principally for its direct influence in producing a superior quantity of fruit. As it is placed on the market, it contains about the same per cent of potash as the muriate.

"Double manure salts" contain in addition to sulphate of potash, thirty per cent sulphate of magnesia. Magnesia is particularly useful on potatoes, but the double sulphate is more expensive. All these salts mentioned differ in character and appearance, the sulphates being in form of white or grey powder, while the muriates are in form of grey or light brown erystals. All of them as they stand have a tendeney to solidify, but with the excep ion of kanit they are easily pulverized. Crops most benefited by the application of potash salts are potatoes, grasses, and small and orehard fruits.

To use manures successfully, one has to understand the nature of the ingredients. With nearly all nitrogenous manures it is wise not to apply them in any considerable amount before the crop is growing because the nitrogen is immediately available. Nitrogen in the form of ammonia, though completely soluble in water, is absorbed by the soil and requires some time to change it into a nitrate, the form in which the plant can take it. As we have shown, there is a wide range in the substances containing nitrogen and the length of time required for them to become arailable, as for instance the difference between blood and hair or leather, the latter needing a long time to reduce them to a condition of availability. In the case of the phosphate manures, they, when reduced by acid to a soluble form are immediately available and must not be applied a long time before the plant requires them. Ground bone and course rock decay slowly and all such substances must be applied in the soil a long time before the plant can possibly receive any benefit from them. While potash from the Strassfurt mine is soluble in water, it should be applied some time before the 
actual need of the plant to secure complete distribution throngh the soil.

Crops growing on what is commonly called "poor soil" are as a rule greatly benefited by the application of nitrogen, while rich soils are more productive by application of phosphates and potash. Phosphates are best for heary soils and nitrogen for light dry soils. Sandy soil is generally benefited by potash, in which it is usually defieient, while clay soil is generally supplied with sufficient quantities of potash.

The method of growth of crops is an important factor in determining how manures should be applied. Crops, like the beet, carrot, parsnip and most root crops can go deep for their sustenance, while shallow rooted plants like the strawbery, tomato and kindred plants are shallow feeders, so if the fertilizer were put in the soil deep down the shallow growing plants would find it beyond their reach.

\section{THE UNIT SYSTEIM IN FERTILIZERS.}

The wholesale fertilizer trade now uses the unit system in selling their goods; that is the unit is one per cent or twenty pounds per ton. For example: A manufacturer offers dissolved bone black guaranteed to contain sixteen units of available phosphoric acid at 70 cents a mit $(16 \mathrm{x} \$ 0.70=\$ 11.2$ () per ton $)$.

A quotation of $\$ 1.50$ per unit available phosphoric acid means $\$ 1.50$ for each twenty pounds contained in the material quoted.

\section{COMINERCIAL VALUATIONS.}

"Food for Plants" gives the following illustration for computing fertilizer values. Example: Nitrate of soda is guaranteed to be 95 per cent pure; that is the total impurities in it amount to five per cent: $.95 \times 16.47$ equals 15.64 per cent of nitrogen: $15.64 \times 15$ cents-trade value for nitrogen-equals $\$ 2.3 \pm$ value in one hundred pounds. $\$ 2.3 \pm \times 20$ equals $\$ \pm 6.80$ the value of a ton.

Fertilizers are sold as "high grade", "medium high", "medium grade", "low grade". In high grade, you get 19.60 pounds of plant food in a hundred pounds; in low grade you get 12 pounds of plant food to the humdred. The percentage of phosphoric acid does not vary greatly in the different classes of fertilizer. 'The per- 
centage of potash and nitrogen increases in higher grades. Hence the total amount of plant food in a hundred pounds increases in the higher grades with the increase of nitrogen and potash.

The cost of one pound of plant food, whether nitrogen, phosphoric acid or potash, is greatest in the low grade goods. The least amount paid for one pound of nitrogen in low grade goods is twenty cents, in high grade thirteen and one-third cents. Similar relations hold good in respect to the other grades of plant food. In general the higher the cost of the goods the lower the cost of each pound of plant food. It is unwise to buy "cheap" fertilizers.

\section{VALUE OF FARIM MANURES.}

From careful experiments made by the University Experimental Station, the value of manure from cows per ton in nitrogen was found to be 51 per cent; in phosphoric acid, 35 per cent; in potash, 51 per cent; total value $\$ 2.27$.

From horses alone the manurial value of a ton is $\$ 2.79$. Ten horses in eleven days produced manure to the value of $\$ 4.71$, or for each horse per day, 42 cents.

Sheep produce one and one-half cents worth per day, with a low percentage of phosphoric acid but rich in other elements. The summary per ton in value of manurial constituents is: Horse, $\$ 2.79$; cow, $\$ 2.27$; sheep, $\$ 4.19$; swine, $\$ 3.18$. This of course does not include the mechanical value imparted to the soil and here is where the farm manures have the advantage over the chemical fertilizers in relation to the physical changes made by each.

\section{WHAT THE PLANT TAKES FROIM THE SOIL.}

When we know what the plant removes from the soil in its life course, from seed to maturity, we know what to replace in order to keep the fertility of the land we are eropping up to standard so it will not disappoint us in returning its tribute to our expectation and toil. There are, as we have previously shown, three principal ingredients or constituents of the soil that are absolutely needed in order that the erop we plant may do its best. If any one of the trio is lacking, the soil will only be as strong for its work as the least element contained in the soil is in evidence. It is the old illustration of the chain being no stronger than the weakest link. If there is a superabundance of nitrogen and a 
lack of phosphorie acid or potash, the plant will express its life in going to tops and leaf, with but little fruitage. If the phosphoric acid is fairly in evidence with a lack of nitrogen, the plant will make a desperate attempt to produce untimely fruit, and leaves will be conspicuous by their absence. If potash is needed (which is hardly ever the ease in California, we are so near nature's storehouse where she has but recently ground it down), the fruit will be inferior in quality and never attempt perfection. There are a host of side elements such as phosphorus, lime, magnesia and many others that have their place and bear about the same relation to the necessity of the erop as condiments, pepper and salt, do to the meal of the gardener. Lime, however, as before set forth is very essential and will in almost every instance in California soils (except the calcareous) assist the crop to find hidden in the soil, if already there, the desired morsel it is searehing for.

It must be remembered the plant cannot change restaurants. It is dependent solely on what you bring to its needs after it has exhausted the supply nature placed there for it to begin its eareer. If, after repeated croppings, the platter should grow lean and the eupboard bare, some one must supply the lack. As before stated, there may be a partial supply, all bone and no bread, or all bread and no bone, (plants dearly love acidulated bone), and to know what you need you must know what has been eaten up, and what must be supplied in order to make the meal a satisfying one. To assist you in determining what has been taken out of the soil by a crop you have raised we give the following table made from numerous experiments and tests from various State and Govermment Experimental stations: 


\begin{tabular}{|c|c|c|}
\hline $\begin{array}{c}\text { Pounds per Acre } \\
\text { Nitrogen }\end{array}$ & $\begin{array}{l}\text { Phosphoric } \\
\text { aeid }\end{array}$ & Potash \\
\hline Cabbage ............213 & 514 & 125 \\
\hline Cauliffower ............202 & 265 & 76 \\
\hline Turnips ..............187 & 426 & 74 \\
\hline Carrots .............166 & 190 & 65 \\
\hline Corn ...............146 & 174 & 69 \\
\hline Green Fodder ...........122 & 230 & 66 \\
\hline Cucumbers ............142 & 193 & 94 \\
\hline Lettuce ............. 41 & 72 & 17 \\
\hline Onions .............96 & 96 & 49 \\
\hline Peas .................153 & 69 & 39 \\
\hline Potatoes ............. 119 & 192 & 55 \\
\hline Sweet Corn...........518 & 107 & 37. \\
\hline Sorghum ............4t6 & 561 & 90 \\
\hline Sugar Beet ............ 95 & 200 & 44 \\
\hline Tobaceo ..............127 & 148 & 33 \\
\hline Tomato .............185 & 136 & 72 \\
\hline Wheat .............111 & 58 & 45 \\
\hline Oats............. 89 & 96 & 35 \\
\hline Rye ............... st & 76 & 44 \\
\hline Rape $\ldots \ldots \ldots \ldots \ldots \ldots \ldots \ldots$ & $12 t$ & 79 \\
\hline Sojo Beans ..........207 & 87 & 62 \\
\hline Vetch ...............149 & 113 & 35 \\
\hline Cow Peas .............171 & 169 & 64 \\
\hline Barley .............. 78 & 62 & 35 \\
\hline Buckwheat ..........6 62 & 17 & 40 \\
\hline
\end{tabular}

\section{WHAT THE PLANT WANTS.}

It is not only necessary to know what amount of nutrients the plant in its growth has taken out of the soil, but it is essential to know the proportion to again place in position so it can be well fed. The early growth of erops is needed as the early price is the best. We give in proportionate figures the requirements of different plants, and whether you give 2 pounds, 20 pounds or 200 pounds the relative proportions are here given for the three elements. You can always, in sandy or loamy soil add lime with positive good results, and especially in clay soil. Give as much lime as you do of the highest named ingredient. For instance, if an acre of cabbage requires 200 pounds of nitrate of soda to 
furnish nitrogen; 350 pounds of superphosphate to furnish phosphoric acid and 100 pounds of sulphate of potash to furnish required amount of potash, then add :350 pounds of lime. It is best to plow it in before you put in the other elements. The figures are given for the acre, but you can measure your plot, lot or tract and take the acre as the guide to the amount needed for a larger $o r$ smaller tract.

\section{FORMULAS:}

\section{Nitrate}

of Socla

Cabbage ..............200 lo.

Cantaloupes ..............t(0) los.

Tomatoes ...............t00 lbs.

Sweet Potatoes (top dressing).200 lbs. Strawberies, ...........200 lbs.

Melons, two applications.....so(o lbs. Potatoes ...............20 los. Corn ..................200 libs.

$\begin{array}{cc}\begin{array}{c}\text { Super. } \\ \text { phosphate }\end{array} & \text { Potash } \\ 350 \mathrm{lbs} . & 100 \mathrm{lbs} . \\ 500 \mathrm{lbs} . & 200 \mathrm{lbs} . \\ 400 \mathrm{lbs} . & 100 \mathrm{lbs} . \\ 200 \mathrm{lhs} . & 100 \mathrm{lbs} . \\ 400 \mathrm{lbs} . & 100 \mathrm{lbs} . \\ 800 \mathrm{lbs} . & 100 \mathrm{lbs} . \\ 300 \mathrm{lbs} . & 100 \mathrm{lbs} . \\ 400 \mathrm{lbs} . & 200 \mathrm{lbs} .\end{array}$

\section{THE USE OF NITRATE OF SODA}

Nitrate of Soda for use in all garden operations, raising nursery stock and stimulating leaf growth is most beneficial.

The consensus of opinion as published by various experimental stations of the govermment give these conclusions. The agricultuxal authorities by careful experimentation estahlish the fact that 100 pounds of Nitrate of soda applied to the crops named below will produce increased yields as here given:

Barley-increase 400 pounds grain.

Corn-increase, 280 pounds grain.

Oats-increase, 400 pounds grain.

Rye-increase, 300 pounds grain.

Wheat-increase, 300 pounds of grain.

Potatoes-inerease, 3,600 pounds of tubers.

Hay-increase, 1,000 pounds cured hay.

Cotton-increase, joo pounds seed cotton.

Sugar Beets-increase, $t, 000$ pounds in tubers.

Beets-increase, 4,000 pounds in tuber's

Sweet Potatoes-increase 3,000 pounds in tubers.

Cabbage-increase, 6,000 pounds. 
Carrots-increase, 7,800 pounds.

Onions-increase 1,800 pounds.

Turnips-increase, 37 per cent.

Strawberies-increase, 200 quarts.

Asparagus-increase, 100 bunches.

Tomatoes-increase, 100 baskets.

Celery-increase, 30 per cent.

Plants take up most of their nitrogen during the early period of their growth.

There is no danger of the nitrate being leached out of the soil where irrigation is the practice, as the moisture seldom reaches deeper than the root system of the plants. Nitrate of Soda looks much like common salt and if cattle can get to it they sometimes eat it in quantities sufficient to injure them. Soak the empty hags in a barrel of water; it will be sufficient to make good liquid fertilizer.

Break all lumps with back of shovel on the barn floor so it will dissolve evenly. If you mix it with superphosphates or othur fertilizer, put the desired quantity of each in separate piles on a floor, then mix all evenly. Nitrate of Soda, mulike sulphate of ammonia, dried blood and other mixed fertilizers, can be mixed with lime or ashes without loss of nitrogen. Nitrate of Soda costs from 3 to 5 cents per pound. If 100 pounds are to be applied it should be divided into two periods of application several weeks apart.

\section{SOIL INOCULATION OR NITROGEN CULTURE}

The new is ever catching the heels of the past. It is not many years since the thought was uppermost that the soil was simply a mass of inert particles that were acted on by the rains and the seed and only revivified by the action of the plow and the harrow. There was not knowledge of the germ theory as relates to soil. It was confined to the realm of vaccination to improve or destroy functional diseases. But the wand of knowledge, rich with the spoils of research, has unfolded to the wondering eyes of the world that soils contain living bacterial germs that can be used to improve the quality and quantity of crops. They can be taken from the fertile fields and placed in the sterile and presto! the change is truly magical.

Both with green manuring and the use of "cultures" is the object of increased fertilization accomplished. The leguminous 
plants such as peas, beans, retches, brrr clover, cow peas and fenugreek possess the quality of nitrogen gatherers from the atmosphere, where 90 per cent 'of it resides and must by some means be extracted and put into the soil in order to keep up the supply of nitrogen yearly taken out by the crops. Nitrogen being the most costly element the gardener or farmer has to supply, these plants are used as cover crops to collect through their system of leaves, branches and roots the nitrogen in the atmosphere and. store in nodules on their roots, whence in turn they give it to the soil. Such erops as Whippoorwill Peas. White Canadila and Scotch Blue Peas are sown broadcast or drilled in in the orchards or tracts of land that need rejuvenation, and the effect is the same, only magnified, as in the plowing under of clover after land has lain fallow.

The bacterial germs discovered in unlimited quantities aid the leguminous plants very materially in their work of returning to poor impoverished soil a copious supply of nitrogen from the air, and making good soil more productive. They supplant artificial nitrogenous manures and are easily handled.

The method of inoculation is extremely simple. The seed is moistened in a solution of the cultures you obtain from the government or from seedsmen who keep them. 'They usually come in dry cotton, as they can be transported more easily this way. When the seed is moistened as per directions which aceompany the package and then permitted to dry, it has been inoculated with the bacterial germs that will when put in the soil and covered bring to life millions of minute organisms that will cause the roots of the plants to respond to the action of the germs and form nodules filled with nitrogen. If you were to see the difference in size, evidence of vigor and prodigious growth between the plant that had been grown in inocvlated soil and the one not so grown. your surprise would be bordering on amazement.

Soil for instance from an inoenlated field of alfalfa taken to a field of poor sickly-growing alfalfa, if sufficient water is at hand and reasonably fair conditions obtain, would immediately stimnlate the growth and revive the drooping field. Soil inoculation is one of the imnovations of this progressive age that is bringing the world to understand that the occupations of the agrieulturist and horticulturist are along truly scientific lines and producing beneficial results. 


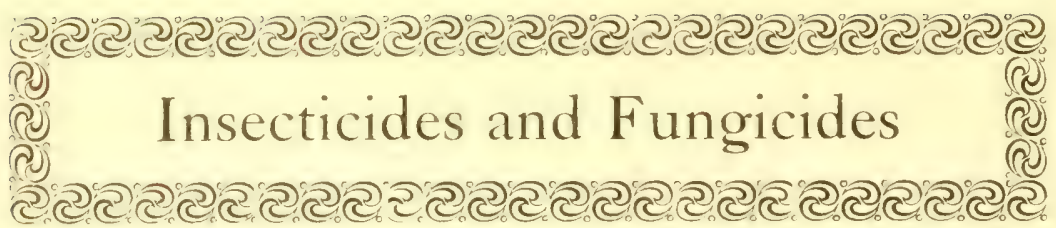

\section{INSECTICIDES.}

In a country where almost minterupted conditions exist for perpetually producing insect life, the wonder is that there are not more insects to destroy garden and field crops. But it must be remembered that nature ever strives to maintain a balance and permit no more injurious insects than can be kept in abeyance by predaceous and parasitic insects, that in turn prey on the cmemies of vegetation. It is only when by some means the balance is disturbed or upset that some bug, worm or fly, becomes unusually active and consequently destructive. Then it is that artificial remedies other than those supplied by nature are called in requisition. These in the form of sprays, baits, emulsions, dustings and repellants, to be successful must be used with TIMELI-

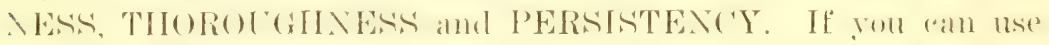
a timely repellant and keep the enemy away, it is far better than to have to nse more drastic measures involving time, expense and more danger to the plant.

There are two general classes of insects you will have to be ready to fight. To avoid going into a labyrinth of entomology, which would require a volume to merely outline, we will forego the seientific appellations and divide them into two classes, to-wit: BITING and SUCKING insects. A biting insect flies or crawls on the plant, is not stationary but constantly moving and feeding on the plant. A sucking inseet punctures the tender bark and inserts its beak or mouth parts and sucks the life sap from the plant. It will be seen that different methods must be used in any work of eradication. Any insecticide put on the OU'TSIDE OF THE PLANT would fall harmless from the back of the insect that had his bill fastened in the plant and was getting his sustenance from the sap. The first thing to know is how the enemy feeds. Ts he chewing and leaving the debris behind him as evidence of his presence? If so, you must feed him something that will kill him, and at the same time not injure the plant beyond repair. If he is a sucking insect you must use something that will 
destroy him by CONTACT; when the liquid strikes him it must be of a mature that will destroy him and not the plant.

Having thus briefly laid down the rule and reason for the practice, we proceed to more specific details along these remedial lines.

\section{REPELLANTS.}

A repellant is a mixture of ingredients that are so obnoxions 10 an insect that it will avoid all possible contact with them, and if these ean be suecessfully used the danger is easily averted because the enemy does not storm the citadel. The list is not a long one, and we grive thosp most easily obtained and used.

Unslaked lime scattered under vines and plants will dispe] slugs, suails or roaches. Most crawling insects avoid lime. Coal oil and ashes mixed and seattered under plants repel insects. Snuft, sulphur and lime mixed and dusted under and over the plants and carbolic acid mixed with lime and then dried to a powder are excellent repellants for nearly all caterpillars.

Other preventatives, though not classed as repellants are the various ways of trapping insects: laying bones where ants can find them and when completely covered dropping into hot water; placing boards, sacks or piles of refuse where bugs, crickets and roaches will crawl under and into them and when trapped destroying by any easy means at hand. In this eomnection the burning of tar paper, (or coal tar fumes) is an expedient commonly used and successfully employed against aphis, a species of sucking insect, that lives on the underside of leaves and is difficult to reach with ordinary sprays and emulsions.

Baits are made by chopping grass or green leaves quite fine and mixing one ounce of Paris green or London purple with 8 ounces of the chopped leaves; add enough syrup to work into balls which are spread about in the garden to catch wire worms. beetles and erickets. When grasshoppers become epidemic use instead of the leaves, hran and middlings; 40 pounds bran, 15 pounds middlings and 20 pounds arsenic; syrup (any thick kimel). 2 gallons; mix with soft water to a paste and scatter where the pests are abundant. A pint of crude carbolic acid mixed with 50 pounds of lime or gypsum-land plastex-then dried to a powder and thrown over trees troubled with cureulio has been found to be a repellant. To burn webs of worms and caterpillars that weave tents and hang themselves in the trees and on weods, take 
a torch made of rags wound around a stick and dipped in kerosene. One ounce of copperas-(blue stone) dissolved in a pail of water will destroy insects at the roots of plants or trees.

Flooding beds infected with ants, wire worms and grubs, keeping the water on for twenty-four hours will destroy the insects. The water must be kept in by basining-piling up the earth on the ontside in form of ridge to hold the water where the worms or insects may be working.

\section{PARIS GREEN}

This preparation can be applied either dry or in form of spray. The dry formula is Paris green eight ounces, flour, lime or road dust five pounds well mixed and dusted dry on the plants or trees when plant or tree is damp. The wet formula is also used against codlin moth, eanker worms, caterpillars and any biting insects: Paris green, five ounces, lime, six pounds and water fifty gallons. Paris green is a metallie preparation and sinks to the bottom of the mixture if not kept constantly stirred.

It can be used in connection with Bordeaux mixture and thus be of double service as an insecticide and fungiside combined. Place five onnces of Paris green in fifty gallons of the Bordeaux solution.

\section{ARSENITES}

Dissolve four pounds of sal soda crystals in water enough to cover them, add one pound of white arsenic and boil the mixture till clear, then add enough water to replace amount evaporated to make one gallon. Use one pint of this solution in fifty gallons of water using it as a spray with either Bordeaux or distillate.

\section{KEROSTNE EMULSION}

Kerosene one quart, one and a half pounds of whale oil (preferable) Babbitt's, ivory or other good soap, soft water one gallon. Shave the soap into hot water and churn through a hand force pump until it is emulsified. Dilute with two and a half gallons of water making the mixture one part kerosene to fourteen parts of water, or a seven per cent solution.

Two gallons of water will give an eight per cent solution; one and a half gallons will give a nine per cent solution; one gallon of water produces an eleven per cent solution; two quarts a fifteen per cent solution. It is best to begin witli the standard seven per 
cent solution (few plants will stand the stionger solution). This is used for scale and aphis and all sucking insects.

\section{BI-SULPHIDE OF CARBON}

This volatile liquid which is as inflammable as gasoline is used in destroying insects in stored grain, weevil in peas and beans, or worms in potatoes. In stored grain it is poured down tubes into the bins. It can be poured in gopher holes in the ground and the holes closed with wet soil. The vapor flows down and kills the rodent. To destroy life it requires one teaspoonful of the liquid to each cubic foot of bin space where grain or peas are stored. A spoonful poured down a hole made near the roots of a tree infected with wooly aphis will destroy them; in ants' nests, gopher holes and mole rums it is a sovereign remedy.

\section{BORDEAUX IVIXTURE}

Borleaux mixture is composed of blue-stone-copper sulphate-four pounds, quick lime four pounds or if stronger is refced up to six pounds, water forty to fifty gallons, as per strength required. Dissolve the blue-stone in crock of water, slake lime in enough water to make cream of lime, pour both together at one time into a wooden vessel, stirring vigorously as you add the water. It costs less than one cent a gallon and is very useful against all fungus diseases of plants, shrubs, or fruit trees, especially for curl leaf in peaches, shot hole fungus in plums and aimonds. For peach trees which are especially tender, the mixture is some times made weaker: a $3-9-50,3$ bluestone, 9 pounds lime, 50 gallons of water instead of the $4-4-40$ or $4-6-50$ mixture. The addition of more lime is to prevent burning of foliage. When Paris green is used with it, it should not be stirred in until just before using.

\section{COPPER SOLUTION}

This is used to spray the ground around tomato plants, to prevent blight and to cure it when it appears. Four ounces of bluestone in fifty gallons of water; drench the soil with it before planting the tomatoes.

\section{AQUIS AIVIMIONIA SOLUTION}

For plants you do not wish to discolor with lime and bluestone, take copper carbonate six ounees, strong aqua ammonia (26 deg.) two quarts, water fifty gallons. Mix the copper carbon- 
ate to a paste with soft water and dilute the ammonia with onehalf gallon of water, stir in the copper mixture till it is well dissolved making two gallons of stock solution, put in a glass bottle with rubber stopper. When used, dilute each quart of the above with six gallons of water.

\section{CORROSIVE SUBLIIVATE}

This is used to disinfect seabby potatoes. Put the potatoes in a sack, suspend in a barrel and use two ounces of the corrosive sublimate in thirty gallons of water, soak the tubers in the liquid for two hours before cutting into seed pieces. This is a violent poison, so great caution must be used in handling it.

\section{LIIVE, SULPHUR AND SALT}

Lime and sulphur wash is excellent for winter application in California to destroy pernicious (San Jose) scale. Use unslaked lime twenty-one pounds, flour of sulphur eighteen pounds, water fifty gallons. Make a paste of the sulphur in cold water then stir the same into fifteen gallons of boiling water, add the lime and stir constantly while it boils. Boil moderately for forty minutes and as it boils add enough water to make fitty gallons. Spray while hot. 'This is used against scale, plum pocket, leaf curl and blackknot and kindred diseases of trees. This is an easier formula that the old style "lime sulphur and salt."

\section{LYE AND SULPHUR}

This formula is used against mites and spiders on plants, citrus and deciduous trees. The sulphur can be used dry on trees and plants afflicted with mites. Take ten pounds of sulphur and mix to a paste in a barrel with a little water, a gallon or more, add ten pounds of lye and as the lye boils the sulphur, add water to keep it from burning or caking. dilute to make a barrel of spray.

\section{ROAD DUST}

When melon vines are afflicted with black greasy aphis, caused by neglecting too long before destroying them, gather up some pailsful of dry dust and sprinkle on the vines until they are completely covered, then turn the under side up and dust them thoroughly, leave it on twenty-four hours, then spray the vines with dean cold water and the aphis will be destroyed if the work is well done. 


\section{BUHAC}

This is a powder made from a very ornamental flowering plant that grows splendidly in California and should be in evidence in every garden, "Pyrethrum cinerarifolia" - just call it buhac plant. The home grown variety is apt to be best as it has not lost its strength by agre. A light brown powder is made from the flower buds, and while poisonous to insect life is not considared so to the human family. It is used dry and in this form is deadly against thrips and lice on roses and other plants infested with them; also for aphis on cabbage and melons or on any plant in the garden troubled by them. It of course must be applied, as any other powder you wish to adhere to the plant, when the plant is damp. You can use a diluter such as flom or dry road dust with any poison used in the proportion of one part to from six to thirty of the diluter.

As a fumigator buhae may be spread on hot coals, held in a pan-the better way is to moisten it and monld it into balls and place on the coals, it will last longer and give better results. In this form it is used against mosquitoes and flies with good results.

As a decoction, the whole buhac flowers are treated with boiling water and left to steep, preventing evaporation. Do not boil the flowers, it destroys their value. Water extract can also be made by pouring 2 quarts of hot water through half a pound of pyrethrum, in a bag, then adding cold water enough to make two gallons. This is effective against cabbage worms and aphis.

Fumigation for sucking insects like lice, aphis, melon aphis and mealy bugs, is done by covering the plant and buxing the buhac under it.

\section{TOBACCO}

Tobaceo stems are used for smudging under plants and in closed houses where you are raising plants. The stems are dampened and put on coals of fire. Also boil the stems or dust thoroughly and strain; then add eold water mil the decoction contains two gallons of liquid to one pound of tobaceo.

\section{HOT WATER.}

This simple remedy is one of the most useful and if you are provided with a spraying apparatus by which you can put it on the plant up to a heat of 125 degress it is death to all insects it comes in contact with and is one of the very best contact sprays.

Salt and water can be used with excellent effect on cabbage, 
cauliflower and broceoli. Sprinkled or sprayed into the heads, it is a sure remover of lice and aphis.

\section{REMEDIES FOR EACH PARTICULAR PEST}

We give the remedy best known to destroy insects working on plants. The list includes both for the mandibulae (biting insects) and those which suck their food, known as true bugs.

\section{ANGLEWORIMS.}

Angle Worms sometimes destroy plants by burrowing. Lime water in the soil burns them; bi-sulphide of carbon used by driving down iron pin and pouring the liquid in the hole so made, then covering it with moist earth fills the soil and destroys insect life of any deseription. It is inflammable like kerosene and should not be used near a light, unless you wish to use it as you would kerosene poured into the soil and fired.

\section{ANTS.}

Use the bi-sulphide of carbon or kerosene lighted in the burrows. A teaspoonful of the bi-sulphice in a hole six inches deep made with a picket pin, then closed, is a remedy where ants burrow in lawns.

In strawberry beds and places where they are burrowing at the roots make a basin of earth around the plant or bed and keep filled with water for $2 t$ hours. Do not keep the water on longer at one time, it might injure the plant.

\section{APHIS OR PLANT LICE}

These occur on melons, cabbages, turnips and various plants in the form of small green, black or purple lice. They cover the leaves and stems and sometimes the entire plant. Use hot water up to 125 degrees Fahrenheit on cabbage, eauliflower and similar plants on which they feed. Use on eauliflower quite strong brine then wash off with fresh water. Wash them off by force with water from the hose. Use on plants that will bear it kerosene and water. One part kerosene to ten parts water. Cover melons or kindred plants entirely with road dust for 24 hours, then wash oft and the aphis will disappear. Bi-sulphide of carbon may also be used against the plant lice family, by covering the hill of vines with a tub or small low tent so the fumes cannot escape; putting earth around the bottom after putting in a small dish containing a tablespoonful of the liquid. In evaporating, it de- 
stroys the insects. This plan can be used when the lice are on the underside of the leaves and cannot be reached by other means, but generally to tmon the vines over" and eover with dust will remove them if thick enough and left on sufficient time. Coal tar fumes, burning tar paper under vines, are useful remedies against nearly all insects.

\section{CATERPILLARS}

These hairy, crawling insects are the larvae of butterflies, the best known being the "army worm" the larvae of the buttertly known as Lncania unipunctata, the fore wings being pictured with spots. These pests appear in myriads, when it happens that the conditions are unfavorable for the natural enemies to keep them down. They devour everything in sight in the line of vegetables and are an illustration of what would happen if permitted to go unmolested. As they are biting insects, remedies must be used that will kill them by dusting or spraying the plants with some poison such as Paris green or London purple, both preparations of arsenic. If used dry, take one part of the arsenical preparation to fifty parts flour, air slaked lime, road dust or wood ashes. In using the dry preparations the best time to apply the dust is when the plants are damp. This is the strongest dry mixture recommended and some plants will not stand it so strong, even 100 to 200 parts of the diluter being sufficient. If used wet in form of spray to treat tomatoes, potatoes and other plants, the poison must be mixed with lime to prevent burning the foliage, and it must be kept stirred up or the metallic poison will sink to the bottom and leave the water on the top. This would injure both ways; you would waste time in putting the water on, and the poison would be so strong in the bottom of the barrel it would kill everything it touched in the form of plant life. Not more than one pound of the poison to 250 gallons of water, and for trees where codlin moth is to be killed 300 gallons of water should be used. If the Arsenate of Lead is used-a compound that stays on better and lasts longer, one pound in 75 gallons of water is used. The above remedies are employed against all biting insects whether on plants or trees, only recuiring judgment as to the amount when a plant is tender or of stronger nature and growth.

This treatment applies to all caterpillars, corn worms, tomato worms, measuring worms, roaches and heetles, encumber worms and yellow bugs (that attaek all the melons, squash and pumpkins) 
harlequin or calico bugs, snout beetles, slugs and snails, in fact all the running, creeping, crawling things on top of the earth that bite and eat aray the plant instead of sucking only the sap. The monstrous green caterpillars, the larvae of giant Cecropia moth, can best be disposed of by hand picking, for while large and formidable they are not generally numerous.

\section{CUT WORMS}

These members of the caterpillar family are not hairy and range in color from a dirty grey to a dirty yellow. They hide in the daytime and when it is too warm to be above ground, at the base of a plant and feed on it but at night come out and fill up on everything in sight, so of course can be destroyed by the same remedies used against their hairy cousins. Sometimes we have an epidemie of "climbing cut worms," the larvae of the moth known as the "Carneades scabens" and sometimes called army worms, they are so destructive. These worms do not like potash, especially kanit, so its use in the soil generally serves the good purpose of cleaning them out and at the same time furnishes the needed supply.

IIeavy doses of lime in the soil are obnoxious to all root feeding insects, cut worms, wire worms, erawigs, sow bugs, slugs and snails that keep in or close to the surface and feed on, erode and girdle plants. The asparagus beetle comes in this elass, though he comes up on the plant and feeds on the very tender shoots. The white grub, often seen curled up when moving manure piles is a mischievous enemy, but is adverse to liming. Always use unslaked lime for all purposes where it is to penetrate the soil; the air slaked will do as a dilutent or repellant, but its most caustic quality is needed where you wish to destroy insects of any kind in the soil. Most of these earth worms come out at night and if bait made of bran or poisoned elover, chopped grass or leaves is used it will kill many. 'Traps like pieces of board, rags or refuse under which they can crawl will collect many of them.

\section{POD RUST.}

"Anthracnose" or pod rust attacks string beans, showing in reddish brown spots. Lima beans are also attacked by a felt coating on the pods and the young shoots and leaves are also injured. The remedy is to use the Bordeaux on first appearance, and it may require several applications to entirely eradicate either dis- 
case. If the beans mildew, dry sulphur should be applied on the first appearance of the downy looking monld.

\section{BEET DISEASES.}

Leaf spot begins with an ash grey eoloring of the leaf that finally becomes ragged and dead. Root rot and scab) (same as attacks potatoes) are treated with application of Bordeaux. In case of scab, rotate and plant in a different place next crop. After adding lime to the soil, work it in instead of leaving it above. T'o sweeten the soil, it requires about 75 bushols to the acre. The lime is a remedy for the similar disease in radish. tumip and kindred plants. If you have fed the stock the seabby roots you may expect the retum of the clisease in the mamure, which can be cured by mixing it with lime before putting it in the soil.

Celery sum-seald appears in yellow spots on the leaf which later tum brown and die. It is cured by application of Bordeanx.

\section{MILDEW}

Another class of plant disease is mildew, relative to the mould rou see on mouldy bread. It is successfully treated with sulphur dusted on dry. Especially peas and beans in very wam weather, are apt to mildew. In planting the peas it is well to sprinkle some sulphur in the drills where and when you plant, and after coming up if any sign of the disease shows on the leaves, dust with the elry thom of sulphur. It is usecl with telling effect against all plants, trees and shrubs that are troubled with the mite and red spider family. It must be dusted on when plants are wet and when it is likely to be a day of fizl sunshine, as it reduires the heat of the sum to raise the fumes that destroy the insects. If made into a spray, it has to be dissolved by heat; or after being mixed to a paste with cold water caustic soda (concentrated lye) is added and it boils or dissolves the sulphur much as water slakes lime. Enough water must he added (as it cooks in the potash) to keep it from burning or forming into a solid cake. This sulphur spray can also be used in connection with the fungicides as before mentioned, in a similar manner, where mites and fungus are working on the same plant or tree. Sulphur should never be used as a means of fumigation except in rooms where the object is to destroy insect life, in stored articles or to rid buildings of roaches. bugs or moth. It cammot be used as a fumigator to kill insects on 
plants, as it will kill the plant as well as the insects. For the purpose of fumigation, plants can be covered and cyanide of potassium dropped into sulphuric acid will produce deadly fumes that will kill insects, and if used in the right proportion will not kill the plant. The method is used in killing seale on trees. Sulphur as found on the market is largely adulterated if cheap goods are purchased.

\section{FUNGUS}

A fungus is some disease either transmitted from other plants, carried by wind or transmitted by insects, but generally an inherent trouble arising from the disturbance of life cells by other organisms that enter the life functions of the plant. It may be slow in progress, or its work suddenly destructive; the plant may linger in distress struggling for life or it may be suddenly eut off by undiscovered causes. Most of the known diseases are well defined and remedies can be applied to save and restore, but of course there is consequent loss. As with the insect trouble it is best to nip the evil in the bud, and so fungieides are used to first give relief and prevent the appearance of deadly disease, whether above or beneath the surface. The remedies are used both wet and dry, but generally in the form of sprays.

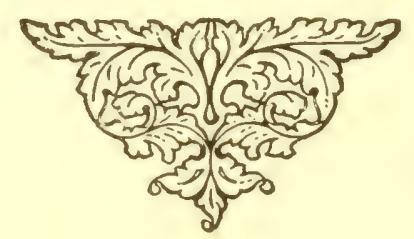




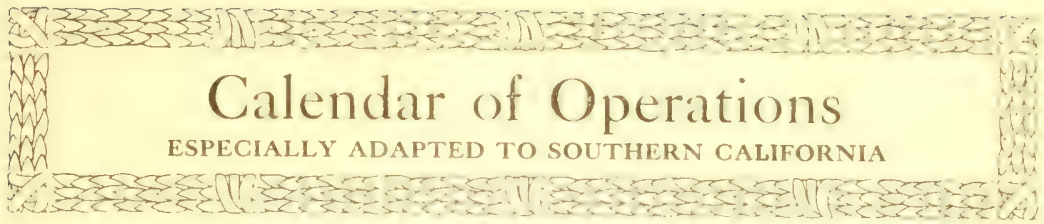

JANUARY.

Flower Garden-Continue to plant lilies. All kinds of evergreen and deciduous shrubs can now be planted. The planting of hyacinths, tulips, narcissi, etc., should be completed this month. Hardy annuals may be sown out-of-doors, and, where artificial heat is obtainable, half-hardy annuals may be sown. A hotbed of stable manure is easily prepared by piling it + or 5 feet in height, well watered and trampled down, over which place a large box or frame, with glass sash, taking care to air and sweeten the bed well before using.

$V$ egetable Gardcn-For main crop sow broccoli, carrot, chicory and parsnip. At the end of the month, in warm, sheltered situations, early Rose potatoes may be planted. Plant asparagus, horseradish and rhubarb roots. These all require deeply worked ground. Dress beds already planted with about 3 inches of wellrotted manure. Cucumbers, eggplant, melons, peppers, squashes and tomatoes may be sown under glass for after-planting. A safe plan is to sow about 5 seeds of each variety on reversed pieces of sod, about + inches square. On planting in the ground, insert the sod with the growing plants and firm the soil in the usual way. By this method the growing plants will suffer no injury. Stick and hill up peas and other crops requiring it, and attend strictly to cleanliness.

\section{FEBRUARY.}

Flower Garden-General planting of evergreens and shrubs should be completed as soon as possible. Also finish planting lilies, anemones and ranunculi. Commence planting gladiola bulbs for succession. Sow hardy annuals out-ofdoors, especially sweet peas, and half-hardy annuals as recommended for last month. This is the best month in which to sow acacia seeds. Soak for 24 hours before sowing, or where practicable, spread dry leaves or bushes over the beds after sowing and watering and set fire to them. This is the best manner of sowing, all hard tree seeds.

Vegctable Garden-This and the next month will be the busiest of the year in this department, as nearly all crops may be sown in these two months. Continue planting asparagus and other roots as recommended for last month. Plant main crop of potatoes. Attend to weeding and hilling up. Thin out turnips, carrots and other root crops requiring it.

\section{MARCH.}

Flower Garden-Continue planting gladioli bulbs for succession. All hardy and half-hardy annuals may be sown in the open ground this month. Alternanthera and other border plants can be planted with safety, as all danger from even slight frost is now over.

Vegetable Garden-Nearly all vegetable seeds may be freely sown this month. Plant out cucumbers, melons and other plants previously sown under glass. Hill up rows, keep down insects, slugs and vermin, and attend strictly to cleanliness. 


\section{APIIIJ.}

Flower Garden-Plant dahlias, gladioli, tuberoses, tigridias, tuberous begonias and all summer-flowering bulbs. Continue sowing hardy and half-hardy annuals. Watch rose-bushes, and if troubled with green aphis, use tobacco dust freely:

Vegelable Garden-Plant out eggplant, pepper, tomato and sweet potato plants, the latter in light, rich soil, well worked, in rows 6 feet apart, and 2 feet in the rows, and keep the soil well worked. Cultivate well and hill up as reonired.

\section{MAY.}

Flozeer Garden-As hyacinths, tulips, narcissi, etc., die down, the bulbs should be dug up, and stored away in a cool, dry place till fall, when they may be replanted. The vacancies thus created should be filled with other flowering plants. Halfhardy and other annuals may still be sown, and summer-flowering bulbs be planted. The garden should now be brilliant with flowers, and all sowing, planting and general cleaning up should be completed this month, ready for the summer season.

Vegetcble Garden-Pinch out points of shoots of cucumbers, melons, squash, etc., as soon as they commence flowering. Sow vegetable seeds for succession, and keep surface of soil well broken.

\section{JUNE.}

Flower Garden-Trim edgings of borders and hedges, and carefully attend to watering. Dahlias and gladioli may still be planted. Sow eucalyptus and cypress seeds for winter planting.

Vegetable Garden-Hill up all growing crops and stick pole-beans and tall peas as required.

\section{JUL).}

Flower Garden-Continue to dig up and store bulbs as they ripen. Trim edgings and hedgerows and sow perennial flower seeds in shady situations. Continue sowing eucalyptus and cypress seeds.

Vegetable Garden-Cultivate well between the rows. Sow vegetable seeds for succession. If manure is used during this hot month, it should be in liquid form.

\section{A LGUS'T.}

Flower Gorden-This is the best month in the year in which to sow hardy perennials. Most varieties if sown this month will flower the next year. Also sow calceolaria, cineraria, pansy and primula seeds. Contines sowing eucalyptus and cypress seeds.

Vegetible Garden-Plant second crop of potatoes. Sow cabbage, cauliflower and spinach for main crops.

\section{SEPTEMUIER.}

Flower Garden-Commence planting hyacinths, tulips, anemones and other Dutch bulbs toward the end of the month. Prick off calceolarias, cinerarias and primulas sown last month, into small pots, and continue sowing same for suc- 
cession. Pansies can be grown better transplanted into a well-manured bed than in pots, as they are not so liable to be attacked by the red spider. Pansy seed may be sown for succession until the end of November. Also sow all the hardy annuals and perennials.

$V$ egetable Garden-Many varieties of regetable seeds may be sown this month. Plant out cabbage and cauliflower plants sown in July.

\section{OCTOBER.}

Flower Garden-Hyacinths and other Dutch bulbs should be planted freely this month; also early lilies. Cineraria and primula seed may still be sown for late flowering. Continue sowing hardy annuals.

Vegetable Garden-Sow largely peas, onions and spinach for main crop; also other seeds for succession, especially winter radishes.

\section{NOVEMISER.}

Flower Garden-Continue planting hyacinths and other Dutch bulbs, and lilies of all kinds; also plant roses, evergreens and deciduous shrubs of all kinds. Form new lawn and renovate old ones. Carry out landscape alterations, if required; dig and manure borders, and energetically proceed with all heavy work.

legetable Garden-Sow seeds as recommended in reference table for this month, and hill up young crops. Keep the ground thoroughly clean, and dig or plow manure in all unoccupied ground for future use. Keep down slugs by free use of salt, lime, or any other dressing which is beneficial to the growing crop.

\section{DHCWMBER.}

Flower Garlen-Operations same as last month.

legetable Garden-Operations same as last month.

\section{PIANTS BEST FOR FORCING IN A GLASS OR CIOTH HOLSW.}

Asparagus, bush beans, carrots, cauliflower, cress, cucumber (white spine) parsley, peas, tomato, muskmelons.

\section{GIIIIIG PRUNES.}

Cur California prunes are usually graded in six sizes by using wire mesh of dimensions given below:

$$
\text { Grade. }
$$

Width of Mesh

For Green Fruit. For Dried Fruit.

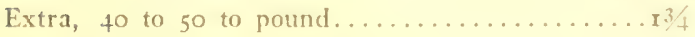

No. $\mathbf{r}, 50$ to 60 to pound................ $\mathrm{r}^{\mathrm{I}} / 4$

No. 2, 6o to 70 to pound................ I ${ }^{1} 1$

No. 3,70 to 80 to pound..............

No. t, so to go to pound.................

No. 5,90 to roo to pound............ $3 / 4$

$I^{T / 4}$
$\mathrm{I}^{\mathrm{T} / 4}$
$\mathrm{I}$
$\vdots \vdots$
$\vdots$




\section{Useful Information}

\section{WEIGHTS PER WUSHEL,}

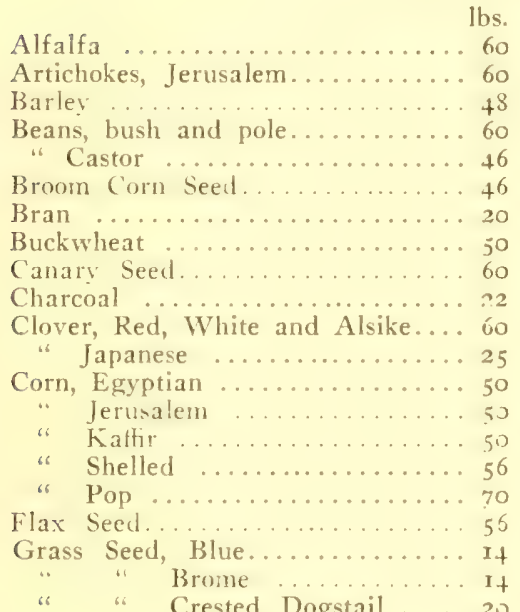

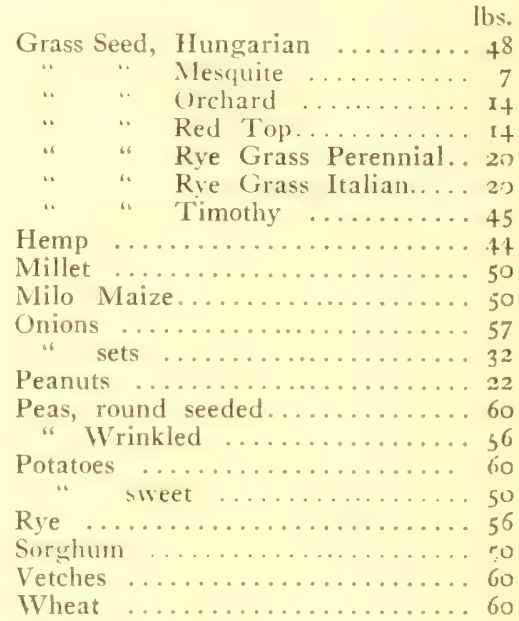

\section{SOIVIV TABLE FOR THE GARDEN.}

Quantity of seed required to produce a given number of plants, or to sow a given quantity of ground.

Artichoke

Asparagus

I oz. to 500 plants

... I oz. to $60 \mathrm{ft}$ of drill 500 plants Beans, Dwarf..... lb. to $50 \mathrm{ft}$ of drill Beans, Tall.......... lb. to 75 hills Beets........ oz to $50 \mathrm{ft}$. of drill Broccoli ........ oz to 2,000 planis Brussels Sprouts.. I oz. to 2,00o plants Cabbage ....... oz to 2,000 plants Carrot ........ I oz. to $\mathrm{I} 50 \mathrm{ft}$. of drill Cauliflower...... oz to 2,000 plants Celery.......... I oz. to 5,00o plants Chicory........ I oz. to $100 \mathrm{ft}$. of drill Corn............. I lb. to I 50 hills Cress.......... I oz. to Ioo $\mathrm{ft}$. of drill Cucumber.......... oz. to roo hills Eggplant....... I oz. to 2,000 plants Endive......... oz. to 3,000 plants Kale........... I oz. to 2,00o plants Kohlrabi......... I oz. to 2,00o plants Leek.......... I oz to $100 \mathrm{ft}$. of drill Lettuce.......... I oz. to 5 , 000 plants
Melon, Water........ oz, to 30 hills Melon, Musk........ I oz. to roo hills Okra......... I oz. to $50 \mathrm{ft}$. of drill Onion Seed.... I oz. to roo $\mathrm{ft}$. of drill Onion, Top Sets.. I lb. to $60 \mathrm{ft}$, of row Onion, Bottom Sets, rlb. to $75 \mathrm{ft}$. of row Parsnip........ I oz. to Ioo $\mathrm{ft}$, of driil Parsley........ $\mathrm{i}$ oz to $100 \mathrm{ft}$ of drill Peas.......... I lb. to $50 \mathrm{ft}$. of drill Pepper......... oz to $\mathbf{r}, 000$ plants Pumpkin............ I oz. to 25 hills Radish......... I $0 \ell$. to $50 \mathrm{ft}$. of drill Salsify......... I oz. to $50 \mathrm{ft}$ of drill Sage......... I oz. to $r o 0 \mathrm{ft}$. of drill Spinach........ I oz, to $50 \mathrm{ft}$. of drill Squash, Early........ I oz. to 50 hills Squash, Winter...... oz to 15 hills Tomato......... I oz. to 3 , 000 plants Tobacco....... I oz to ro,ooo plants Turnip, Early.... I oz. to $75 \mathrm{ft}$. of drill Turnip, Rutabaga. I oz. to Ioo ft. of drill 


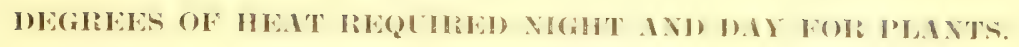

Under cloth or glass in winter.

VEGE'TAIBLIS.

\begin{tabular}{|c|c|c|c|c|}
\hline Name. & $\mathrm{D}$ & & & \\
\hline Asparagus & $\ldots \ldots .85$ & deg. & & \\
\hline Beans .... & $\ldots \ldots \ldots 70$ & "6 & 68 & \\
\hline Cucumber & $\ldots \ldots .80$ & 66 & 70 & \\
\hline Cauliflower & $\ldots \ldots 50$ & 46 & 40 & \\
\hline Lettuce ... & $\ldots \ldots . .50$ & "6 & 4 & \\
\hline Radish ... & $\ldots \ldots \ldots .55$ & $\therefore$ & & \\
\hline Tomato .. & $\ldots \ldots .75$ & 66 & 6 & \\
\hline Melon .... & $\ldots \ldots 80$ & 66 & & \\
\hline
\end{tabular}

\section{FLOTERS.}

\begin{tabular}{|c|c|c|c|}
\hline Name & & & light. \\
\hline Rose $\ldots \ldots \ldots \ldots 65$ & " & 55 & \\
\hline Lily, Easter.......65 & " & 50 & \\
\hline Lily of Valley......90 & 16 & 90 & \\
\hline Carnations $\quad \ldots \ldots \ldots 60$ & " & 55 & \\
\hline Chrysanthemums $\quad \cdots 50$ & " & 7 & \\
\hline Smilax .... & “ & $6 x$ & \\
\hline Asparagus Plumosa.70 & " & 60 & \\
\hline Violet $\ldots \ldots \ldots \ldots$ & “ & & \\
\hline
\end{tabular}

\section{TIME IN WHICH SEEIS GERMINATE。}

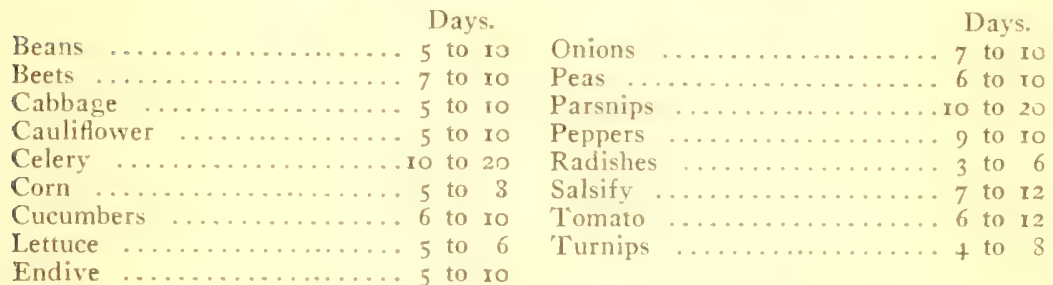

\section{SEED REQUIRED FOR AN ACRF.}

Pounds.

Alfalfa, clean seed........................

Barley, broadcast ..............

Beans, dwarf or bush, hills.......4 40

Beans, dwarf or bush, drill...... 80

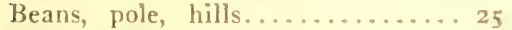

Beets, garden................ 6

Beets, sugar................6 6

Beets, stock, mangles......... 6

Broom Corn, in drills........... 12

Cabbage, sown in beds to transplant $1 / 2$

Corn, sweet, in hills............ I 5

Cucumbers, in hills........... I to 2

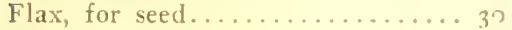

Flax, for fiber............... 50

Vetches, broadcast............. rno

Wheat, broadcast.............. roo

Grass, Bermuda............... ro

Grass, Kentucky blue.......... 50
Hemp

Melon, Water, hills........2 to 3

Melon, Musk, hills.........2 to 3

Oats, broadcast.............. 8o

Onions, drills................ 4

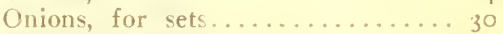

Parsnips, drills...............

Peas, in drills.............50 to 80

Peas, broadcast................ 50

Potatoes, in hills..............60.

Pumpkin, in hills............ 3

Radish, in drills............ I2

Rve, broadcast.............. roo

Spinach, drills.............. 12

Squash, hills.............. t

Tomatoes, in beds, transplant.... $1 / 2$

Turnip, broadcast........... to t 


\section{MISCEI IANEOUS MEASURES.}

56,000 liquid grains make a gallon.

One-tenth of an inch, one line-American measure.

One-third of an inch is a "size" in footwear.

Three inches is a palm measurement.

Four inches is a "hand" measure.

Four inches is one "span" measure.

Nine inches is one "span"-horse measure.

Eighteen inches is one cubit.

Three and three-tenths feet is a pace, $2^{1 / 2}$ feet, a military pace. One gallon, wine measure, is 23 I cubic inches.

A dry gallon is 268.8 cubic inches.

An Imperial gallon, $277.27+$ cubic inches.

United States bushel $2 \times 50 .+$ cubic inches.

A pint of water equals r.043I pounds.

A gallon of water equals $8.24+6$ pounds.

A cubic foot of water equals $52 .+25$ pounds at 39.2 Fahr. deg.

A statute mile is 1760 yards.

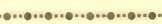

\section{HOUSEHOLD MEASURES.}

60 drops of water is one teaspoonful.

One teaspoonful equals one fluid drachm.

Two tablespoonfuls equal one fluid ounce.

A common sized tumbler holds half a pint.

One pint of wheat is equal to one pound.

One pound two ounces of Indian meal is equal to one quart.

One pound of melted butter is equal to one pint.

One pound of sugar equals one pint.

One pint of pure water equals one pound.

\section{HOLEIGN COINS.}

French franc, nearly twenty cents-r9.3.

German mark, about $2+$ cents.

Italian lira nearly 20 cents.

Dutch florin, 40 cents.

Spanish peseta 20 cents.

Russian rouble about $5+$ cents.

Austrian florin about 33 cents. 


\section{CALIFORNIA FUUT'T MEASTREMENTS.}

The major portion of sales transactions of fruit in California marketing are by pounds in weight, but a bushel measure is nineteen and a half inches in diameter outside; half bushel, fifteen and a half inches; a peck is twelve and a half inches.

Produce sold by dry measure must be heaped as full as the measure will hold, but usually grain is sold by sacks weighing one hundred pounds or less.

For apples and pears the boxes are twenty-two inches in length, ends ten by twelve inches. This is called a fifty pound box, but it is short weight.

Cherry boxes are fifteen and a half inches long and the ends eight and a half by three and a half.

Fig boxes (twenty pound-two layer) are twenty inches long; ends two by three and a half. Single layer boxes are same length, but two inches deep and hold nearly twelve pounds.

Grapes are usually shipped either in baskets containing four pounds, eight of which baskets make a whole crate. Boxes generally contain twenty-five pounds. Sometimes grapes are shipped in baskets filled between with sawdust.

Oranges are shipped in boxes with partition in center as support, dimensions being twenty-two inches long by seven and three-fourths deep by seventeen and a half wide. This comprises the flat box, but the one most used is twenty-six and a half by eleven and one-fourth.

Lemon boxes are similar in form to orange boxes and weigh seventy pounds when filled.

Canteloupe crates are thirty-eight inches long by sixteen inches in width and fifty inclies deep.

Watermelons are usually shipped in bulk in car or in any sort of large crate or boxes.

Dried fruits are shipped in eighty-pound sacks.

Plums are packed in twenty-pound boxes, nineteen and a half long by twelve and a half inches wide and four and one-fourth inches deep.

Peaches are usually in twenty-two-pound boxes of the same size as the plum box. The twenty-five-pound, twenty-seven-pound and thirty-pound are the largest sizes. 


\section{Useful Reference Table}

Showing at a glance the best time to plant the different kinds of seeds and plants, average time to mature and distance apart.

\begin{tabular}{|c|c|c|c|c|c|c|c|c|c|c|c|c|c|c|c|}
\hline VARIETY. & 鬲 & $\left|\begin{array}{l}0 \\
0 \\
14\end{array}\right|$ & 趟 & $\left|\begin{array}{l}2 \\
\overrightarrow{4} \\
2 \\
4\end{array}\right|$ & 究 & $\begin{array}{l}0 \\
\tilde{E} \\
5\end{array}$ & $\frac{2}{3}$ & $\begin{array}{l}80 \\
\text { है }\end{array}$ & $\mid \begin{array}{l}+ \\
8 \\
0 \\
0\end{array}$ & $\mid \begin{array}{l}+3 \\
0 \\
0\end{array}$ & 占 & 递 & Iraturity Ial & \multicolumn{2}{|c|}{$\begin{array}{c}\text { Distance to } \\
\text { Plant }\end{array}$} \\
\hline $\begin{array}{l}\text { rtichoke, Globe........ } \\
\text { sparagus (seed)....... }\end{array}$ & - & S & S & $\begin{array}{l}\mathrm{S} \\
\mathrm{S}\end{array}$ & - & - & - & -- & - & - & -- & - & $\begin{array}{l}\text { itlis } \\
\text { rs }\end{array}$ & \multicolumn{2}{|c|}{$\begin{array}{l}24 \times 36 \text { inclies } \\
36 \times 18\end{array}$} \\
\hline sparagus (roots)...... & $\mathrm{r}$ & $\mathrm{P}$ & $\mathrm{P}$ & $\int_{-}^{0}$ & - & - & - & - & & - & $\bar{p}$ & p & Second year & $\begin{array}{l}36 \times 18 \\
36 \times 18\end{array}$ & .. \\
\hline eet, Table Varieties.. & $\mathrm{s}$ & S & S & $\mathrm{S}$ & - & - & s & s & s & & & - & 7 to 8 weels & $18 \mathrm{x}+$ & " \\
\hline eans, Broad or Fnglish & S & S & - & -1 & - & - & - & - & s & s & s & $s$ & 3 months & $24 \times \quad 4$ & “ \\
\hline eans, Dwarf or Busli.. & - & S & $\mathrm{S}$ & $\mathrm{s}$ & s & $s$ & $\mathbf{s}$ & - & - & - & - & - & 6 to 8 weeks & $30 \times 2$ & “ \\
\hline 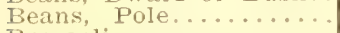 & -- & - & $\mathrm{S}$ & $\mathrm{s}$ & $s$ & - & - & - & - & - & $\ldots$ & - & $8 \mathrm{we}$ & $36 \times 30$ & “ \\
\hline coli $\ldots \ldots \ldots$ & $\mathrm{s}$ & s & $1-$ & $1-$ & $\ldots$ & - & $\mathrm{s}$ & s & s & $\mathrm{s}$ & s & s & $3 \mathrm{n}$ & $36 x^{2}+4$ & “. \\
\hline russels, Sprouts. & $\mathrm{s}$ & S & & - & - & - & s & s & $s$ & s & s & s & 41 & $\because 4$ & • \\
\hline abbage, Early (seerls). & s & s & s & & - & - & - & $s$ & s & s & s & s & $31 / 2$ & 24 & * \\
\hline Cabbage, Early (plants) & - & $P$ & $\mathrm{P}$ & $\mathrm{P}$ & $\ldots$ & $1-1$ & -- & - & $p$ & p & $\mathbf{p}$ & p & $31 / 2$ & 21 & * \\
\hline Cabbage, Late (seeds)... & - & - & $s$ & $\mathrm{~s}$ & s & s & $=$ & - & - & - & -- & -1 & $4 \mathrm{~m}$ & 36 & . \\
\hline Cabbage, Jate (plants). & -- & - & - & - & $\mathrm{P}$ & p & $p$ & -. & - & - & - & - & $4 \mathrm{r}$ & 36 & • \\
\hline 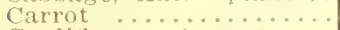 & s & S & s & s & $\mathrm{s}$ & - & - & $s$ & s & s & s & s & 31 & is & . \\
\hline nliflower (seeris)..... & s & s & s & s & $\ldots$ & $\ldots$ & s & s & $s$ & s & s & s & 4 to $5 \mathrm{r}$ & 3 & • \\
\hline aulitlower (plants).... & 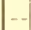 & $P$ & $\mathrm{P}$ & $\mathrm{P}$ & p & - & - & - & p & $\mathbf{p}$ & p & - & 4 to 5 & 3 i & 。 \\
\hline elery $\ldots \ldots \ldots \ldots \ldots$ & & $=$ & S & S & s & - & - & - & -1 & & - - & $\ldots$ & 51 & 8 & ‘ \\
\hline hervil $\ldots \ldots \ldots \ldots \ldots$ & & s & S & S & s & $\ldots$ & - - & . & $s$ & s & - & -.. & 6 & 4 & • \\
\hline ives $\ldots \ldots \ldots \ldots \ldots$ & $\mathrm{P}$ & $\mathrm{P}$ & $\mathrm{P}$ & $\mathrm{P}$ & $\ldots$ & $\ldots$ & $\ldots$ & $\ldots$ & $\mathbf{p}$ & $p$ & $\mathbf{p}$ & $p$ & onths & 4 & ‘ \\
\hline$\ldots \ldots \ldots \ldots$ & & $S$ & S & $s$ & $\ldots$ & - & - & -- & - & - & - & $\ldots$ & 3 & 18 & "4 \\
\hline Clicory : & - & S & S & s & - & - & - & - & - & - & -- & - & 6 & 1 & “ \\
\hline Corn, Swe & - & - & S & s & $\mathrm{s}$ & s & -- & - & - & $\ldots$ & -- & - & $3 t$ & 36 & "4 \\
\hline 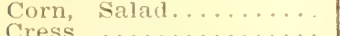 & s & $\mathrm{S}$ & $\mathrm{s}$ & s & - & & - & s & s & s & - & - & 6 to 7 & $1 \approx \times 6$ & * \\
\hline 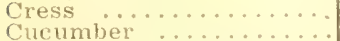 & $\mathrm{s}$ & S & S & s & $\mathrm{s}$ & $\mathbf{s}$ & s & $\mathbf{s}$ & s & s & s & s & $\frac{1}{7}$ to 2 & $\operatorname{ckly}$ & . \\
\hline ndelion $\quad \ldots \ldots \ldots \ldots \ldots \ldots$ & & $\vec{s}$ & S & $\mid \begin{array}{l}S \\
S\end{array}$ & $S$ & s & - & - & s & s & -- & - & 8 to 9 weeks & 68 & « \\
\hline plant (seeris)..... & & $\sigma^{\circ}$ & S & s & s & s & $\left\{\begin{array}{l}-- \\
--\end{array}\right.$ & -1 & - & - & -- & - & 3 to $4 \mathrm{~m}$ & $36 \times 36$ & “ \\
\hline plant (plants)..... & & & - & $\mathrm{P}$ & $\mathrm{P}$ & p. & $p$ & - & - & - & - & - & 3 to 4 months & 36 & st \\
\hline 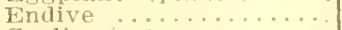 & $\mathrm{s}$ & S & s & s & & & 19 & $\mathbf{s}$ & s & s & s & s & 6 weeks & $12 \times 6$ & . \\
\hline lic (s & $\mathrm{P}$ & $\mathbf{P}$ & $\mathrm{P}$ & $\mathrm{p}$ & - & - & - & $\mathbf{p}$ & p & $p$ & p & $\mathbf{p}$ & ntins & $18 \times 4$ & « \\
\hline rse-rar & $\mathrm{P}$ & $\mathrm{P}$ & $\mathrm{P}$ & $\mathrm{P}$ & & - & & & & & $p$ & $\mathrm{p}$ & $6 r$ & $12 \times 4$ & $*$ \\
\hline$\ldots$. & s & s & S & 1. & $1-$ & - & s & s & s & s & s & s & nths & $2+x 12$ & * \\
\hline ollinabi & S & 5 & $\mathrm{~S}$ & - & $1=$ & - & - & s & s & s & - & - & 41 & $18 \times 6$ & * \\
\hline$\ldots \ldots \ldots$ & S & s & s & s & ... & & -- & - & s & s & s & s & 3 to 4 & $12 \times 5$ & . \\
\hline$\ldots \ldots \ldots \ldots$ & s & s & S & $\mathrm{s}$ & $\mathrm{s}$ & s & $s$ & s & $s$ & s & s & s & 4 to $7 \mathrm{we}$ & $24 \times 13$ & $\cdots$ \\
\hline Musk....... &.- & - & $S$ & s & s & s & -- & $\ldots$ & - & $-\infty$ & & & 4 to $5 \mathrm{n}$ & 60 & “ \\
\hline Ielons, Water........ & & & s & s & $s$ & s & - & - & - & - & $\ldots$ & -1 & 3 to $4 \mathrm{mo}$ & $96 \times 96$ & . \\
\hline Iustard $\ldots \ldots \ldots \ldots \ldots \ldots$ & s & s & s & $\$$ & s & s & s & s & s & s & s & s & 1 to 2 weeks & Thickly & \\
\hline kia & & & $\mathrm{s}$ & s & s & s & 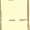 & & & - & & & 3 & $36 \times 12$ & a \\
\hline nion (s & & $\mathrm{S}$ & s & 5 & $\mathrm{~s}$ & & & s & s & s & s & & $31 / 2$ to $5 \mathrm{~m}$ & $12 \times 4$ & A. \\
\hline nion & $\mathrm{P}$ & $\mathrm{P}$ & $\mathrm{P}$ & $\mathrm{P}$ & & & & & & $\mathbf{p}$ & $\mathbf{p}$ & p & $31 / 2$ to 51 & $12 \times 4$ & 16 \\
\hline rsley & $\mathrm{s}$ & $\mathrm{s}$ & s & s & & & & s & s & s & s & S & 0 weeks & $12 \times 6$ & \\
\hline arsnip & s & $\mathrm{S}$ & s & $\mathrm{s}$ & $\ldots$ & & & s & $\mathbf{s}$ & s & s & & 41 & $18 \times 6$ & \\
\hline Peas .... & s & s & $\mathrm{S}$ & s & $s$ & s & $\mathbf{s}$ & s & s & s & s & s & 6 & 30 & \\
\hline $\begin{array}{l}\text { Pepper (seeds) } \\
\text { Pepper (plants) }\end{array}$ & & & s & s & $\mid \begin{array}{l}\mathrm{s} \\
\mathrm{p}\end{array}$ & s & & & & - & $-\cdots$ & & $\begin{array}{l}4 t \\
4 t\end{array}$ & $\begin{array}{l}2 \\
3\end{array}$ & \\
\hline Potato (sets).......... & & $\vec{P}$ & $\vec{P}$ & p & $\begin{array}{l}\mathrm{P} \\
\mathrm{P}\end{array}$ & $\mathbf{p}$ & $\begin{array}{l}p \\
p\end{array}$ & $p$ & & & & -1 & $\begin{array}{l}+10 \\
21 / 2 t\end{array}$ & 30 & 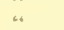 \\
\hline Potato, swee (prancs). & & -1 & & p & $\mathrm{p}$ & p & $p$ & p & d. & - - & & - & 3 to & 48 & " \\
\hline 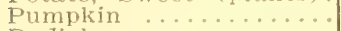 & & - & 5 & $\mathrm{~s}$ & s & s & & - & L & - & - & -- & ths & $96 \times 96$ & • \\
\hline Radish. & S & s & s & $\mathrm{s}$ & $s$ & $\mathbf{s}$ & s & s & s & s & s & s & 3 to 5 weeks & $8 \times 2$ & " \\
\hline abarb & & $\mathrm{s}$ & S & s & - & - & - & - & - & - & -1 & & 3. & 48 & \\
\hline ubarb & $\mathrm{P}$ & $\mathrm{P}$ & $\mathrm{P}$ & & & & & - & - & - & $\mathbf{p}$ & p & $\mathrm{Sec}$ & 48 & \\
\hline sify. & - & $S$ & s & s & s & $\ldots$ & 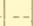 & - & - & - & & - & I to 5 montlis & $18 x+$ & “ \\
\hline atch & $\mathrm{s}$ & s & S & s & s & $s$ & s & $s$ & s & $s$ & s & s & $n t h$ & Thickly & \\
\hline Tobaren & & $S$ & $\mathrm{~S}$ & s & $\ldots$ & & & - & - & & & & iths & & \\
\hline Tomato & $\mathrm{s}$ & S & S & $\mathrm{s}$ & $s$ & & & & 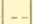 & & & & 3 to 5 mon & 48 & \\
\hline Tomato (plants). & & & $\mathrm{P}$ & P & $p$ & $\mathbf{p}$ & & & 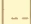 & 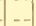 & & & 3 to 5 months & $48 \times 18$ & \\
\hline 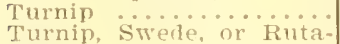 & & S & S & $\mathrm{s}$ & s & & $\mathbf{s}$ & $\mathbf{s}$ & s & s & & -- & 8 to 10 weeks & $18 x+$ & \\
\hline 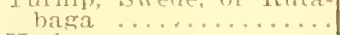 & & $s$ & $\mathrm{~s}$ & s & s & $\mathbf{s}$ & s & - & & & & & ionth & & \\
\hline$\ldots \ldots \ldots \ldots$ & & & s & $s$ & s & & & & $s$ & & & & ow thinly in & irills & \\
\hline
\end{tabular}







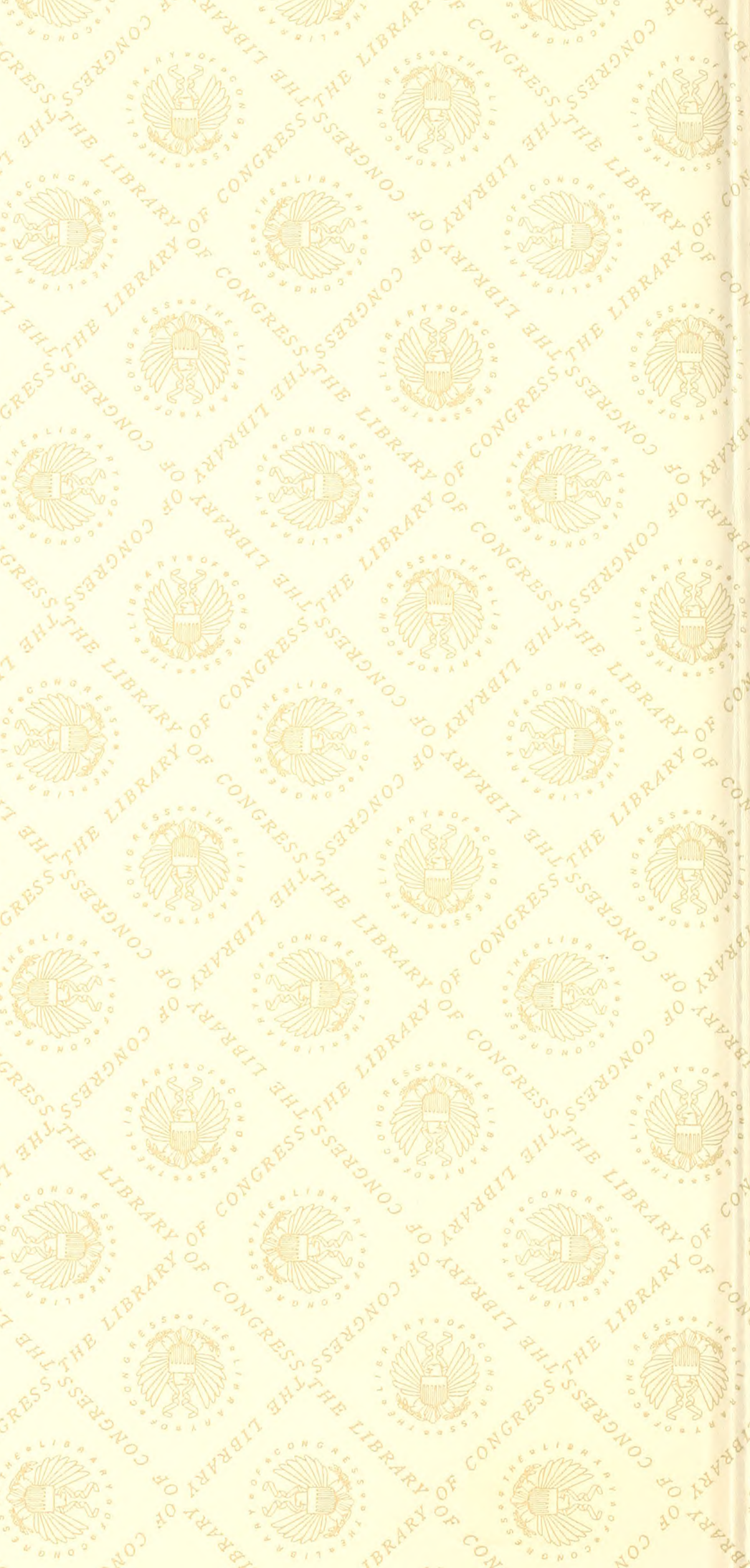



LIBRARY OF CONGRESS

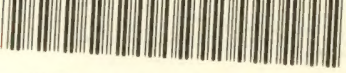
口०00928381A - 